Portland State University

PDXScholar

1998

\title{
An Evaluation of a Staff Mentor Program for At-Risk Students in an Oregon High School: CAKE (Caring About Kids Effectively)
}

Gail Lenore Hayes

Portland State University

Follow this and additional works at: https://pdxscholar.library.pdx.edu/open_access_etds

Part of the Educational Leadership Commons, and the Elementary and Middle and Secondary Education Administration Commons

Let us know how access to this document benefits you.

\section{Recommended Citation}

Hayes, Gail Lenore, "An Evaluation of a Staff Mentor Program for At-Risk Students in an Oregon High School: CAKE (Caring About Kids Effectively)" (1998). Dissertations and Theses. Paper 4278. https://doi.org/10.15760/etd.6175

This Dissertation is brought to you for free and open access. It has been accepted for inclusion in Dissertations and Theses by an authorized administrator of PDXScholar. Please contact us if we can make this document more accessible: pdxscholar@pdx.edu. 


\title{
AN EVALUATION OF A STAFF MENTOR PROGRAM FOR AT-RISK STUDENTS IN AN OREGON HIGH SCHOOL: CAKE (CARING ABOUT KIDS EFFECTIVELY)
}

by

GAIL LENORE HAYES

\begin{abstract}
A dissertation submitted in partial fulfillment of the requirements for the degree of
\end{abstract}

\author{
DOCTOR OF EDUCATION \\ in \\ EDUCATIONAL LEADERSHIP : \\ ADMINISTRATION \\ Portland State University \\ 01998
}




\section{DISSERTATION APPROVAL}

The abstract and dissertation of Gail Lenore Hayes for tine Doctor of Education in Educational Leadership:

Administration were presented December 16, 1997, and accepted by the dissertation committee and the doctoral program.

COMMITTEE APPROVAIS:

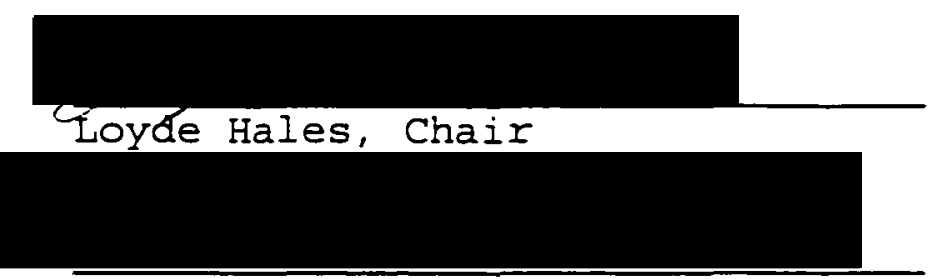

Tom Chenoweth

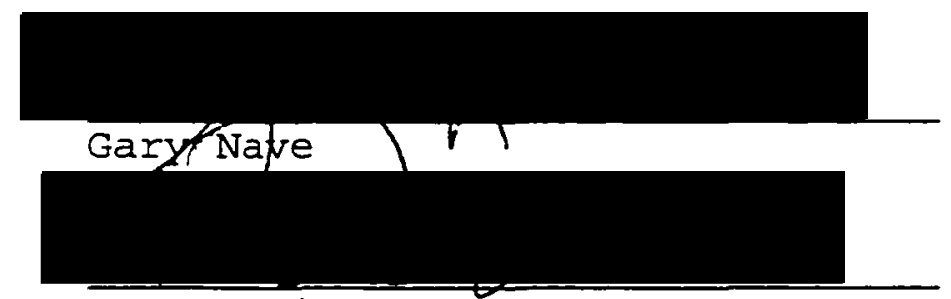

Ron Petrie

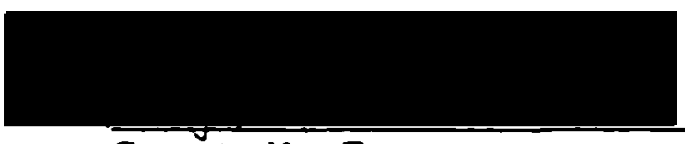

Grant M. Farr

Representative of the Office of Graduate Studies

DOCTORAI PROGRAM APPROVAL:

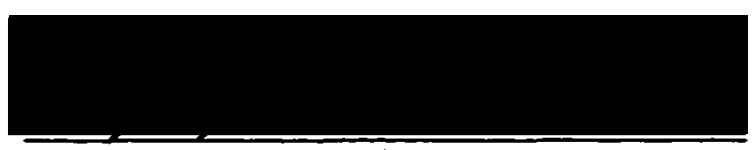

Robert B. Everhart, Dean

School of Education 


\begin{abstract}
An abstract of the dissertation of Gail Lenore Hayes for the Doctor of Education in Educational Leadership: Administration presented December 16, 1997.

Title: An Evaluation of a Staff Mentor Program for AtRisk Students in an oregon High School: CAKE (Caring About Kids Effectively)
\end{abstract}

This study examined the effect of a staff mentoring program with students identified as at-risk of becoming early leavers. This mentoring program, Caring About kids Effectively (CAKE), was implemented at a suburban secondary school in oregon serving grades 9 through 12.

The study of the CAKE program had four research components: (a) indicators of school success (GPA, attendance, and attitudes toward school) were compared between at-risk students and those not at-risk; (b) indicators of school success were analyzed over the time at-risk students were mentored to find any significant change; (c) indicators of school success and enrollment status at graduation was compared between students at-risk, with and without mentors; and 
(d) participants' perceptions of the mentoring program, using a researcher-constructed questionnaire given to mentees and mentors to determine activities that were successful and those which needed reevaluation.

Using analysis of covariance, the findings showed: (a) a significant difference ( $\underline{p}<.05)$ in attitudes, GPA, and attendance at the beginning of the study between two groups of students identified as at-risk and not at-risk; (b) a significant difference $(\underline{p}<.05)$ in attitude toward school at the end of year $I$ between those students at-risk with mentors scoring higher than at-risk without mentors and not at-risk students; (c) GPA and attendance declined for at-risk students, with or without mentors, although at-risk students with a mentor seemed to lessen the decline; and (d) no significant differences $(\mathrm{p}<.05)$ in GPA and attendance between at-risk with or without mentors, although more at-risk students with mentors continued in school or received GEDs after four years. Finally, students and staff agreed (75\%) that they were "satisfied" that the mentor program helped at-risk students develop positive attitudes toward school; however, only half were satisfied concerning their participation, and felt that administrative support and time available to meet with students were crucial to the success of a mentor program. 
Based upon these findings, it was concluded that the CAKE staff mentoring program had a positive influence on attitude toward school and retention of at-risk students. 


\section{ACKNOWLEDGMENTS}

I am indebted to and wish to acknowledge the many people who have contributed to the successful completion of the dissertation. I am especially appreciative of the time and caring spent by staff mentors who worked with atrisk youth, at Milwaukie High School, and particularly Larry wilkins and Sue Johnson, coordinators of the CAKE mentoring program.

My committee members who have been patient each made contributions for which I am indebted: Dr. Loyde Hales, who chaired the committee, provided valuable feedback and constant support; Dr. Gary Nave, who gave the CAKE committee great insight into evaluation tools; Dr. Tom Chenoweth and Dr. Grant Farr who recognized the importance of such research and gave valuable feedback; and finally, Dr. Ron Petrie, who helped me visualize my goal and stayed with my committee, even into his retirement.

Many other people provided support and encouragement at various stages of my doctoral work and the writing of this dissertation. A very special thank you to my good friends Dr. Gaynelle Nolf and Dr. Virginia Anderson, who have been a constant source of strength and challenged me

to finish this last obstacle; to Joyce Harris, who gave me 
the expertise to tackle the statistics portion of the dissertation, and to Joe Walker, whose editorial and technical knowledge along with long hours at the keyboard, enabled a "photo finish" at the defense.

I am especially grateful to my husband, Dr. Mike Davis, and my three children, Mike, Kelly, and William, for their understanding of the valuable time away from family needed to finish this program, and finally, my parents, Billie and Burke Hayes, for their unwavering support which ultimately instilled in me the resiliency to continue when I felt the weakest.

I dedicate this dissertation to my beloved mother, who passed away before she witnessed my final graduation. 
TABLE OF CONTENTS

PAGE

ACKNOWLEDGMENTS . . . . . . . . . . . . . . . . . . . . i i

LIST OF TABLES • . . . . . . . . . . . . . . . . . viii

CHAPTER

I INTRODUCTION . . . . . . . . . . . . . . 1

Statement of the Problem . . . . . . 1

Background . . . . . . . . . . . 4

Rationale . . . . . . . . . . 13

Purpose of the Study . . . . . . . . 18

Definition of Terms . . . . . . . . 19

Iimitations . . . . . . . . . . 23

II REVIEW OF THE LITERATURE . . . . . . . . . . 27

Educational Reform. . . . . . . 27

Characteristics of At-Risk students . 40

Characteristics of Programs for At-

Risk Students........ . 52

Mentoring . . . . . . . . . . 63

Definition and Historical Background of Mentoring

Roles and Characteristics of Mentor Relationships

Development and Implementation of Successful Mentor Programs

The At-Risk Student and Mentoring

Teachers as Mentors for At-Risk

students 
III METHODOLOGY . . . . . . . . . . . . 87

General Plan of Study . . . . . . . 87

CAKE (Caring About Kids Effectively) • 87

Quantitative Research Components . . . 89

Independent Variables . . . . . . . 90

Characteristics of High School/School

District . . . . . . . . . . 91

subjects . . . . . . . . . . . 93

Instruments . • . . . . . . . . 96

The Quality of school Life

Survey, or QSL

CARE Survey

Procedures . . . . . . . . . 103

Overview of the Data . . . . . . . 108

Data Analysis Procedures . . . . . 109

IV RESULTS • • • • . . . . . . . . . 122

Pretreatment Analyses . . . . . . . 122

Pretreatment . . . . . . . . . . 124

Question 1. Comparison of At-Risk and

Not At-Risk Students . . . . . 125

The Quality of School Life Scales Attendance

Grade Point Average

Question 2. Comparison of At-Risk

students with Mentors, At-Risk

Students without Mentors, and Not

At-Risk Students . . . . . . . 133

The quality of school Life scales Attendance

GPA 


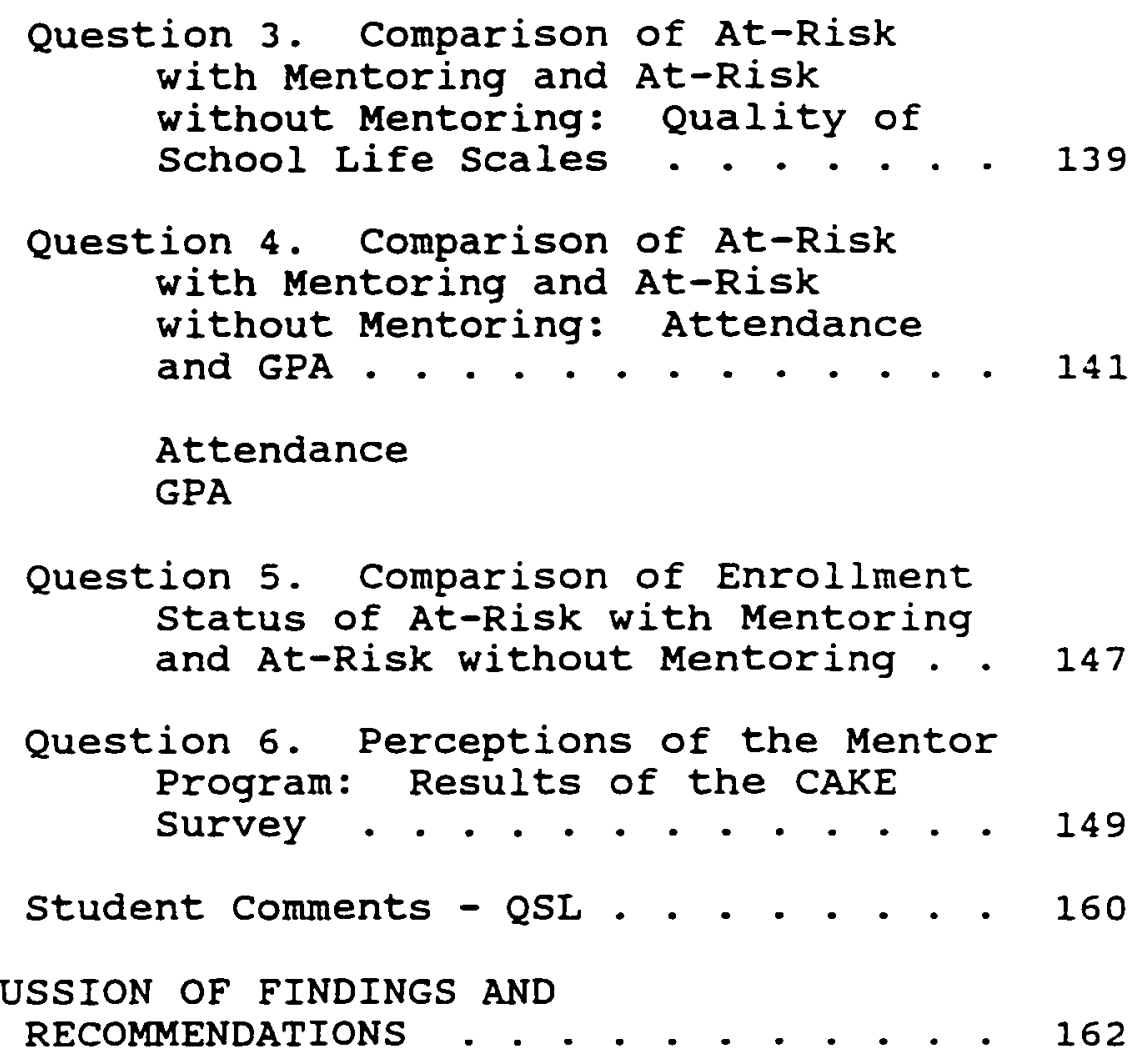

Question 4. Comparison of At-Risk

with Mentoring and At-Risk

without Mentoring: Attendance and GPA . . . . . . . . . . . . 141

Attendance

GPA

Question 5. Comparison of Enrollment Status of At-Risk with Mentoring and At-Risk without Mentoring . . 147

Question 6. Perceptions of the Mentor Program: Results of the CAKE Survey . . . . . . . . . . . . 149

Student Comments - QSL . . . . . . 160

RECOMMENDATIONS • . • • • • • • • . . 162

$V$ DISCUSSION OF FINDINGS AND

Statistical Findings:

Interpretations . . . . . . . . . 164

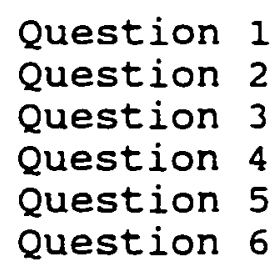


APPENDICES

A QSL ITEM CHARACTERISTICS . . . . . . . 204

B MENTOR (STAFF) CAKE SURVEY . . . . . . . 206

C MENTEE (STUDENT) CAKE SURVEY . . . . . . . 217

D PRETREATMENT ANALYSES . . . . . . . . . . 228

E ANALYSES OF QUESTIONS 1 THROUGH 4 . . . . . 230

F HUMAN SUBJECTS CONSENT FORM . . . . . . . . 240 


\section{LIST OF TABLES}

TABLE

PAGE

1. Gender of subjects . . . . . . . . . . . . 94

2. QSL Questionnaire, Subscale, and Total

Scale Means and Standard Deviations

for Research Sample for Norms and

Study Sample of Students in the $9 \mathrm{th}$

Grade • • . . • • . . • . • . . • . 99

3. Overview of QSL Sample Sizes within the

Three Cohorts... . . . . . . . 101

4. Overview of Data Collected from Year 0

through Year 5 . . . . . . . . . . . . 109

5. Analysis of Variance with Respect to

Pretreatment Comparisons: Cohorts 1,

2, and 3, At-Risk and Not At-Risk . . . . 113

6. Analysis of Covariance with Respect to Quality of School Life Scales (QSI)

At-Risk versus Not At-Risk Combined

Cohorts................. 115

7. Analysis of Covariance with Respect to

Attendance Rates At-Risk versus Not

At-Risk Combined Cohorts . . . . . . . 115

8. Analysis of Covariance with Respect to

Average Annual GPA At-Risk versus Not

At-Risk Combined Cohorts . . . . . . . . 116

9. Analysis of Covariance with Respect to Quality of School Life Scales; At-Risk With Mentors, At-Risk Without Mentors, and Not At-Risk Combined Cohorts . . . . . 117

10. Analysis of Covariance with Respect to Attendance Rates for students At-Risk With Mentors, At-Risk Without Mentors, and Not At-Risk Combined Cohorts . . . . 
11. Analysis of Covariance with Respect to the Quality of School Life Questionnaire for At-Risk students with and Without Mentors -- Year 1 to Year 2, Cohorts

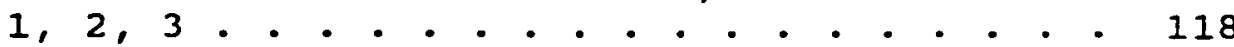

12. Analysis of Variance for Attendance by AtRisk Students with Mentors versus No Mentors (All Possible Subjects) . . . . . . 119

13. Analysis of Variance for GPA (Average) by Mentors versus No Mentors Cohorts 1

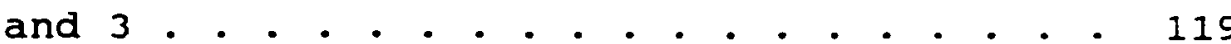

14. Percentiles and Chi-Square Analysis of Enrollment Status After Year 4 for All At-Risk Students . . . . . . . . . . . 120

15. Selected Survey Questions: Comparisons Between Mentor and Mentee Responses . . . . 121

16. Analysis of Variance with Respect to Pretreatment Comparisons by cohort for At-Risk and Not At-Risk . . . . . . . . 123

17. Analysis of Variance Prior to Treatment, Total Quality of School Life Scale. At-Risk versus Not At-Risk, Combined Cohorts... . . . . . . . . . . . 126

18. T-test Analysis Prior to Treatment on Attendance and GPA, At-Risk versus Not At-Risk, Combined Cohorts . . . . . . . 128

19. Analysis of Covariance with Respect to Quality of School Life Scales (QSL) At-Risk versus Not At-Risk Combined Cohorts . . . . . . . . . . . . . .

20. Analysis of Covariance with Respect to Attendance Rates At-Risk versus Not At-Risk Combined Cohorts . . . . . . . .

21. Analysis of Covariance with Respect to Average Annual GPA At-Risk versus Not At-Risk Combined Cohorts . . . . . . . . 
22. Analysis of Covariance with Respect to

Quality of School Life Scales, At-Risk

With Mentors, At-Risk Without Mentors,

and Not At-Risk Combined Cohorts . . . . 135

23. Analysis of Covariance with Respect to

Attendance Rates for students At-Risk

With Mentors, At-Risk Without Mentors,

and Not At-Risk, Cohorts 1 and $3 .$. ..

24. Analysis of Covariance with Respect to GPA for Students At-Risk With Mentors, AtRisk Without Mentors, and Not At-Risk

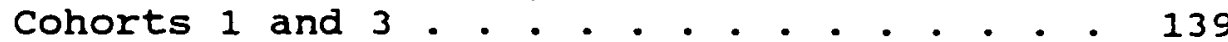

25. Analysis of Covariance with Respect to the Quality of School Life Survey (QSL) for students At-Risk: Mentor versus No Mentor Combined Cohorts . . . . . . 141

26. Analysis of Covariance with Respect to Attendance for Students At-Risk Mentor versus No Mentor Cohorts $1 \& 3$. . . . . . 144

27. Analysis of Covariance with Respect to GPA for students At-Risk Mentor versus No Mentor Cohorts $1 \& 3$. . . . . . . . . .

28. Chi-Square and Percentage with Respect to Enrollment Status After Year 4 for All Students At-Risk Mentor versus No Mentor

29. CAKE Survey - Selected Questions: Rate of Participation for both Mentors and Mentees . . . . . . . . . . . . 150

30. CAKE Survey - selected Questions:

Program's Value for both Mentors and Mentees . . . . . . . . . . . . . .

31. CAKE Survey - Selected Questions: Expectations of the Program Mentors . . . 151

32. CAKE Survey - Selected Questions: Mentee in Mentor's Class . . . . . . . . . . . . 152

33. CAKE Survey - Selected Questions: Interest Match between Mentor and Mentee . . . . . 
34. CAKE Survey - Selected Questions:

Meetings/Activities with Mentor and

Mentee

35. CAKE Survey - Selected Questions:

Communication between Mentor and

Mentee . . . . . . . . . . . . . 155

36. CAKE Survey - Selected Questions:

Training/Inservice for Mentors . . . . . 157

37. CAKE Survey - Average Ranking of Mentor

Expectations/Need for Inservice

Training

38. CAKE Survey - Selected Questions: Outcomes

from CAKE Program Mentees . . . . . . . 158

39. CAKE Survey - Selected Questions: Ranking

of Attributes for Success of CAKE

Mentoring Program Mentors . . . . . . . 159 


\section{CHAPTER I}

\section{INTRODUCTION}

statement of the Problem

Public concern for fiscal responsibility, accountability, and student achievement has generated questions regarding the quality of current educational programs. Are schools educating young people to take their place as the next generation of workers? As a nation, approximately one in four of today's teenagers drop out of high school. In an attempt to curtail the dropout rate, the business and education sectors are becoming more involved in attempts to re-engage at-risk students in schools and in mentoring young people, thereby bridging the gap between school and the workplace. This mentoring process has been defined as "the linking of a person of specific experience in a learning-oriented relationship with a younger, less experienced person" (Lambert \& Lambert, 1982, p. 12). Around the country, schools are already using the concept of mentoring in a variety of forms: some are business or community oriented, others use peer students as mentors, and a few use school personnel. 
The purpose of this study was to evaluate a high school mentoring program, CAKE (Caring About Kids Effectively), particularly related to its effects on students identified as at risk of dropping out of school; staff, both teachers and support personnel, were used as mentors. This research examined the literature on student mentorship programs and reported longitudinal data on such indicators of school success as student achievement, attendance, attitudes, and dropout information. In addition, this study examined participant perceptions on the usefulness of program activities and characteristics that appear to be successful.

For a variety of reasons, mentoring has emerged in schools as an intervention strategy for at-risk students. It is also popular with the educational sector. According to Freedman (1991), mentoring appears simple. As one-onOne materials state, "Maybe you can't change the world, but you can make a difference in the future of at least one young person" (U.S. Department of Education, 1992, p. 1). In some cases, mentoring may meet the needs of public concern for fiscal responsibility; it uses volunteers. Mentoring is direct, as youth experience personal contact without layers of bureaucracy. Mentoring is legitimate and positively perceived:

It is a sanctioned role for unrelated adults to play in the lives of youth, as reflected by the 
many stories that help maintain its honored place in our culture. (Freedman, 1991, p. 37) Lastly, mentoring is flexible. Mentoring has a positive effect on both the mentor and mentee. As Freedman (1991) states:

At one level, mentoring speaks to the American traditions of individual achievement, progress, and optimism. It is connected to an improved work force and economic competitiveness... At the same time, mentoring has another, more subtle allure. This aspect speaks to yearning for community lost, to a time of greater civility and responsibility for strangers. (p. 37)

The key question then becomes, what are the outcomes, if any, of planned mentoring programs involving teachers linked with at-risk students? Flaxman and Ascher (1992) noted, "Unfortunately, we know very little about what mentoring will accomplish, because there is very little research on its effects" (p. 8).

The study of the CAKE program had five quantitative research components. Indicators of school success (GPA, attendance, and attitudes toward school) were compared between at-risk students and those not at-risk. Indicators of school success were analyzed over the period of time at-risk students were mentored to find any significant changes. Indicators of school success and enrollment status at graduation were compared between atrisk students, with and without mentors. And, participants' perceptions using a researcher-constructed 
questionnaire were given to both mentees and mentors to determine those activities that were successful, and those that needed to be re-evaluated.

This study provided a comprehensive evaluation of mentoring as an intervention and thereby could provide guidance to other schools striving to keep students in school and functioning successfully in the educational setting.

\section{Background}

The American public is concerned with the lack of preparation of today's youth. According to the report by the National Commission on Excellence in Education, our nation is at risk because "the educational foundations of our society are presently being eroded by a rising tide of mediocrity that threatens our very future as a nation and a people" (National Commission on Excellence in Education, 1983, p. 5). In response, most states have enacted sweeping school reform measures, including school districts in oregon. Administrators and teachers are attending staff development sessions on instructional strategies and curriculum developed in establishing and maintaining a climate conducive to academic learning and achievement. Increases in credit hours mandated for graduation and state-wide assessment of content areas have 
been implemented in an effort to assure the public that high school graduates meet the academic standards required in a global economy. While all the good news remains in the forefront of our policy discussions, most educational reform ignores some of the bad news. That is, students at risk will suffer.

According to the National Center for Education Statistics (1996), the national dropout rate (25\%) remains unchanged for the past ten years. When comparing high school graduates with nongraduates from the class of 1994 with the preceding year, U.S. schools had a graduation rate of $72 \%$ (or $28 \%$ early leavers). The dropout rate in the urban cities jumps to $35 \%$ and in some districts averages $50 \%$ (Schwartz, 1995). In addition, dropout rates are much higher for Native American, Hispanic, and Black students, ranging from $35 \%$ to $85 \%$. The dropout rate among Blacks is twice as high as that among whites, although four out of five dropouts are White. Urban students drop out more frequently than suburban students, Hispanics more frequently than Blacks, and males more frequently than females (Rhodes \& McMillan, 1987, p. 34).

The nation's dropout problem cuts across all ethnic, social class and geographic lines, with poverty, race, and the changing family structure compounding the problems facing today's youth. over the past decade, the 
environment in which children grow up has changed

dramatically. According to recent estimates compiled from the Bush Center in Child Development and Social Policy at Yale University:

Sixty-five percent of all students now have working mothers, compared with $46 \%$ in $1976 ; 50 \%$ of marriages end in divorce; 15.3 million children or $25 \%$ of all children live with just one parent compared to $17 \%$ of all children in 1976; and one out of five American children lives in poverty. (Mernit, 1990, p. 35)

It would be reasonable to assume that the figures since 1990 have continued to rise as well.

students from racial or ethnic minorities and recent immigrants with limited proficiency in English not only have the risks inherent in poverty, but also prejudice, bias, and differential access to opportunity structures. The majority of dropouts throughout the nation fall within the average IQ range; therefore, they have the ability to complete a high school education. However, students with low-average ability face an even tougher challenge. The most depressing figures are those $25 \%$ of the country's most intelligent students (IQ above 110) who drop out prior to graduation.

It is estimated that between 18 and $25 \%$ of gifted and talented students drop out. This number may appear to be insignificant when one considers that the gifted population probably represents no more than $10 \%$ of the entire student body; however in the eyes of many, this group represents a major loss of potential to self and society. (Robertson, 1991, p. 62) 
Add to this the problem of dysfunctional families, a greater influx of non English-speaking refugees, drugaffected and abused children entering the school system, and increasingly fewer resources for the educational sector to rely upon in dealing with these pressures. These factors will ultimately have additional and potentially catastrophic effects on the nation's dropout problem.

Although Oregon's dropout rates have traditionally mirrored the national rate, in recent years this rate has jumped from $5.7 \%$ in 1991-92 to $7.2 \%$ in the 1995-96 school year. As reported in the yearly publication of oregon's dropout rates by Oregon's Department of Education (1997), the four-year dropout rate for the class of 1996 in oregon's schools is $26.6 \%$; it was $25 \%$ in 1983 . Even more staggering are the reports from the National center for Education statistics (1995) of the large increase in dropouts at the 8 th grade level. In $1990,7 \%$ of the 8 th grade class of 1988 were dropouts; they were not enrolled in school and had not finished high school. In 1992, 12\% were dropouts. Additional findings in oregon include a dropout rate for Hispanic students that is more than double the overall statewide rate, males had a slightly higher dropout rate than females, and one-third of 
dropouts were enrolled in the school district one year or Iess.

Compounding the problem, taxpayers in oregon have passed several property tax-cutting measures that have and will continue to reduce the amount of money available to educate students. As stated in an article on educational funding in the oregonian,

Since Measure 5 passed in 1990, the money available for public schools in oregon has declined about $15 \%$ per student when adjusted for inflation. (Carter \& Herzog, 1997, p. Al)

The average revenue from all sources per student in 1991 was $\$ 4,033$ versus $\$ 3,439$ in 1997 . There is little dispute that schools face public pressure to improve the skills that graduates possess, but at the same time must expand services to at-risk students that are both cost-effective and reduce the number of dropouts.

The costs of dropouts are staggering when one considers that $70 \%$ of the nation's prison inmates never completed high school. A recent survey of oregon's inmate population revealed that $71 \%$ were high school dropouts (Jones, 1997). The cost in oregon to incarcerate an inmate is $\$ 53.73$ per day versus $\$ 6.00$ a day per student to operate a dropout prevention program in terms of an alternative school-within-a-school. This figure approaches $\$ 20,000.00$ per year per inmate in oregon's 
prisons. That figure is very close to the salary of one beginning school teacher for one year!

This figure is even more staggering, considering the cost estimates projected by Levin (1972) at $\$ 71$ billion lost tax revenue from high school dropouts aged 25 to 34 , welfare and unemployment costs of $\$ 3$ billion, and crime and crime prevention costs of $\$ 3$ billion. These numbers continue to grow. In 1985-86, more than 600,000 young people dropped out of school, at a projected cost to society of $\$ 120$ billion in lost productivity during their Iifetimes. The U.S. General Accounting office in 1986 estimated that the disparity between earnings for graduates and dropouts increases every year. For example, in 1966 the difference was $12 \% ;$ in 1978 the difference was 24\% (Catterall, 1987). Today, according to schwartz (1995), the differences between dropouts and high school graduates continues to be evident:

- In the last 20 years the earnings level of dropouts doubled, while it nearly tripled for college graduates.

- Recent dropouts will earn $\$ 200,000$ less than high school graduates, and over $\$ 800,000$ less than college graduates, in their lives.

- Dropouts make up nearly half the heads of households on welfare.

- Dropouts make up nearly half the prison population. (p. 4) 
These costs should also be measured in terms of potential cognitive development and productivity of its citizens, particularly in our complex and changing technological society. At a time when declining birthrates might indicate a smaller pool of potential employees, the nation's economic growth demands higher numbers of entrylevel employees. Business leaders are increasingly worried about this ill-prepared pool of workers and will have to rely on these workers if the current trend continues (Education Commission of the States Business Advisory Commission, 1985, p. 17).

The era of school dropouts securing jobs requiring little or no skill is past.

The gap between dropouts and more educated people is widening as opportunities increase for higher skilled workers and all but disappears for the less skilled. (Schwartz, 1995, p. 4)

It is estimated that, by the year 2010, the growth of the knowledge economy will reduce the need for low-skilled jobs in agriculture and industry to only $2 \%$ of the workforce. In addition, "between 1994 and 2005, job openings will average 1,040,000 annually, while college graduates joining the labor force are expected to average $1,340,000$ each year" (Slater, 1997, p. 7). Assuming this statistical forecast is correct, it is apparent that an unskilled worker will have an extremely difficult time competing for jobs. 
since many of these dropouts come from families who also have had limited educations and higher rates of unemployment, the failure of schools and society to keep these students in school contributes to the continuation of this cycle of poverty. Other social costs related to unfinished high school educations include the likelihood of dropouts becoming involved in delinquent and criminal activities. This then leads to the higher utilization of services such as welfare, unemployment compensation, and other social services that have higher costs than most dropout prevention programs (Green \& Baker, 1986, p. 3). The growing concern over the state of education in the nation, resulting in the National commission on Excellence in Education's 1983 report, A Nation at Risk: The Imperative for Educational Reform, spawned a nationwide movement to reform our educational system to foster excellence. Oregon's answer was the development of the certificate of Initial Mastery (CIM), certificate of Advanced Master (CAM), and additional requirements for graduates. This will divert funds from alternatives to supporting these new programs. Not only does the current excellence movement divert much needed attention from the dropout problem, it may actually contribute to its increase. A recent report by the Education Commission of the states (1985) noted that 
As emphasis on higher academic achievement rises, low achievers are likely to throw in the towel... Unless schools take special measures to keep "on the edge" students from going over the edge we can expect dropout rates to rise. ( $p$. 3)

This is not likely to change. An open debate continues as to the effects of balancing equity and funding. The cost here is the issue of equity. This excellence movement may have discriminatory effects on the education of at-risk children, many of whom are minority children.

There is another economic reason that the rising dropout rate deserves considerable attention: increased controversy over the sources of school revenues and declining school enrollments which in turn causes declines in school revenues. Most school districts around oregon have alternative programs in place to combat the dropout problem. These programs are now in jeopardy, with the passing of such tax-limiting measures as Ballot Measure 5 and Ballot Measure 47 from 1990 to 1996 in Oregon. Millions of dollars are being cut from school districts' budgets. Programs with low student/teacher ratios are cut first. These will include alternative programs, electives with low student numbers, and other elective, creative, but more costly programs. The students who will suffer the most are the at-risk students. Now, not only are the standards for receiving a high school diploma higher and more difficult to obtain with state testing requirements 
and the CIM/CAM programs, but the programs that help keep our at-risk students in school could increasingly disappear. Not only for the sake of the nation's future, but for the immediate future of individual schools, administrators and school boards must meet the demands of the at-risk population of students (Wehlage, 1983, pp. $16-17)$

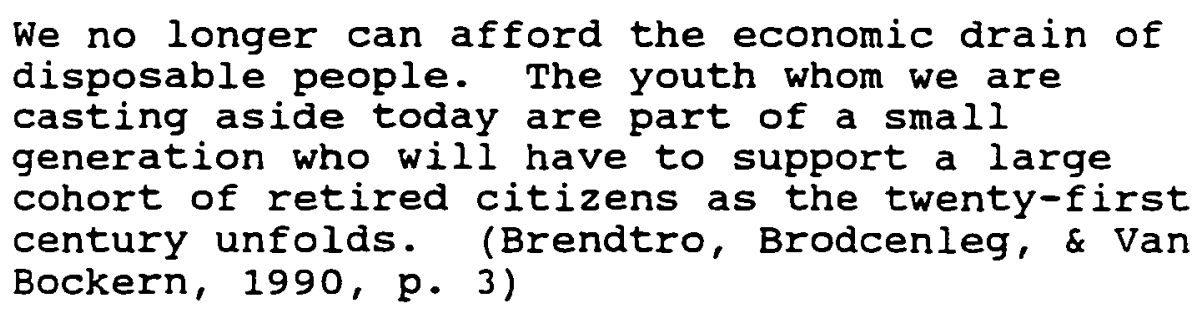

Rationale

A great deal of literature surrounds the characteristics of students at risk of dropping out of school. There exists a multitude of factors outside of school that put students at risk; add to that the interaction of those students with certain school experiences and the results are often discouragement and withdrawal. Educators can do little to influence or $f$ ix environmental factors placing students at risk, but they can take active roles in responding to fundamental needs unmet by contemporary schools. Current research literature suggests that potential dropouts share common characteristics. Among these, students perceive school as 
a hostile place where they continue to experience failure and frustration (Rhodes \& MCMillan, 1987). Another is the inability to develop positive relationships with teachers, adults, and even peers who are seen as an authority figure (Pallas, 1986).

One need shared by most students is a sense of school membership and having adult role models who encourage, advise, and care. Although teenagers turn to peers for advice on current styles or trends, when there are questions of important life crises or future options, they look to adults for answers (Ianni, 1989). Due to the changing nature of traditional sources of support in the family unit for adolescents, it has become increasingly important for the non-related adult to facilitate the healthy development of our youth (Schonert-Reichl, 1992). Positive teacher-student relationships have been widely documented as having a direct and beneficial influence on student achievement in school. This could be one area for solutions to the dropout problem (Cuban, 1989; Rhodes \& McMillan, 1987).

Researchers have found that school dropouts often cite, as one of the primary reasons for leaving, the absence of one person who cared about them. The assumption that all adolescents need support or advice from adults does not address the fact that the more at- 
risk adolescent does not know how to ask for help. The literature suggests that our schools and communities need to make it easy for adolescents to seek help and even advertise that adult resources are available (Ianni, 1989). That being the case, help does not always reach the target groups.

Research, such as Werner and Smith's (1982) longitudinal research of 700 youth growing up in high risk environments, found that an adult relationship (i.e., mentoring) provided a protective factor for youth in stressful family conditions. One caring adult can make a big difference in a young person's life (Smink, 1990). Augmenting these long-term examinations of the effects of a mentoring relationship are many biographies and case studies of successful individuals that affirm the pivotal role supportive adults played in the success of youths' lives that they mentored. For example, Bernard Lefkowitz's (1989) book, Tough Change: Growing Up on Your Own in America, is based on interviews with 500 disadvantaged youth, a majority of whom credit their success to the mentoring and support of a caring adult in their lives. The positive effect on gifted students of a mentoring relationship has also been well established in the review of the literature (Kaufman, Harrel, Milam, Woolverton, \& Miller, 1986; Levinson, 1978). 
The Education Commission of the states (1985) has listed mentoring as one of the five short-term imperatives for reversing the high dropout rate among high school students. Flaxman, Ascher, and Harrington (1988) concluded, in their study involving disadvantaged youth, that mentoring is a powerful way to provide adult contacts for youth who are isolated from adults at home, in schools, and in their communities.

The self-perceived needs of at-risk students include having teachers who are supportive and caring, getting good grades, being a part of the school, and having positive communication on the options available to them (Applegate, 1981; Beardon, Spencer, \& Moracco, 1989; Mahan \& Johnson, 1983). Many of these perceived needs can be addressed in a mentor program, especially where teachers mentor at-risk students. While the literature on mentoring has grown significantly in the last seven years, most program evaluation research which links the success of at-risk youth with having a caring adult relationship created through a planned mentoring program exists primarily as descriptive rather than experimental. Research on mentoring using experimental designs is scarce. Examples of program research using experimental designs include Cave and Quint's (1990) evaluation of "Career Beginnings," McPartland and Nettles" (1991) study 
of "Project Raise," Ferguson's (1990) study of programs for African American males, and Higgins' (1991) study of the "I Have A Dream" program.

There is a lack of clear evidence on the effects of a teacher mentoring relationship on the low-achieving, potential high school dropouts. Results of studies have reported effects of using teachers as mentors. Abcug's (1991) evaluation of TASK found positive effects on attendance, achievement, discipline, and attitudes toward school on at-risk students when using teachers as mentors over a year's time. Studies and articles on staff mentoring programs in individual secondary schools nationwide are also reporting positive effects on the attendance, achievement, attitudes, and environment of the school.

For this reason, a mentor program was developed and implemented to assist in reducing the dropout rate of students identified as at-risk of dropping out prior to entering the 9 th grade in a selected suburban secondary school. The program, CAKE (Caring About Kids Effectively), had as its primary function to establish relationships between teachers and support staff (as mentors) and students identified as at-risk. These staff mentors were to provide support and guidance to at-risk students by placing a great deal of emphasis on 
interpersonal relationships, problem solving techniques, and communication skills, and by encouraging positive behavior, study habits, and attendance.

Each one of these at-risk 9 th grade students need one staff member, a counselor, or teacher, to guide him through his high school career... and this person should get to know the student well. (wiles, 1963, p. 165)

An evaluation of this staff mentoring program for at-risk students will add to the needed longitudinal studies already in existence.

\section{Purpose of the study}

The purpose of this study was to examine the effects of a mentoring program, CAKE, matching at-risk students with staff from a secondary suburban high school. Data from attendance and GPA records, along with a school Life Survey which measures attitude towards school and a program survey, were analyzed in the investigation of the following questions:

1. Are there significant differences on the subscales and total scale of the Quality of School Life Scales (QSL), attendance rates, and GPA between students identified as at-risk and students not at risk?

2. Are there significant differences on the subscales and total scale of the quality of 
School Life Scales (QSL), attendance rates, and GPA between students identified as at risk with mentors, at-risk without mentors, and not atrisk?

3. Are there significant differences in attitudes as measured by the QSL between at-risk students with mentors and at-risk students without mentors?

4. Are there significant differences regarding attendance rates and GPA for at-risk students with mentors and at-risk students without mentors?

5. Are there significant differences in the enroliment status for the at-risk students with mentors and the at-risk students without mentors?

6. What are the participants' perceptions of the effectiveness and characteristics concerning the CAKE program?

Definition of Terms

A number of terms used in this study require specialized definitions. These appear below:

At-risk. In this study the term is used to denote students at risk of failure to complete an appropriate 
academic program. This term became known with the publication of A Nation At Risk (National Commission on Excellence in Education, 1983). Students become at-risk for a variety of reasons: economic, intellectual, physical, psychological, sociological, and racial biases. For the purposes of this study, students having three or more characteristics of the following behavior:

1. Attendance problems

2. Low performance and achievement, subject and grade failure, many times one or two grades below level

3. Comes from a lower socioeconomic background

4. Negative attitude about school

5. Low self-esteem

6. Family history of school failure

Attendance. This term refers to the total number of days a student attended school out of a possible 180 days offered. Data were gathered through records supplied by the attendance secretaries at both the middle and high schools.

\section{CAKE (Caring About Kids Effectively). This term} refers to a staff mentoring program for students at a secondary high school in oregon who were identified as atrisk of dropping school prior to completion. 
Cohort. This term describes a single group of students who began the mentor program during a specific time period.

Dropout. This term is sometimes used in the literature and school district policies to describe students who leave school (early leavers) for any reason except death before completing an educational program.

Enrollment status. This term refers to the student's status at the end of four years at the high school. For purposes of this study, enrollment status is identified as graduated, transferred, GED, dropped out, or returning (to school for a fifth year).

GED. This term refers to a General Equivalency Exam, a test given to students as an alternative way to earn a high school equivalency degree (General Education Diploma).

GPA. This term refers to a grade point average, whereby the letter " $\mathrm{A}$ " $=4.0$ points, " $\mathrm{B}$ " $=3.0$ points, " $\mathrm{C}$ " $=2.0$ points, $" D "=1.0$ points, and "F" $=0.0$ points .

Mentee. This term refers to one who feels his or her personal or professional growth was or is fostered by another (Krupp, 1985). In this study, a "mentee" or "protege" was the student at risk of dropping out of school who had a staff employee of the high school as a mentor. 
Mentor. According to the Thesaurus of ERIC Descriptors (1990), "mentor" refers to the

trusted and experienced supervisors or advisors who have personal and direct interest in the development and/or education of younger or less experienced individuals, usually in professional education or professional occupations. (p. 161)

In this study, the "mentor" was a certified teacher or other support staff person currently employed at the high school who agreed to serve in the role of mentor.

Mentoring. This term refers to a process by which a trusted and experienced supervisor or advisor takes a personal or direct interest in the development and education of a younger or less experienced individual (Thesaurus of ERIC Descriptors, 1990). In this study, "mentoring" is a highly complex people-related skill, involving a one-on-one relationship between a caring adult and a student who needs support to achieve academic, career, social, or personal goals.

Mentorship. This term refers to a cooperative arrangement between two people that exists to share the practical experiences, knowledge, and expertise on the part of the mentor that are designed to enhance the professional or personal growth of the protege. In this study, the "mentorship" was the formal match-up of an atrisk high school student and a staff member from the same high school as part of the CAKE mentoring program. 
Treatment. This term refers to the assignment of a staff mentor to a student identified as at risk of dropping out of school.

\section{Limitations}

One must be cognizant of limitations inherent in the design of any study. Therefore, concerns or limitations as seen by this researcher at the outset of this study are seen as means to caution readers in advance as to areas which may be flawed. However, it may be noted that every avenue or record available to the researcher was investigated thoroughly for this research. Responsibility for limitations inherent in any process reliant on accurate record keeping is non-specific and diffuse.

Threats to internal validity in research involving at-risk students are evident in this study. The threat to validity in terms of mortality is evident in the data set. Missing elements and incomplete data on some students are due to either subjects leaving the district prior to all testing being completed, or records nonexistent for GPA and attendance for some students prior to the 9 th grade. GPA data in this school district were not kept in a printout form for students prior to 1988 in the 8 th grade. Thus, the Pretreatment data for Cohort 2 was extracted from 9 th grade records for Questions 1 through 4 . This 
researcher was able to extract 8 th grade attendance data for cohort 2 from individual cumulative files, in order to compare the cohorts as being equivalent prior to analysis for Questions 1 through 4. Half of the 130 students identified for the study in cohort 1 left school during the first five months of the first year. Inherent in the study of at-risk students is the mobility of this group, particularly those without mentors.

Threats to instrumentation are also apparent in the study. The researcher had no control over students actually identified to be mentored. Criteria for selection of at-risk students were given to 8 th grade counselors, described in Chapter III. These Iists were given to the 9 th grade counselors to match with mentors. Both the number and severity of factors that contributed to the "at-riskness" of that student makes generalizing the data difficult.

Due to ethical and practical constraints, the random selection for experimental and control groups was not used. Mentees were selected by either the 9 th grade counselor due to severity of at-risk characteristics or at the request of the staff member due to similar interests. It was difficult to assure the at-risk students' composition of the control group, those without mentors, 
actually shared the same characteristics as students who were "chosen" as mentees.

The difference in sample size between those students with mentors and without creates problems for any explanation of significant differences. The researcher had no control over the mentors transferring or retiring during the study. This made sample sizes and demonstrating causal relations difficult to demonstrate. The experimental treatment was not tightly prescribed. The researcher had no control over the level of participation mentors had with their mentees. Evidence of the disparity in activities and levels of involvement are evident in chapter IV's review of Question 5. The researcher was dependent on teachers to administer the attitude survey. Communication was given as to the importance of this kind of data in evaluating any program, but as evidenced in the sample sizes, some chose not to participate.

Maturation could be a minor threat to validity in this study. The fact that cohort 2 is comprised of students one year older than cohorts 1 and 3 is a factor. The researcher used pretreatment analysis and analysis of covariance to lessen the effects of maturity due to this.

The researcher and reader must also be aware that the Hawthorne effect and regression towards the mean may also 
threaten any demonstration of causality between those students with mentors and those without. Student knowledge that the program existed may have caused the positive effect on at-risk students with mentors. It is evident that regression toward the mean is a factor for the data on at-risk students followed over the four-year period of time. It is apparent to this researcher that changes in attitude, grades, attendance, or enroliment status were not necessarily due to the presence of an adult mentor. A variety of environmental factors, such as a change in family conditions, maturity, and environment, could have also accounted for some of the changes in behavior.

This researcher was aware of the numerous threats to validity and limitations inherent in studying at-risk students. The importance of the subject overshadowed these difficulties. The plight of at-risk students is very real. Just because pristine research cannot easily be conducted with the group does not mean it should not be done at all. This researcher is left with a strong belief that the threats to validity illustrate how resistant to change at-risk students find themselves to be. The researcher believes that, by continuing to examine research, results with clear implications for practice will be found. 
CHAPTER II

REVIEW OF THE LITERATURE

The review of the literature is presented in four sections: (a) a review of educational reform in general and its relationship to students at risk, (b) the characteristics of at-risk students, (c) programs for at-risk students, and (d) mentoring.

Educational Reform

This section of the review of literature will focus on the national educational reform reports and studies which have had an impact on state and ultimately district level decisions regarding at-risk students.

of all the educational reports calling for reform in the 1980s, the 1983 report from the National Commission on Excellence in Education, entitled A Nation at Risk: The Imperative for Educational Reform, was the first major report to give impetus to the need for drastic educational reform. This report offered little to those students at-risk. Among other things, the report recommended increasing the number of required academic courses in high schools, student discipline codes that would make more efficient use of class time, more rigorous textbooks, 
longer school days and years, grouping and promotion of students according to progress rather than chronological age, and incentives for teachers.

In analyzing the movement for school reform and its implications for potential dropouts, the recommendations seem directed largely at the upper third of the student body, with scant concern for the student at-risk, and fall in three broad areas: course content, use of time for instruction and learning, and student achievement. Recommendations by the National Commission on Excellence in Education (1983) included more demanding sequences of basic courses such as science and mathematics and elimination of the soft, nonessential courses. Better use of time in class and longer school days were recommended, along with more time spent on homework, the initiation of rigorous grade promotion policies by which students will be promoted only when it is academically justified, and the use of standardized tests to monitor student achievement. These recommendations are all based on the assumption that there will be no negative consequences associated with more demanding standards. They fail to consider the student in the most fragile position and in the greatest need - the potential dropout.

A paper, presented at the National Invitational Conference on Holding Power and Dropouts by professors of 
Education at Columbia University, summarized the effect of raising standards on the potential dropouts' chances of finishing high school.

The main reasons students dropout of school are poor grades and family and money problems. Raising standards for time spent in school, content of the curriculum, and amount of homework may further compound students' problems and cause even more of them to drop out. (Nafriello, McDill, \& Pallas, 1985, p. 11)

When the curriculum is narrowed from a fairly broad choice of classes to a more academic focus, students with limited ability (typically displayed by potential dropouts) have to face repeated failure. A more flexible curriculum that includes the "not-so-basic" courses allows those students some sense of success and perhaps a positive environment, rather than a negative one.

Duke (1985), in his article "What is Excellence and Should We Try to Measure It?" said:

It could be argued that higher standards for passing courses and meeting graduation requirements provide necessary incentives. But practical experience tells us that this prescription will not work for all students, particularly the reluctant learners. (p. 673)

Analysts have concluded that student attitudes play a major role in determining performance. Students are found to perform close to their own estimates of their ability.

If you want to increase achievements in math and science. you should look... into how you can increase a kid's interest in becoming an engineer, for example. (Duke, 1985, p. 673) 
Motivation is also the key to encouraging students to spend additional time on school tasks, namely homework. Longer school days and years may add little to real learning time. Such demands, particularly for the potential dropout, may be problematic; these students are more likely than other students to have assumed adult responsibilities related to families and jobs. Furthermore, increasing time spent on school work may prevent participation in extracurricular activities, thus denying those students who need a tie to the school other than just their classroom work. These extracurricular activities provide an attachment to school and provide an avenue of success. Increasing time demands on the potential dropout is easily resolved by leaving school. Because of such time constraints placed on the potential dropout, flexible time options should be provided these students (MCDill et al., 1987, p. 189).

It is clear that, if academic standards are raised and students are not provided substantial remediation within the limited time they can devote to classroom work, socially and academically disadvantaged students will be more likely to experience frustration and dropout of school. Duke (1985) forecasted this danger in the excellence movement (or standards movement) of the 1990s, as measured by standardized tests, as too much stress 
being placed on "one best way" and the single "right way" or "right answer".

We must ask whether an overemphasis on conformity during the formative years exacts too great a price in human development and creativity. (p. 673)

Fortunately, about the same time as the aforementioned reports came out, more useful suggestions were offered in studies by Goodlad (1983) and Boyer (1983) for students at risk of dropping out of school.

Boyer's (1983) book, High School: A Report on Secondary Education in America, followed the National Commission on Excellence in Education Report (1983) by only five months. Moreover, "High school is one of the longest and probably the most comprehensive of the reform studies" (Presseisen, 1985, p. 67). Boyer's book was based on a two-year research project of 15 schools and funded by the Carnegie Foundation for the Advancement of Teaching. He recommends strong studies in the arts, health, technology, and introductory vocational education, as well as the usual academic areas. Students would take a core curriculum one-third of the time in school, with the remaining for electives to meet individual needs and interests. Pertaining to students at-risk, Boyer advised close relationships between students and counselors or teachers who are trusted by students. He suggested also identifying failure patterns as early as possible and 
providing alternative programs for those students who need it. These programs should set reasonably high standards while passing a feeling of belonging to their students. A Place Called School: Prospects for the Future by Goodlad (1983) was the culmination of an eight year examination of 38 schools, 17,163 students, 1,350 teachers, and 8,624 parents; it sounded the alarm for at-risk students. He was especially concerned about the large

group of students who do not grow up in academically oriented households, or who experience cumulative difficulties with school-based learning, or who are not turned on by academics, or simply cannot or do not wish to defer employment. (p. 91)

According to Goodlad,

there is evidence to suggest payoff for these students from intervention programs that comprehensively include a more careful sequencing of the curriculum, more frequent use of motivational devices and alternative approaches to learning. (p. 91)

He mentioned concern about the passiveness in students and the rather traditional style of teaching. He recommended a balanced academic curriculum, and insists that if one instructional method does not work with a student, others should be tried. He advised teachers to humanize the learning and knowledge to make learning less abstract. He recommended avoiding inflexible schedules and ability tracking, in favor of non-graded, continuous progress 
reporting that accepts individual differences and supports differentiated development. All of these recommendations are extremely important to the student at-risk.

Sizer (1984), in his book, Horace's Compromise: The Dilemma of the American High School, observed that:

Far too few modern American adolescents are hungry...that the American high school student, as student, is all to often docile, compliant, and without initiative. Some who have initiative use it to undertake as little engagement as possible with school. They await their education and take in such of it that interests them. Such students like to be entertained. Their harshest epithet for a teacher is "boring"... There are too few rewards for the inquisitive; there rarely is extra credit for the ingenious proof. The constructive skeptic can be unsettling to all too many teachers, who may find him cheeky and disruptive. Questing can be costly. (pp. $54-55)$

This passage fits the profile of many at-risk students who do not exhibit an initiative to achieve in school. He called for the personalization of the educational process to help promote a student's self-esteem.

Personalization absolutely implies options for students, different ways and setting for differing individuals. While total personalization is practically impossible, much is clearly attainable within the kinds of constraints usually found in many high schools. The biggest hurdle will be adult attitudes, particularly those that confuse standardization with standards... Every adult likes to be respected and enjoys being given responsibility... Adolescents are no different from us in this respect. Therefore, set them a clear goal, give them some sensible 
guidance... and put the burden of learning on them. (p. 67)

Following the release of our Nation at Risk (National Commission on Excellence in Education, 1983), several national reports that addressed the problem of students at-risk of dropping out of school, and specifically the issue of excellence and of equity, were published. In 1986, the National Coalition of Advocates for students published the results of a year long study, Barriers to Excellence: Our Children at Risk. The report addressed specific barriers to educational excellence for all students, such as inflexible structures, abuses of tracking, and misuses of testing. During the testimony of students, dropouts, teachers and others in preparation for this report, the Board of Inquiry found that education for students at-risk was lacking and in even greater jeopardy in light of the reform movements' higher standards (Green \& Baker, 1986; National Coalition of Advocates for Students, 1986).

Also in 1985, the Charles Stewart Mott Foundation issued its report, Who's Looking out for At-Risk Youth (MDC, 1985). This report was the result of surveys given to various excellence commissions in 32 states. The survey found that only $27 \%$ of the respondents had even one recommendation targeted at a group of at-risk youth. 
Yet another report in 1985, with Consequences for Al1. A Report from the ASCD Task Force on Increased High School Graduation Requirements, issued by the Association of Supervision and Curriculum Development (ASCD), concluded that many at-risk students may drop out of school earlier and send the dropout rates even higher (cited in Green \& Baker, 1986, p. 7). The report by the Education Commission of the States, Business Advisory Commission (1985), Reconnecting Youth: The Next stage of Reform, felt the need to address our alienated youth at-risk of being lost as productive citizens. Their report suggested ways in which the business community could work with the schools to help at-risk students learn more about the world of work and become responsible citizens.

In the 1990s, educational reforms focused on the use of time for instruction in an attempt to help more students reach the higher standards set forth in the 1980s. Strategies such as longer school days, block scheduling, more testing and reporting, higher standards, and better assessment practices tended to ignore the improvement needed in the teaching and learning process.

The Secretary's Commission on Achieving Necessary Skills (SCANS) report (U.S. Department of Labor, 1992) required a range not only of basic skills but also of 
personal qualities, including working in groups and thinking skills. According to this report, these skills are not taught well through conventional instructional practice with its emphasis on individualized rather than cooperative learning, abstract principles and decontextualized context, and fact acquisition rather than problem-solving. Thus, the scaNs report called for changing instruction and set the stage for further research on teaching and learning.

students who dropped out of high school most frequently cited irrelevant course work and teaching techniques that did not match their learning styles, along with the impersonal educational system, as the major causes for leaving school.

One of these reform efforts focused on school programs related to real world experiences, or contextual teaching. In 1985, Dale Parnell wrote The Neqlected Majority, which incorporated more applied academics into the classroom and has grown into a comprehensive nationwide program coupled with the national school-tocareers movement. Jobs for the Future (1996) has defined School-to-Careers:

To help young people make more successful transitions from school to careers and further learning, educators and employers have come together in states and communities around the nation to create stronger linkages between their two worlds. (p. 4) 
The goals of the school-to-careers movement were to provide better education, stronger employment prospects, positive adult role models, and multiple post-secondary options for all students. School-to-careers experiences were designed to develop young people's competence, confidence, and connections that could ensure successful citizenship (Jobs for the Future, 1996).

An element of brain-based teaching and learning, espoused by Eric Jensen (1994) in The Learning Brain, focused on ways to assist students to make learning connections and to change instruction to match learning styles. This connections theme was evident in much of Boyer's (1995) research on teaching and learning. "The Education Person" described school problems as youth problems.

Far too many teenagers feel unwanted, unneeded, or unconnected. Without guidance and direction, they soon lose their sense of purpose, even their sense of wanting purpose. Great teachers allow their lives to express their values. They are matchless guides as they give the gift of opening truths about themselves to their students. I often think of three or four teachers out of the many I have worked with who changed my life. What made them truly great? They were well informed. They could relate their knowledge to students. They created an active, not passive climate for learning. More than that, they were creative human beings who taught treir subjects and were open enough to teach about themselves. ( $p .24)$

contextual teaching, combined with "Integrated Thematic Instruction" (Kovalik \& Olsen, 1994, p. 2), provides 
meaningful content and combines two or more subjects. It offers content that excites the interest of the students and the teachers, and is useful to students, thus creating an emotional bridge between the teachers and the learners. Interdisciplinary instruction offers students (particularly at-risk students) learning opportunities at different developmental levels and varying abilities and encourages differentiated learning activities and forms of assessment (Association of Supervision and Curriculum Development, 1992, p. 1).

Deborah Meier (1995), in The Power of Their Ideas, described the efficient learning environment as based "on the fact that we learn best when our natural drive to make sense of things is allowed to flourish" (p. 152). Meier said that human bonds or connections developed between peers and teachers are essential to the learning environment. "We organize schools as though the ideal was an institution impervious to human touch" (p. 154). Herein lies the explanation of students listing "impersonal schools" or "a lack of someone who cares" as reasons for dropping out of school. Among other conditions, Meier believed that Excellent schools were small schools that encourage human connections between students and teachers, and build in "lots of time for 
building relationships and reflecting on what's happening" (p. 184).

Current research involved in the study of resilient children stressed the importance of children being connected to a network of friends, teachers, or other adults during adolescence. This research demonstrated that "resilient kids have an uncanny ability to make school a refuge from society's ills, [and that they need to be able to] turn to people they have grown to trust" (Bushweller, 1995, p. 18). Wolin and wolin (1993) found that resilient children spent extra time at school, often to escape trouble at home, and developed more meaningful relationships with adults at school than they would ever develop with their parents.

Resiliency studies, some of which have followed children into adulthood, revealed some of the same findings. According to Werner and Smith (1992), authors of an extensive resiliency study conducted over 40 years, found connections and increased bonding between the individual and a trusted adult to be the key to building resiliency.

In fact, it seems almost impossible to successfully overcome adversity without the presence of a trusting relationship, even with a single adult, that says "you matter."

(Henderson, 1996, p. 14) 
This newest body of educational research and restructuring paradigms incorporated the elements of not only sustaining the not at-risk student in school, but has helped to bridge the gap between educational practices and reasons cited by at-risk students for dropping out of school prior to graduation.

\section{Characteristics of At-Risk Students}

Much has been written about dropout rates and the characteristics of students who leave school. The general profile found in the literature describing the student at risk of dropping out of school contains many, if not most, of the characteristics listed below:

1. Dislikes school, including the teachers and the school environment

2. Have few teachers as friends

3. Poor attendance

4. Low performance and achievement, subject and grade failure, many times one to two grade below level

5. History of school failure

6. Likelihood that his total family, including parents, brother(s) and sister(s) are all dropouts

7. Comes from a lower socioeconomic background 
8. Parents apathetic and negative about school

-- does not see any value in education

9. Social contacts are with others like

himself, includes family and friends

10. Feelings of alienation

11. Low self-esteem

12. Customs, values, and attitudes dissimilar to those of the urban middle class

13. Many come from a large impoverished household and headed by a female

14. Family background does not provide a positive self-image

In addition, in the urban areas, the following characteristics are prevalent:

1. Concentrated in slum areas

2. Many are unemployed and unemployable

3. Role models of success are frequently ghetto pimps, hustlers, drug pushers, or those involved in other criminal or illegal activities

4. Alienation because of deprivation and what they perceive as social inequities, injustice and neglect 
(Compiled from the writings of: Beck \& Muia, 1980;

Glasser 1969 ; Hahn, Danzberger, \& Lefkowitz, 1987; Martin, 1980; Pallas, 1986; Wehlage \& Rutter, 1986)

The Phi Delta Kappa study of students at Risk lists among the characteristics of dropping out of school, the following ten top indicators:

1. Attempted suicide in the past year

2. Used drugs or engaged in substance abuse

3. Has been a "drug pusher" during the past year

4. Student's sense of self-esteem is negative

5. Was involved in pregnancy in the past year

6. Was expelled from school during the past year

7. Consumes alcohol regularly

8. Was arrested for illegal activity

9. Parents have negative attitude towards education

10. Has several brothers or sisters who dropped out. (Frymier \& Gansneder, 1989 , p. 142)

The research that centers around the question as to why students drop out of high school is not only extensive, but dates back to a National Education Association meeting in 1872 , where a paper was presented on the causes and remedies of early withdrawal of students 
(Harris, 1973). Most dropout Iiterature was published in the 1960 s due to extensive grants offered by state and federal agencies to study the problem. During this time, one of the most extensive studies was conducted by Elliot and Voss (1968). These researchers collected data on 2,617 students in California schools between 1963 and 1967. They concluded that the strongest indicators to dropping out of school are: academic failure, difference from school norms, social isolation, sibling dropouts, and commitment to peers. These characteristics are similar to those listed by later researchers cited in this study. Hewitt and Johnson (1979) conducted a study that illustrated how little the indicators for identification of potential dropouts change from year to year. They explored the numbers and causes of dropping out at different points in time: 1924, 1937, 1952, and 1977. They found that students exhibited similar characteristics (low achievement, poor attendance, and grade retention) in all four periods of time.

In the oregon Department of Education (1980) study of early leavers, 529 students who left school during the 1979-1980 school year were interviewed. In order of frequency, reasons given for leaving school were:

1. Teachers

2. Dislike of school in general 
3. Credits

4. Dislike of specific school

5. Boredom/lack of interest

6. Desire for alternative school

7. Pregnancy

This list is very similar to the recent reasons students gave for dropping out of school in the 1995-96 school year. Reasons for leaving most often expressed by these students include irrelevant coursework, falling behind in credits, peer pressure, teaching techniques did not match learning styles, lack of personal attention in class, and lack of support for cultural identity (Oregon Department of Education, 1997).

Most, if not all, of the research and literature surrounding the characteristics of at-risk students includes three indicators: poor attendance, poor academic performance, and negative attitudes about school. Poor academic performance is usually evidenced by low grades, low test scores, and being held back in one or more grades before high school. A study by Hunt and Holt (1979) indicated that academic failure is one of the most important dropout indicators. The researchers found that failing grades were the most important indicator of the New York City 9 th grade students who dropped out. In their study, Wehlage and Rutter (1986) also found low 
achievement and truancy to be primary causes of dropping out of school. His evidence indicates that students whose achievement falls into the lowest $25 \%$ are the most likely to drop out. "Dropping out most often results from truancy and other disciplinary problems, low achievement and course failure" (Wehlage \& Rutter, 1986, p. 378).

Subject failure and grade retention are the prevalent complaint of at-risk students. Glasser (1969) made a strong point against failure and retention.

The major problem of the schools is a problem of failure. Too much of our present educational system emphasizes failure and too many children who attend school are failing. Very few children come to school failures, none come labeled failures; it is our schools and schools alone which pin the label of failure on children. (pp. 7-8)

Indeed, there are many studies that have determined that grade retention is a main characteristic of dropouts. Livingston (cited in Voss, Wendling, \& Elliott, 1966) wrote

That of all dropouts who withdrew prior to entering 9 th grade, every one was retained at least one grade and $84 \%$ were retained two grades. (p. 365)

In the recent report on dropouts in oregon, a significant deficiency in credits toward graduation was found in these students who left school early (Oregon Department of Education, 1997). Moreover, grade retention is a highly 
negative experience for the student and reinforces the student's low self-esteem.

Many researchers feel that family background, including socioeconomic level, in conjunction with failure, retention, and student alienation to school (poor school climate and negative teacher attitudes) influences the students decision to drop out.
As we descend the socioeconomic ladder, the incidence of dropouts increases sharply. Among youth in the upper class... only $2 \%$ dropout. While the second rung (lower- upper class) the figure rises to $10 \%$. In the upper-middle class, $17 \%$ of the youth do not complete school, and the lower-middle class and upper-lower class, the rate of school dropouts rises to an incredible $25 \%$. At the bottom rung(the lower-lower class) a full $50 \%$ of the youth quit school. (Beck \& Muia, 1980, p. 67)

Blough (1957) also found poverty to be the factor most frequently associated with dropping out of school.

Many of the at-risk students come from poverty-stricken single-parent homes. As reported in Children in Need (Research and Policy Committee of the Committee for Economic Development, 1987):

In $1985,66 \%$ of black children, over $70 \%$ of Hispanic children, and nearly one-half of all white children living in female-headed households lived in poverty... Children from poor and single-parent households are more likely than others to be children of teenage parents themselves. (p. 9)

As a result of low socioeconomic status, many of the at-risk students "do not see the value in homework, and 
all too many come from households where there is little support for homework or outside academic enrichments" (Hahn, Danzberger, \& Lefkowitz, 1987, p. 18). At-risk children are handicapped as a result of little or no value placed on education from parents who have little or no education themseives.

Recently, researchers such as Wehlage and Rutter (1986) have gone beyond the traditional characteristics (low socioeconomic status and poor school performance) and identified other variables, such as negative attitudes about school, as important. These variables included students' perceptions about teacher interest in students, the effectiveness of discipline, and the fairness of school discipline. They suggested that a student's decision to drop out is the culmination of a number of student and school characteristics.

Research concerning why students drop out of school has identified the importance of social bonds that connect the student to the school (Wehlage, 1983; Wehlage, Rutter, \& Turnbaugh, 1987). The term "social bonding" describes an outcome in which a student is attached, committed, involved, and has belief in the norms, activities and people of an institution (Hirschi, 1969). A student is socially bonded to the extent that he or she is attached to adults and peers, committed to the norms of the school, 
involved in activities, and believes in the legitimacy of that school. It is that part of school membership, "attachment," that this research will focus its attention. When students have low attachment to teachers and administrators, they do not care what these people think about them, especially as students. Dropouts perceive that these adults do not care about them. Under these conditions, it is easy to feel rejected by the school and, in turn, to justify rejecting the school.

Alienation from teachers and school is a common characteristic for dropouts. Hershaff (1980) compared the feelings of alienation and attitude towards school of dropouts and graduates. He found that dropouts have greater feelings of meaninglessness, alienation, powerlessness, and overall negative attitudes. At-risk students tend to lack problem-solving skills. They often are not able to see cause and effect relationships between actions and their consequences. They feel powerless and removed from any consequences of their actions and thus blame others.

This feeling of disconnection is also manifested in student attendance rates and academic performance (Abcug, 1991). The High School and Beyond studies found that dropouts projected a more external locus of control than did graduates, and the low level of self-esteem improved 
once they left school. Leaving a situation that is the source of negative experiences would then be replaced with feelings of relief (Wehlage \& Rutter, 1986). Bronfenbrenner (1986) suggested that the forces of the alienation are growing, and the best way to counteract them is by creating connections within the schools. The personal relationships between students and teachers are distanced in high school. Research shows that at each progressive level of the education system, relationships increasingly lack meaning and personal satisfaction. Many teachers in the comprehensive high schools believe that it is important to create social distance between themselves and their students as a means of maintaining discipline and helping students to become more independent and responsible.

Students and teachers do not relate to one another as whole persons, but in narrow circumscribed roles. Communication is restricted to what one can and must do in a 50minute hour where a highly structured setting is a sanction against all but teacher-directed behavior. (Brendtro et al., 1990, p. 10)

This social distancing is a major source of strain for all students; it is particularly a problem for the at-risk student, who needs the more supportive environment that parents may not be able to provide (Benson, Williams, \& Johnson, 1987). 
Isolation, another impediment to school membership, refers also to the social bonding that occurs between the members of the institution and the student. Although isolation from peers can be troubling to students, equally serious is the isolation from adults, especially when the stress of the home environment increases, as is more likely with an at risk student. This is particularly important because the social institutions that traditionally provided adult-adolescent support, such as church and voluntary organizations, have declined in their influence. School is often the only place for some students to find a rewarding adult relationship. Much of the literature surrounding at-risk student concludes that schools must be viewed by the students as a caring, helpful place to be and, most importantly, that the teachers care about all students.

Negative attitudes towards school prevails in the research concerning characteristics of those students who dropout of school. For example, the coleman Report (released in 1966) made it explicit that attitudes of positive self-image are crucial to students' experiences of success in school. Mayeske's (1973) study concluded

that influences on student achievement tended, when analyzed, to resolve themselves into attitudinal and motivational factors... and that attitudinal and motivational factors were by far the more important. (p. 3) 
Students' attitudes toward school are influenced by their teachers, peers, family, and other institutions and environmental factors. As was mentioned earlier, with the age-segregated environment of society today, and with more and more households consisting of a single-parent configuration or both parents in the workplace, schools may play an increasingly important role in developing positive role models and attitudes towards education for those students at risk for dropping out of school. Factors contributing to a student dropping out of school may begin initially as an environmental factor, such as low socioeconomic status, little or no parental support for education, and possible learning difficulties. As these students progress through the school system, many experience failure and disengagement, which in turn reinforces low self-esteem and a sense of disempowerment. Schools push the at-risk student further into dropping out with their large, impersonal bureaucratic organizations and overcrowded classrooms, irrelevant curriculum, and teaching strategies that do not match the student's learning style. Schools and teachers cannot change the environmental factors that continue to put students at risk, but they can develop programs that are more user friendly and that address the issues students face prior to dropping out of school. 


\section{Characteristics of Programs for \\ At-Risk students}

A review of the dropout literature and surveys aimed at identifying programs around the nation that seem to keep at-risk students in school revealed a variety of programs and strategies. Rather than describe these specific programs from all parts of the country, this review of the literature will review characteristics found common among the various dropout intervention strategies and programs for at-risk students.

Kushman and Kinney (1989), in "Understanding and Preventing School Dropout," divided dropout prevention approaches into two categories: the "clinical approach" and the "systemic approach."

The "clinical approach" deals directly with the student and the characteristics that make that student at-risk. It begins by looking at the predictors intrinsic to the student at-risk in three areas: the home, personal traits or circumstances, and school behaviors. Most of these programs utilized guidance and counseling, remedial education and alternative education programs. This emphasis was also found in the review of the literature on dropout prevention prior to the 1980s.

Most prevention programs involved guidance and counseling as part of their program. As cited in Green 
(1966), following the enactment of the National Defense Education Act of 1958, prevention studies, such as the one by schrieber (1964), described the importance of such guidance activities. Green considered guidance to be a key ingredient to drop out prevention; it is up to the counselor to make the first move. Not all researchers agreed that the counseling functions should be carried out only by certified school guidance counselors. Wrenn (1967) proposed that this function can be cared out by all educational workers - teachers, administrators, and counselors.

Counseling on careers is seen in some studies as an important factor in dropout prevention. In a program initiated by the Arkansas State Department of Education (1980), dropout prone students were given special counseling sessions with a emphasis on careers. This was so successful, a second program was added. Camp (1980) agreed; his review of California's statewide prevention programs indicated that the greatest success with at-risk students happened when the prevention programs combined counseling with career awareness.

The astute counselor must zero in on these factors (dropout characteristics) and begin to develop a planned, coordinated response of prevention and treatment. (Kushman \& Kinney, 1989 , p. 356) 
A recent edition of National Association of Secondary School Principals' (NAASP) (1988) The practitioner identified specific counseling activities which include: establishing a peer counseling program to help high-risk students develop a sense of belonging; assigning each student a teacher who advises and counsels him on school related academics or activities; providing counseling to parents of high-risk students on how to give support to their children; and identifying and using dropouts who have re-entered school as positive role-models for students at risk.

Remediation is another method mentioned in the literature. As has already been established, many at-risk students have been retained in at least one grade. Another remedial approach is ability grouping that places students with lower abilities in slower classrooms so that they will catch up. Research has shown that placing students with academic and behavioral problems in the same classroom will not improve their situation, and in many cases lowers self-esteem and increases behavior problems (Kulik \& Kulik, 1982; Rosenbaum, 1980). However, when slower students are placed with average or above-average students, they improve. Remedial strategies seem to be effective only when grouping students part of the day, and individualized learning within the classroom is practiced. 
other forms of remediation that seems to work in drop-out prevention includes peer-tutoring and cooperative learning (Kushman \& Kinney, 1989).

one of the most documented and successful approaches for addressing the needs of at-risk children is to place them in an alternative program. "Alternative program" is a term used to describe non-traditional elementary and secondary school programs housed either within the traditional school or outside, on a separate campus. Alternative programs are characterized by having caring teachers, willing and specially suited to work with at-risk students, a more individualized curriculum, flexible scheduling to meet the needs of teenage parents and those who work, and counseling services designed to better meet the needs of at-risk students (Berkowitz, 1971; Buckner, 1976; Gordon, 1972). Wehlage (1983) presented some specific guidelines for effective programs for these at-risk students. These characteristics are organized in four categories and summarized as follows:

Administration and organization:

1. Small size of classes to provide flexibility and responsiveness to individual needs

2. Program autonomy which gives teachers ownership to be more effective 
Teacher culture:

1. Professional accountability for student success

2. A caring extended role to work with the whole student

3. Optimistic, but realistic judgements of individual academic abilities

4. Collegiality

Student Culture:

1. Family atmosphere is created through caring for each individual

2. Cooperative iearning versus competitive learning

3. Supportive peer culture in matters such as rules and student progress

Curriculum and Instruction:

1. Individualized and cooperative

2. Real-life problems used

3. Experiential in terms of career internships, community involvement, outdoor activities and community service

Wehlage (1983) summarized his findings on effective programs by identifying two major areas on which to focus efforts: (a) social bonding, the positive attachment to parents and other significant adults which leads to the commitment to participate in the institutions of society; 
and (b) intellectual growth and development of abstract thinking, beyond the basic skills.

Kushman and Kinney (1989) felt that a better approach to students at-risk of dropping out of school is treating the "whole" student, rather than just those characteristics that are difficult to change, such as poverty, cultural differences, and dysfunctional families. Limitations to the clinical approach include making students simply feeling better about themselves will not necessarily improve their performance in school. Many clinical interventions carry a negative stigma or further segregate students from the norm and decrease their already fragile self-esteem and even become labeled as "slow" or "dropout."

The school that supports the systemic approach recognizes the fact that, with the diverse makeup of any student body, it is necessary to design a school system that is flexible and meets the needs of all its students. Schools are student-centered. Kushman and Kinney (1989) outlined four major factors within a school that need to be structured for the benefit for all students:

1. Organizational structure

Students who attend a large school feel overwhelmed particularly in the transition grades of between middle school and high school. School hours that are rigid leave 
little flexibility for working students. The organization of most traditional schools leaves little or no transfer of subject matter from one class to another.

\section{Procedural Practices}

Procedural practices are those rules and regulations that make a school run smoothly.

It makes little sense to suspend a student who is skipping school, or to give a failing grade to a student who, for some understandable reason, is having difficulty with a subject. The disciplinary action does not solve the problem. (Kushman \& Kinney, 1989, p. 361)

3. Instructional strategies

Keeping in mind that students have different learning styles, teachers must utilize a variety of teaching methods. In addition, the curriculum must not be disengaged from the student's out-of-school life and must be challenging.

\section{Educational Inequity}

Teacher expectations must be the same for all

students and not lowered because of ethnic or economic background.

Ironically, these students may not have suffered from low self-esteem until they were put into a situation where little was expected of them. It is only when a student begins to question his or her self-worth that insecurities and low self-esteem are created. (Kushman \& Kinney, 1989 , p. 362)

In addition to staff attitudes and expectations, the more obvious type of educational inequity is placing at-risk 
students in programs that fail to equip them for the outside world and cheats them of a full education. This includes "slow classes" and some alternative programs that provide a caring environment, but do not have a full or challenging curriculum.

There have been several surveys of dropout prevention programs in vocational education. Significant among these studies is a review of 14 programs by weber and Silani-Lacey (1983). Their findings are organized into three categories: content, methodology, and organization. (a) Content suggestions include having clear goals and objectives for students, and the criteria for judging success is directly tied to the content.

(b) Methodological suggestions include: identifying dropouts early; avoiding "labeling;" having an integrated program which combines basic skills to vocational/occupational training; individualized instruction; using a variety of materials or adapting materials to meet students needs; including paid work experience to content of schooling; providing recognition and rewards to motivate students; using peer-tutoring; and providing alternative programs. And, (c) Organizational considerations include: inservicing for teachers to better equip them to teach at-risk students, linkup with 
community agencies, and locating the program within the school.

Many school districts around the country have identified the characteristics of effective programs for dropout prevention. The following is a summary of those findings :

1. Caring, skilled staff that believes all students can learn

2. Dropout prevention is a priority at all levels of leadership

3. Instructional program is tied to the individual learning styles of students

4. Challenging courses that relate to the students' personal experiences

5. Employment training and career experiences

6. Grading system builds on success by connecting it to learning tasks set in accordance with students' achievement levels

7. Involve parents as partners in the student's education

8. Establish an inviting school climate - mentoring programs

9. Establish an effective attendance program with immediate response to parents when students are not in school 
10. Professional counseling supplemented by peercounseling

11. A fair, consistent discipline system which establishes a bottom line for unacceptable behavior

12. Identifying at-risk students early

13. Being sensitive to the populations being served

14. Include life-skills training in the curriculum (See: CETA--Education Linkage Unit, 1981; Gadwa, Christenson, Bryan, \& Boeck, 1983; Green \& Baker, 1986; Hathaway, Sheldon, \& McNamara, 1989; NASSP, 1988; New York Public Schools, 1979; Ohio State Department of Education, 1983; Portland Leaders Roundtable Planning Project, 1986)

Most, if not all, of the research on successful programs for at-risk students take into consideration the human connection, or bonding, between teachers and students. Blueprint for Success listed establishing a human connection, knowing students as people, developing positive relationships with another adult, and helping that student in problem-solving as essential to any atrisk program (National Foundation for the Improvement of Education, 1986, p. 9).

In summary, all the programs or methodology used to help prevent students from dropping out of school included the following characteristics: 
1. Staffing: All the dropout prevention programs reviewed had a caring, qualified teaching staff. It was important that teachers and other significant adults established a positive rapport with individual students and developed personal relationships to create a sense of trust and belonging to the school.

2. Curriculum: The curriculum should be relevant and meaningful for at-risk students based on real-life experiences. Programs emphasized personal development, preparation for work, or basic skills remediation or other appropriate academic work.

3. Methodology: Programs were small in student-teacher ratios. Instruction should be individualized in terms of pace and ability. Group work or cooperative learning should also be utilized to foster social bonding and appropriate group behavior. Clear and reasonable expectations should be set so that the student experiences success. Immediate feedback, valid criteria for evaluating performance, and appropriate rewards and rules for students are needed.

4. Administrative Support: Preventative programs and methodology to keep students in school are supported at all levels of leadership in the school district. 
Mentoring

Most people are familiar with the term mentoring from the business world. The idea of mentoring is related to the early concept of apprenticeship. Levinson (1978) discusses the importance of mentors for developing a sense of self in the adult world, particularly as it applies to careers. A landmark study on adult development, conducted by Vaillant (1977) on 95 male Harvard University graduates, found men who were judged to be "best outcomes" had numerous mentor-like relationships, and often became mentors themselves. Sheehy's (1976) book, Passages, looked at female mentors in the workforce. She discovered that women who gained recognition in their careers were at some point mentored by another person.

Formal mentoring programs for adults exist in many fields. Many school districts assign a new teacher to a more experienced teacher with exemplary teaching ability to provide encouragement and assistance. Corporate mentoring programs in place are Federal Express, Honeywell, Eastman Kodak, AT\&T, and BankAmerica, to name a few. All of these programs have one thing in common: a nurturing relationship.

This section of the literature review will focus on mentoring in general. It is divided into the following subdivisions: definition and historical background of 
mentoring, the roles and characteristics of mentor relationships, components of successful mentoring programs, and research on mentoring and the at-risk student, and the teacher as mentor for at-risk students.

Definition and Historical Background of Mentoring

The term mentor can be traced to ancient Greek. Mentor was the name of a trusted and loyal friend of Odysseus. According to the Greek epic poem, when odysseus left his homeland to fight in the Trojan War, he asked his friend, Mentor, to educate and guide his son, Telemachus. other examples from history include socrates and Plato, Aristotle and Alexander the Great, Anne Sullivan and Helen Keller, and Freud and Jung. In each case, the mentor was a caring person who developed an on-going, one-on-one relationship with someone in need.

Today, the word mentor continues to mean any caring person who encourages, listens, gives advice, is an advocate, acts as a role model, and shares information and experience. There are many definitions of a mentor or a mentoring relationship. Parkay (1988) described mentoring as :

an intensive, one-to-one form of teaching in which the wise and experienced mentor inducts the aspiring protege into a particular, usually professional way of life. (p. 196)

Blackwell's (1989, p. 8) definition is similar. 
Mentoring is the process by which persons of superior rank, special achievement, and prestige instruct, counsel, guide, and facilitate the intellectual and/or career development of persons identified as proteges.

Although there are many different definitions of mentoring, two characteristics seem to be constant:

a) there is always reference to one individual, one person, interacting in some way with another; and b) there is some sort of supportive action, such as guidance, support, and counseling. Mosqueda (1990) contended that the appeal of mentoring lies in the fact that it brings individuals together on a one-to-one basis, bypassing bureaucracy and institutions.

It brings people together essentially because it makes sense to have real people talking to real people. It also makes sense that an older and more experienced person will have skills or knowledge from which a younger person might benefit. (p. 3)

Although some of the characteristics of a mentoring relationship involve counseling, tutoring and role-modeling, these alone are not enough to encompass to term mentoring.

A role-model is defined as one whose life and experiences provide a concrete image of who a younger person can become. By contrast, a mentor is someone who lends guidance and support to enable the young person to become whoever they choose to be. If the role model's message is "Be like me," the mentor's implicit message says: "I will help you be whoever you want to be." (The Forgotten Half, cited in Mosqueda, 1990, p. 169) 
A review of nearly 800 references by Gray and Gray (1986) found that there are at least two different types of mentoring. Each type of mentor fills similar functions, but for different periods of time and different outcomes.

1. Informal life mentors. Most people are familiar with the term mentoring from the business world. The idea of mentoring is related to the early concept of apprenticeship. Daniel Levinson's (1978) The Seasons of a Man's Life discussed the importance of mentors for developing a sense of self in the adult world, particularly as it applies to careers. Gail Sheehy's (1976) book, Passages, looked at female mentors in the workforce. She discovered that women who gained recognition in their careers were at some point mentored by another person.

This type of informal mentoring starts with a moreexperienced person who mentors a less experienced person. According to Gray's (1989) findings, $80-90 \%$ of what was written on mentoring before 1988 describes informal mentoring or informal career mentoring, and has only indirect relevance for planned programs for at-risk youth for a variety of reasons. The mentors in this case spontaneously begin their mentoring without the proteges 
knowing. Usually this relationship lasts for 2-15 years, as in the Annie Sullivan and Helen Keller case.

2. Planned project mentoring or Formal Mentoring. This type of mentoring is the more focused, usually with a particular outcome in mind, and lasts a shorter amount of time (4-18 months). Formal mentoring programs for adults exist in many fields. In the business world, planned mentoring programs came as a result of dealing with women and racial minority groups entering managerial ranks in increased numbers, as these females and minorities didn't have natural male mentoring connections. There was a perceived glass ceiling for women rising in the corporate hierarchies, and these formal mentoring programs were established to assist in career advancement (Freedman, 1991). Planned mentoring programs for students originated in the 1980s, probably as a result of antipoverty efforts of previous decades, such as Head start, Title I, and Chapter I (Flaxman \& Ascher, 1992). Many school districts also assign new teachers to the more experienced teacher mentors, with exemplary teaching ability to provide encouragement and assistance. Examples of corporate mentoring programs in existence for students include Federal Express, Honeywell, Pepsi-Cola, Eastman Kodak, AT\&T, and BankAmerica, to name a few. All of these 
programs have one thing in common: a nurturing relationship (Gray, 1989; Smink, 1990).

According to Gray (1989), project or planned mentoring is the easiest to arrange and more schools are beginning to look at this kind of mentoring to help students. These include the enhancement of career awareness, the talented and gifted students, and the at-risk student (Edlind \& Haensly, 1985; Outen cited in Gray, 1989). For years, the gifted student was the only recipient to benefit from mentorships in public education. According to Ellingson, Haeger, and Feldhusen (1986) "gifted children are thought to be particularly good candidates for mentor experiences" (p. 3). In a study of 604 Presidential Scholars, Kaufman et al. (1986) found that the majority $(66 \%)$ reported that their most significant mentors had been teachers, of which about onethird were in their secondary school experience. In his 22-year longitudinal study, Torrance (1983) found that students who had mentors completed more years of education than did non-mentored peers. According to Kaplan (1985), if the mentoring programs are successful for gifted students, then they will be beneficial for the mainstream student, although there is a clear lack of research on the effects of a mentoring relationship with potential high school dropouts. 
Roles and Characteristics

of Mentor Relationships

Many writers have written on the roles and characteristics in mentor-protege relationships. Schein (1978, p. 178) listed seven possible roles for mentors:

(a) teacher, coach, or trainer, (b) positive role-model, (c) developer of talent, (d) opener of doors, (e) protector, (f) sponsor, and (g) successful leader.

To these, other writers have added others. Gehrke (1988) added confidant (p. 43). Clawson (1980) added the concepts of comprehensiveness and mutuality. Comprehensiveness refers to all the aspects of the protege's life, not just the area to be focused on; the concept of mutuality recognizes the need for the relationship to be chosen and valued by both the protege and the mentor.

The main elements in a mentor relationship in the public schools are mentor, mentee, and the resulting relationship of the mentoring process. Lambert and Lambert (1982) described this process as "the linking of a person of specific experience in a learning-oriented relationship" (p. 12). They said,

The mentoring model utilizes a mature expert who desires to develop an in-depth, sharing relationship with a student. Together the mentor and mentee create a linked series of learning experiences which, as a result of the highly individualized and personal relationship, have implications which impact on other areas of the mentee's existence. The mentor shares not 
only expertise, but values problem-solving techniques, and other aspects of his or her life style. It is this mutuality inherent in the relationship which makes mentoring an extremely powerful developmental tool. (p. 12)

Furthermore, mentoring often includes role modeling

outside the classroom and can have a strong effect on the protege on both the educational and personal level (Cox \& Daniel, 1985; Lambert \& Lambert, 1982). Gray (1989) described the major mentor roles in his Mentor-Protege Relationship Model as:

1) Role Model. Models success in life and work and is someone the protege can identify

2) Leadership. Directs, guides, invites joint decision-making

3) Teacher-Coach. Teaches insights or skills, provides practice of those skills, gives feedback on those skills, and fosters self-evaluation and self-improvement

4) Motivator. Provides positive reinforcement and encourages self-motivation

5) Gate-Keeper.

Helps proteges understand realities about the worlds of education and work.

6) Gate-Opener. Helps protege achieve his/her goals and introduces protege to significant others

7) Wise Counsel and confidant Listens, helps clarify possible solutions and shares wisdom. (p. 19) 
The content of adult relationships, along with the outcomes, can vary greatly from program to program, as can the intensity within programs. According to Flaxman et al.'s (1988) review of the literature on mentoring relationships, the goals for that relationship should be clear and within the mentor's power to achieve, and the mentor must be empathetic, able to assess the needs of these students, and be able to apply available resources.

The research surrounding Project RAISE found that, even though mentors are not usually intended to assume the supervisory or discipline roles of parents, mentors' monitoring and pressuring had a significant impact on attendance (McPartland \& Nettles, 1991).

The literature points out that the mentor must be trained to use interpersonal skills necessary to encourage students to develop the capacity to change unacceptable behavior (Gray, 1989). The following strategies can be used by mentors for effective mentoring:

1) Positive Attitude: Encourage mentee to approach life and goals with enthusiasm and to be accepting of self and others

2) Valuing: Encourage the mentee to examine beliefs and ideals in an effort to establish personal values and goals

3) Open-mindedness: Encourage the mentees to keep an open mind to ideas 
4) Interrelations: The interactions between mentor and mentee should be situations of sharing, caring, and empathizing

5) Creative Problem Solving: Encourage the mentee to use a creative problem-solving process

6) Effective Communication: Encourage the mentee to be an attentive listener and an assertive questioner

7) Discovery: Encourage the mentee to be an independent thinker

8) Strengths and Uniqueness: Encourage the mentee to recognize individual strengths and uniqueness and build on them

9) Confidence: Assist the mentee in developing self-confidence

10) Awareness: Stress that the mentee be aware of the environment, be intuitive, be problem-sensitive, and be ready to make the most of opportunities

11) Risk-Taking: Encourage the mentee to be a risk-taker and to be an active participant, not a spectator

12) Flexibility: Share with the mentee the importance of being flexible and adaptable in attitudes and actions, looking for alternatives, and seeing situations/persons from different perspectives. (Borman \& Colson, 1984, p. 196)

The key to a successful mentoring is the mentor-mentee relationship. "Crucial to success of a mentoring relationship is the appropriate match between mentor and mentee" (Richardson, 1987, p. 34). This 
one-on-one relationship can provide support and guidance for students who are at-risk of dropping out of school.

Development and Implementation of successful Mentor Programs

Development and implementation of mentor programs that provide assistance to at-risk students must be carefully planned. "A primary reason mentoring programs fail is that enthusiastic people begin a well-intentioned, but poorly defined, program without planning exactly what they want to happen and how it should unfold" (Haring-Hidore, 1986, p. 240). It is important to identify factors which can contribute to the limitations of mentoring. Haring-Hidore identified the following two factors: a) mentoring requires considerable programmatic and individual effort which may be difficult to sustain over time, and b) it is difficult to involve large numbers of students in a mentoring program because large numbers of potential mentors seldom are available. Thus it is important for the mentoring program to be part of a larger retention program for at-risk students (p. 240).

Gray (1989) pointed out that it is important to have support from the top, as well as a grass roots based program, so that voluntary participation occurs.

Imposed programs seldom work as well as those in which people want to 'buy in' as volunteers because they see the benefits for themselves and the organization, and they can meet program 
expectations. To attract volunteers, the program's structure, organizational expectations, and anticipated benefits must be communicated to potential participants. Focus groups comprised of prospective participants and needed supporters provide useful input for improving the program's design. Having such input increases support for the program. ( $p$. 20)

The program coordinator is also a key element in a successful mentor program.

The program coordinator will...get management's commitment, selectively publicize the effort, decide on goals, recruit volunteers, set up orientation sessions, contact consultants who may be able to help and choose some evaluation strategies. (Phillips-Jones, 1983, p. 40)

Each program should have clear, well-communicated goals. It is deceptively easy to establish "retention" as the long-term goal of the mentoring program. Researchers suggest that short-term goals be established that will ultimately lead to retention of that student. An example given is that each student that participates in a mentor program be engaged in one ongoing school activity at the end of a certain period of time. Such involvement can be facilitated by the mentor and leads to retention (Austin, 1985). The goals should also relate to the needs of the participants, determining mentor/protege selection, type of training to provide, and length of time to which each is committed (Gray, 1989; Haring-Hidore, 1986).

In the planning phase of the mentoring program, a monitoring system snould be designed that will enable 
program staff to obtain feedback from participants throughout the program. Feedback of various kinds can be in the form of successes and/or failures of various activities used with proteges, and suggestions for new ideas communicated in written form or in a meeting. It is also important at this stage to decide on an evaluation tool so that data can be collected proactively. Evaluation should include whether goals are being met and the amount of satisfaction experienced by the participants (Gray, 1989; Haring-Hidore, 1986).

Implementation of the mentor program should begin with the identification and selection of potential mentors.

Mentors must be genuinely invested in the principle of mentoring so they can form a close and meaningful tie with an individual or individuals. (Harding-Hidore, 1986, p. 241)

It is equally important for the match to be mutually agreeable.

One of the most important factors of a successful mentor program is making the right match between mentors and mentees. (Lanier, 1986, p. 42)

Following planning of a mentoring program and selection of participants, the program is ready for implementation. Here attention should be given to orientation and training of participants, and activities for mentor/mentees outlined. 
Gray (1989) added that the major cause of failure of planned mentoring is lack of training.

It cannot be assumed that simply matching mentors with proteges will produce desired results. Before hard-core at-risk students can benefit from what mentors can offer, they need to become receptive to this kind of help. For example, in a Skill Training and Empowerment Program (2-STEP) for at-risk youth, Al Ross (of Vancouver, BC) helps youth break such self-defeating cycles as school failure, delinquency, chemical dependency, welfare dependency, chronic unemployment, and criminality. (p. 19)

While activities can take a variety of forms, Haring-Hidore (1986) suggested two things: de-emphasize the hierarchial nature of the mentoring relationship, and second, activities should be planned so that attention is not always on the protege. Phillips-Jones (1983) believes that orientation should be provided for a variety of reasons, including:

The main purposes of the orientation are to build enthusiasm in the mentors and to help them recognize what they can contribute to their mentees, how mentoring can also benefit mentors, what to expect during a mentor-mentee relationship and how they can enhance their mentoring skills. During the orientation, mentors should receive a manual or other materials to help them with their tasks. Soon after the orientation, they should meet their mentees and begin to initiate action plans. (p. 41)

The At-Risk student and Mentoring

Researchers have found that school dropouts often cite as one of the primary reasons for leaving school is 
the absence of one person who cared about them (Smink, 1990). Their engagement and attachment to school and teachers was weak. Traditionally, parents and family members have fulfilled the mentoring role, but the prevalence of two-earner and single-parent families, combined with the school's isolation from the larger adult community, makes it difficult for students to find adult mentors. Even though parental involvement cannot be stressed enough, mentors outside the family can compliment parental efforts.

This growing awareness that too many parents are unable to meet their adolescent children's needs has generated a host of programs matching at-risk youth with adults. Examples of large programs implemented across the country include I Have A Dream Foundation which encompasses 30 cities in 23 states; One-to-one, which has the goal of matching a caring mentor with every young person who would benefit from such a program (U.S. Department of Education, 1992); and Big Brothers/Big Sisters of America, which has 500 affiliates throughout the nation, with children being mentored from primarily low-income or single-parent families (Smink, 1990). At-risk mentor programs seem to attempt to modify the behaviors and skills of the student, rather than being seen as supplemental to already existing behaviors as in 
other programs that mentor gifted students. In addition, at-risk mentoring programs find some advantages for the mentor. As Freedman (1991) noted in his literature review, program leaders feel that a central objective of their programs is to educate the middle class adult to the circumstances of poor children and reengage them (both mentor and child).

Rigorous research in the particular area of mentoring at-risk youth is scarce. Flaxman and Ascher (1992) discussed two evaluations that satisfied a rigorous research model that used pre-test and post-test measures, with a control group and experimental group. Career Beginnings was created in the 1980 s as a 24-city program that coordinates college, businesses, and non-teaching staff to mentor 11 th and 12 th graders. Evaluation of the program showed that participants were more likely to attend college and have higher educational aspirations than the controls (Flaxman \& Ascher, 1992; Hamilton, 1990). According to this program, the key was the amount of time the mentor invested in the student. The most successful mentoring were the ones that the responsibility for sustaining the relationship was actively pursued by the mentor with a weekly progress report shared with parents (Fehr, 1993). 
Another example, Project Raise, a program for at-risk students in seven middle schools around Baltimore, Maryland, used adults from the community either as advocates or mentors. Those students with mentors were found to be more likely to improve their attendance and English grades, but not their promotion rates or scores on standardized tests. Over this two-year period, the researchers found more positive results with at-risk students in those schools where the one-on-one mentoring program had been strongly implemented and supported (Flaxman \& Ascher, 1992; McPartland \& Nettles, 1991). There are also other, less rigorous evaluations that show positive results of mentoring programs. Linking Up (Flaxman et al., 1988), a mentoring program developed by Cornell University, found that students who have a parent or other adult challenging and supporting them scored higher on measures of cognitive skills. Laughrey (1990), in his evaluation of a florida high school mentoring program, found that students improved in the areas of attendance, test results, and postgraduate planning.

A program for at-risk students, involving business mentors as part of the intervention for 9 th and loth grade students in a small rural school in South Carolina, found improvement in attitudes toward school, a reduction in "D"s and "F"s, and a decrease in the dropout rate from 
$7.2 \%$ in 1990-91 to $1.6 \%$ in June 1993 (Stradford, 1993). Additional, less rigorous research findings reveal both positive effects of mentoring at-risk youth, and trouble in proving links on additional benefits.

Hamilton (1990) found, in his research on the Learning Web, that parents were convinced that this mentor program benefitted their children. The Learning web was a program set up to match students with an adult mentor to teach them a skill. Although there were no clear outcomes of the program identified, about half of the participants named their mentor as one of the five most important adults in their lives.

Davis (1988) analyzed a mentor program to assist in increasing the academic achievement and attendance of at-risk 9 th grade students in Pittsburgh. This study found no significant difference between the group who received mentoring and the group that did not. The study suggested that the failure of the program to be in place prior to the opening of school and the lack of effort to match mentors and at-risk students had a negative impact on the outcome of the program.

Another mentor program, Atlanta's Adopt-a-student program, found that participants were more likely than comparison group members to enroll in post-secondary 
education, but no more likely to graduate from high school (Stanwyck \& Anson, 1989).

One of the most useful studies of mentoring programs is a report by Freedman (1988) for Public/Private

Ventures. This study examined the relationships developed between elder mentors and at-risk youth in five different programs. In his research, Freedman interviewed 47 pairs of youth and adults. He concluded that both mentors and mentees benefitted from the program and suggested further research into such programs. Of interest in his findings was the insight he gives to the types of relationships formed between the mentor and mentees and the effects on the mentees. He divided the relationships into "non-significant," meaning that the people did not interact well or regularly, and "significant" as either "primary" or "secondary." A "secondary" relationship was defined as being a "close relationship" but not bound, whereas the "primary" relationship was viewed as central to the lives of both parties, much like a family relationship.

Three researchers at Columbia University, Flaxman, Ascher, and Harrington (1988), in an analysis of the literature on mentoring, stressed the need for additional studies, program descriptions and evaluations. They warned that mentoring is likely to prove a modest 
intervention, effective only in connection with favorable influences of family, school, and community. Even with the tremendous complexity surrounding the effectiveness of mentoring at-risk students, there is strong observational evidence to suggest that young people who have an adult mentor can profit from the relationship.

Jacobi (1991), in a review of literature on mentoring of university students and academic success, found a lack of studies linking mentoring directly to academic outcomes. She found much of the current research failed to control for outside influences or additional aspects of a program that could explain the outcomes. While research is scarce, many educators are convinced of the effectiveness of mentoring.

The challenges involved in implementing a mentoring program for at-risk students are evident in the high failure rate of mentor/mentee matches. Hamilton and Hamilton (1992) found that, even with a thorough process of matching, only about half the pairs actually met regularly. Freedman (1991) concluded that up to twothirds of mentoring relationships fail.

Cross-gender and cross-ethnic mentoring are also cause for concern. Program organizers suggest that, when possible, mentoring should be between people of similar social origins (Freedman, 1991). When ethnicity is taken 
into consideration when matching mentors with students, activists with the African-American and Latino communities have seen positive results with mentoring efforts. An example is 100 Black Men of Atlanta, a community service organization which targeted a high school in Atlanta with a high dropout rate. It promised students a fully-paid college tuition for those who graduated from high school and acted as mentors and tutors for these students (Glass, 1991).

A mentoring program in the wake county Public School system, North Carolina, found that there was improvement in academic achievement of at-risk black male students in grades 6 through 8 when they were linked with supportive black adult males. Campbell-Peralta (1995) also found positive results in a mentoring program that targeted primarily minority males. She found that cultural sensitivity and awareness inservicing of the adult mentors overshadowed any lack of adult minority mentors available.

Hispanic students from Calexico High School, California, reported on the importance of having a mentor who speaks their language and cares about them. Calexico has gained national attention because $98 \%$ of its students are Hispanic, but only $2 \%$ of these drop out every year (Di Rado, 1997, p. B1). In reality, most of the potential mentors are white, middle class; many of the mentees are 
not. Slicker and Palmer (1993) found that a mis-match or ineffectively mentored students may produce an actual decline in academic achievement, probably as the result of disappointment by that student.

At-risk students often have profound needs or factors that put them at risk; a mentoring program may seem like just a drop in the bucket. Factors such as mobility rate, lower academic achievement, low attendance, negative attitudes associated with school and stress, affect any positive results actually recorded as the result of a mentorship program (Flaxman et al., 1988). For this reason, some mentoring programs for at-risk youth do not target the most at-risk students. Project Atlanta targets students with a "C" average (Glass, 1991). The inner-city mentoring program evaluated by Fehr (1993) targeted students that had moderate, rather than more severe, problems. In contrast to earlier expectations, researchers have cautioned that mentoring at-risk students should be thought of as a modest intervention, not a cureall. Even the ideal of one mentor matched to one mentee is challenged with Freedman's idea of a mentor-rich environment in which a student has many mentors to work with, depending upon the circumstances. 
Teachers as Mentors for

At-Risk students

The self-perceived needs of at-risk students include: (a) having teachers who are supportive, caring, and talk personally with students (Bearden, Spencer, \& Moracco, 1989); (b) getting good grades (Applegate, 1981);

(c) feeling connected to the school (Mahan \& Johnson, 1983); and (d) getting help in negotiating the school's bureaucracy and options available in decisions (Mahan \& Johnson, 1983). Many of these perceived needs may be addressed in a mentor program.

The teacher-student relationship has been widely documented as having a direct and positive influence on student achievement in school (Cuban, 1989; Rhodes \& McMillan, 1987; Self, 1985). Self described the teacherstudent relationship as the most important intervention strategy. When dropouts from New York schools were interviewed, $61 \%$ said that they felt unwanted and defined good teachers as caring and seeing students as individuals. A survey of 1,596 students by Poole (1994) confirms these findings. A significant number wanted more informal relations with their teachers, and the teacherstudent relationship was found to be a significant factor in the satisfaction or dissatisfaction of these students. Examples of programs with positive results involving teachers as mentors include TASK (Teachers Achieving 
Success with Kids). The purpose of TASK was to promote a close teacher-student relationship for at-risk students in an urban middle school. The students met daily with their mentors and weekly assessments were communicated to parents. The research on this program found significant improvement in attendance, discipline, and academic achievement among the targeted at-risk population, as well as a positive change in attitudes about school (Abcug, 1991).

Another evaluation of an at-risk mentoring program, involving the staff in two Texas high schools, found that aciult teacher mentors made a difference in the selfconcept of at-risk loth grade students attending the two schools. The research also found no difference between academic achievement or dropping out as a result of these mentorships (Slicker \& Palmer, 1993). 
CHAPTER III

METHODOLOGY

General Plan of study

This study used quasi-experimental research methodology in examining the effect of a staff mentoring program with students identified by their counselors as being at risk of becoming early leavers. This mentoring program, Caring About Kids Effectively (CAKE), was designed for and implemented at a suburban secondary school in oregon serving grades 9 through 12 . Specifically, such indicators of success in school as attendance and GPA were examined for the entire four years of the program's existence, and attitude toward school for the first two years. The researoher studied the enrollment status of these students over the same period of time.

\section{CAKE (Caring About Kids Effectively)}

CAKE, Caring About Kids Effectively, was a mentor program developed and implemented to assist in reducing the dropout rate of at-risk students identified prior to entering the 9 th grade in a selected suburban high school. 
The primary function of this program was to establish relationships between these at-risk students and staff members from the high school. These staff mentors, volunteers from both teachers and support personnel, provided support and guidance to their student mentees by placing emphasis on interpersonal relationships, problem solving techniques, and communication skills, and by encouraging positive behavior, study skills, and attendance. Staff mentors were asked for their preferences concerning student mentees, such as whether they were in one of their classes, gender, attendance record, self-esteem, and substance/family abuse issues.

The staff mentors met four times during the first year of the program to receive training in at-risk student behavior and provide support for the mentor/mentee relationship. over a four-year period of time, additional mentors were recruited, as staff retired or moved from the school, and each year incoming at-risk 9 th graders were assigned mentors.

In general, mentorship programs such as this one presume that the association between the mentor and the mentee will result in some sort of positive experience for the mentee. In this program, indicators of success (attendance, GPA, enrollment status, and attitude towards school) were examined. 


\section{Quantitative Research Components}

The study of the CAKE mentorship program had four quantitative research components: The first examined the difference in school achievement and attitude towards school by comparing students at risk and those not at risk; secondly, the at-risk students selected from three cohorts were compared prior to any treatment to examine the appropriateness of grouping these students together to provide for a larger sample; thirdly, indicators of school success (grades and attendance) and attitude toward school were analyzed over the period of time students were mentored to find any significant change; and fourthly, the researcher felt it was important to report the enrollment status at graduation for students analyzed in the study. The analysis of these pre- and post-treatment results provided information as to the effectiveness of mentoring on such indicators of school success as attendance and GPA rates, attitude towards school, and the school's holding power in terms of the number of dropouts.

The researcher also examined participants' perceptions of the mentoring program, using data from a survey given to participants in the program. Both student proteges and staff mentors were given a survey to determine those characteristics of the CAKE mentorship program that were successful and those activities or 
components of the program that needed to be reevaluated. The researcher felt that it was important to analyze both any actual change in students' attitudes and progress in school over a period of time and examine the perceived usefulness of the program from both the mentees' and mentors' viewpoints. This provides a comprehensive evaluation of the effectiveness of a staff mentoring program for at-risk students.

\section{Independent Variables}

In this study there were two student-related independent variables: "At-risk status" and "mentoring." The levels of the at-risk status were: (1) students classified as being at-risk and (2) all other students. The levels for the mentoring variable were (1) at-risk students who received mentoring from staff members (treatment group) and (2) at-risk students who did not receive mentoring (control group). The dependent variables were: GPA, attendance, enrollment status (graduated, GED, dropout, and returning 5th-year senior), attitudes toward school as measured by the Quality of School Life (QSL), and perceptions of the mentor program as measured by the CAKE survey. Attitudes, GPA, and attendance also served as covariates. Comparisons within and between groups were made. Because of the method used 
in assigning subjects to treatment, described later, a quasi-experimental design was used.

A third independent variable was staff mentors; the associated dependent variable was perceptions of the mentoring program as measured by the CAKE survey. This part of the study was descriptive.

As indicated in the literature review, it should be noted that mentorship programs are increasing in number in both the private and public sectors. Therefore it makes sense that educators would do well to examine how the mentoring processes and mentorship activities meet the needs and expectations of the students. Due to the limitations of such a study, any inferences of causality cannot be made with any degree of certainty. However, these results, when matched with similar findings of student-teacher mentorship programs in other schools, may make meta-analysis desirable.

Characteristics of High School/School District

The CAKE program was implemented in a suburban high school, one of four secondary schools located in a school district of approximately 14,500 students. A total of 1,365 students, grades 9-12, attended this comprehensive high school. The school district consisted of three comprehensive high schools and one occupational skills 
center. The high school faculty consisted of 65 full time certified teachers, 20 classified staff, four counselors, and four administrators. The ethnic makeup of this high school was primarily caucasian (90.5\%). Others included African-American students (1\%), Hispanic students ( $2 \%)$, Asian/Pacific students ( $4 \%$ ), and Alaskan/Native American $(2.5 \%)$.

The high school used in this research was considered the "poor sister school" in comparison to the other high schools located in the district. At the time of the study, 225 students were on free or reduced lunch, and the mobility rate was much higher than for the other two comprehensive high schools, averaging approximately $25 \%$ Students were absent more often at this high school, averaging $11 \%$ during the years of this research; in comparison, the absentee rate was $6.5 \%$ and $5.5 \%$ in the other two high schools. More students dropped out of this high school when compared to the other high schools. Dropout data from the state indicates a $27 \%$ dropout rate for this high school over the four years of this research, versus $15 \%$ and $13 \%$ dropout rates for the other two high schools in the district. The average income for the parents of this high school was in the low average range, in contrast to average and above average incomes for parents of the other two high schools. Approximately $25 \%$ 
of the high school students analyzed enrolled in college after graduation, $10 \%$ attended a community college, $40 \%$ went directly to the job market, and $25 \%$ dropped out or received a GED.

\section{Subjects}

There were two categories of subjects: (a) staff members who agreed to participate in the CAKE program and serve as mentors $(\mathrm{N}=83)$ and (b) at-risk students who were considered eligible to participate in the CAKE program $(\mathrm{N}=118)$. The at-risk students were partitioned into two groups: (a) students with mentors and who participated in the CAKE program $(\underline{N}=84)$ and (b) at-risk students without mentors $(\underline{N}=44)$. Both students with mentors (experimental group) and without mentors (control group) were the subjects used in this study examining the effects of mentoring.

Mentors were equaliy divided as to gender, whereas there were almost twice as many at-risk male students assigned mentors as females. This was not the case with those students without mentors, as they were equally divided as to their gender. In all three cohorts, there were more males identified as at-risk than females. (Refer to Table 1.) 
Table 1

Gender of Subjects

\begin{tabular}{|c|c|c|c|c|}
\hline Subject & Gender & Cohort 1 & Cohort 2 & $\begin{array}{c}\text { Year } 2 \\
\text { Cohor } 3\end{array}$ \\
\hline Mentors & $\begin{array}{l}\text { Male } \\
\text { Female } \\
\text { Total }\end{array}$ & \multicolumn{2}{|c|}{$\begin{array}{l}37 \\
46\end{array}$} & $\begin{array}{l}30 \\
33 \\
63\end{array}$ \\
\hline $\begin{array}{l}\text { At-Risk Students } \\
\text { With Mentors }\end{array}$ & $\begin{array}{l}\text { Male } \\
\text { Female }\end{array}$ & $\begin{array}{l}33 \\
15 \\
\end{array}$ & $\begin{array}{r}8 \\
4 \\
\end{array}$ & $\begin{array}{l}16 \\
8\end{array}$ \\
\hline Without Mentors & $\begin{array}{l}\text { Total } \\
\text { Male } \\
\text { Female } \\
\end{array}$ & $\begin{array}{l}48 \\
8 \\
8 \\
16\end{array}$ & $\begin{array}{l}12 \\
6 \\
3 \\
9\end{array}$ & $\begin{array}{c}24 \\
10 \\
9 \\
19\end{array}$ \\
\hline & \begin{tabular}{|l|} 
Total \\
Total
\end{tabular} & $\frac{16}{64^{\circ}}$ & $\frac{9}{21}$ & $\frac{19}{43^{*}}$ \\
\hline
\end{tabular}

- 130 ID'd in 1989 - 64 dropped before January. leaving 64 in Cohon I

*- Picked up another group. Cohort 3, but had only 52 left by April. and had only 43 actually take QSL/attendance/GPA.

The subjects in this study were either at-risk or not at-risk and divided into three cohorts: Cohort 1 , students identified as at-risk by their 8 th grade counselor, began their freshman year in high school in Year 1 of the study. Cohort 2 were students identified as at-risk by their 9 th grade counselor and were beginning their sophomore year in Year 1 of the study. Cohort 3 , students identified by their 8 th grade counselor as atrisk, began their freshman year in Year 2 of the study. To qualify as a prospective mentee for cohorts 1 and 3 in the CAKE program, counselors from students in 8 th grade year identified these students as having three or more characteristics of at-risk behavior listed below:

1. Attendance problems 
2. Low performance and achievement, subject and grade failure, many times one or two grades below level

3. Comes from a lower socioeconomic background

4. Negative about school

5. Low self-esteem

6. Family history of school failure This was also the criteria 9 th grade counselors used for students in Cohort 2. A counselor from the high school met with each group of teachers and a counselor at the 8 th grade level and discussed the students recommended as needing the CAKE program.

Mentors were staff volunteers from the high school. They were both teachers and support personnel such as instructional assistants, secretaries, and custodians. The only criteria to become a mentor was to volunteer to mentor an at-risk student for the years that student remained in school. Some staff continued to add mentees as theirs moved, dropped out, or were demonstrating success in school; other staff members did not volunteer to mentor additional students as needed. 


\section{Instruments}

In addition to attendance and GPA records, the researcher used the following to collect data in order to evaluate the effectiveness of the mentor program:

The ouality of school

Life Survey, or QSL

The Quality of Life Survey, or QSL, by Epstein and McPartland (1978), was used to determine students' attitudes and how these attitudes change over time. The QSL is a multidimensional measure of student reactions to school in general, to their classwork, and to their teachers. Three subscales form the 27-item QSL, based on three dimensions of the concept of the quality of school life.

The Satisfaction with School subscale (SAT) examines students' general reactions to school. Epstein and McPartland (1978) stated:

Because school is a major part of youngsters' lives, students who are positive in their evaluation of life in school may be more likely to experience feelings of general well-being. They also may be more likely to behave in socially acceptable ways and help other students in the school setting. (p. 2)

The Commitment to Classwork subscale (COM) deals with the level of student interest in classwork. Epstein and McPartland (1978) explained: 
Tasks and assignments are what make school different from non-school settings. In short, "the work" is what makes school school. students who find class assignments and projects interesting and important may learn facts and concepts more completely, and may develop more positive attitudes toward learning. (pp. 2-3)

The final subscale, Reactions to Teachers (TCH), examines student evaluations of instructional and personal interactions with teachers. Epstein and McPartland (1978) went on to explain:

Student-teacher relationships may be the key to student acceptance of educational goals, student understanding of school procedures, differences in students' independent or dependent behavior, and attitudes toward authority in and out of school. (p. 3)

The reliability of a test concerns the consistency of scores derived from the instrument. Reliability studies on the internal consistency of QSL were conducted for the 4,266 elementary and secondary students in the final survey. The Administration and Technical Manual by Epstein and McPartland (1978) provided reliability coefficients, using KR20 for the subscales and the total scale of the QSL. Procedures that determined the internal consistency of tests took into consideration the variation of student responses to all test items. The reliability coefficients obtained provided an estimate of test consistency at a specific time. The overall KR20 reliability for the QSL was .87 for secondary students. For the subtests, KR-20 reliability coefficients were .79 
for the SAT subscale, .72 for the COM subscale, and .64

for the TCH subscale.

The standard error of measurement is a measure of the discrepancies between obtained scores and true scores. For the QSL, this statistic was computed using the internal consistency reliability estimates (stanley \& Hopkins, 1972). The standard error of measurement for the 27-item QSL scale was 2.14 for the secondary samples (Epstein \& McPartland, 1978).

The research sample has also provided the QSL with concurrent, discriminative, construct, and predictive validity. A test is valid if it provides scores that can be used successfully to define conditions accurately. The items of each scale of the QSL and selected item characteristics (item mean, item-subscale correlations, item-scale correlations) are presented in Appendix A (Epstein \& McPartland, 1978, p. 15). The minimum itemsubscale correlation was .38 ; only four correlations were less than .50. The minimum item-scale correlation was .30 ; three of the correlations were less than .40. All item-subscale correlations were greater than their corresponding item-scale correlations, although in some cases the differences were negligible.

National norms were not available for the QSL. Research norms presented were based on the responses of a 
sample of 4,266 students nationwide. The means and standard deviations of this research norm sample are similar to the means and standard deviations found in the student population sampled for this study (see Table 2).

Table 2

QSL Questionnaire, Subscale, and Total Scale Means and Standard Deviations for Research Sample for Norms and Study sample of students in the 9 th Grade

\begin{tabular}{|l|cc|cc|cc|}
\hline \multirow{2}{*}{ Scale } & \multicolumn{2}{|c|}{$\begin{array}{c}\text { Research Sample } \\
\text { for Norming }\end{array}$} & \multicolumn{2}{c|}{$\begin{array}{c}\text { Sudy Sample of } \\
\text { At-Risk Students }\end{array}$} & \multicolumn{2}{c|}{$\begin{array}{c}\text { Study Sample of } \\
\text { Not At-Risk Students }\end{array}$} \\
\cline { 2 - 7 } & Mean & SD & \multicolumn{2}{c|}{ Mean } & SD & \multicolumn{2}{c|}{ Mean } & SD \\
\hline \hline SAT & 2.94 & 1.78 & 2.15 & 1.7 & 2.77 & 1.6 \\
\hline COM & 4.49 & 2.92 & 4.38 & 2.88 & 5.36 & 2.57 \\
\hline TCH & 5.01 & 2.79 & 5.11 & 2.8 & 6.32 & 2.69 \\
\hline Total QSL & 11.84 & 6.45 & 11.64 & 6.37 & 12.45 & 5.66 \\
\hline
\end{tabular}

Source: Epstein and McPartland (1978, p. 6)

"Older students are generally less satisfied with their school experiences than younger students" (Epstein \& McPartland, 1978 , p. 2). There is a consistent pattern of decreasing satisfaction with school life for the same students on two surveys, one year apart.

The scoring system for the QSL is a tally of the number of positive evaluations for each subscale and for the total scale. The more positive the evaluation, the higher the affective quality of school life. Each item of the scale is worth "1 point" or "zero," with 1 point as the score for a clearly positive evaluation of a school 
experience. A scoring template is provided with the test, but in this study, all scores were entered into a computer program and scored using the scoring instructions for the QSL.

Table 3 illustrates the sample size and year the QSL was administered to participants in this research. The size of the groups participating in the sample decreased each year due to the nature of these students being atrisk of dropping out of school. For example, in cohort 1 , 46 at-risk students took the QSL in the fall of Year 1 and Year 2, but only 11 took the QSL in the fall of Year 3 .

\section{CAKE SurveY}

A questionnaire format was selected as the best way to elicit information from the CAKE participants regarding their perception of the mentor program. Prior to constructing the questionnaire, research references were consulted (Ary, Jacobs, \& Razavieh, 1985; Campbell\& Stanley, 1963; Gay, 1987).

Given that this survey is a data collecting instrument, care was taken in its construction, with particular attention to its intended use in a concensus survey. Gay (1987) noted,

In a census survey, an attempt is made to acquire data from each and every member of the population; a census survey is usually conducted when a population is relatively small and readily accessible. (p. 192) 
Table 3

Overview of QSL Sample sizes Within the Three Cohorts

\begin{tabular}{|c|c|c|c|c|c|c|c|c|c|c|c|c|c|c|}
\hline \multirow{3}{*}{ COHORTS } & \multicolumn{5}{|c|}{ Year 1} & \multicolumn{5}{|c|}{ Year ? } & \multicolumn{4}{|c|}{ Year 3} \\
\hline & \multirow{2}{*}{$\begin{array}{l}\text { H of yrs } \\
\text { in study }\end{array}$} & \multirow{2}{*}{$\begin{array}{c}\text { nut } \\
\text { al-risk }\end{array}$} & \multicolumn{3}{|c|}{ al-risk } & \multirow{2}{*}{$\begin{array}{l}\text { \# of yrs } \\
\text { in study } \\
\end{array}$} & \multirow{2}{*}{$\begin{array}{c}\text { not } \\
\text { at-risk }\end{array}$} & \multicolumn{3}{|c|}{ at-risk } & \multirow{2}{*}{$\begin{array}{l}\text { H of yrs } \\
\text { in study }\end{array}$} & \multicolumn{3}{|c|}{ at-risk } \\
\hline & & & & mentor & & & & & mentor & & & total & mentor & $\begin{array}{c}\text { no } \\
\text { mentor }\end{array}$ \\
\hline \multirow[t]{5}{*}{ Cohort 1} & \multicolumn{5}{|c|}{ Grade 9} & \multicolumn{5}{|c|}{ Grade 10} & \multicolumn{4}{|c|}{ Grade 11} \\
\hline & 1 ycar & $125 i$ & 71 & 3 & 4 & 1 ycar & $23 i$ & $5 i$ & 3 & 2 & 1 ycar & -- & -- & -- \\
\hline & 2 years & $71 i$ & $46 i$ & 34 & 12 & 2 years & $71 i$ & $46 i$ & 34 & 12 & 2 years & -. & -. & -. \\
\hline & 3 yeurs & 01 & 111 & 11 & 0 & 3 years & 0 & 111 & 11 & 0 & 3 years & 11 & 11 & 0 \\
\hline & $1,2,3$ & $196 !$ & $64 !$ & 48 & 16 & $1,2,3$ & $94 !$ & 571 & 43 & 14 & $1,2,3$ & 111 & 11 & 0 \\
\hline \multirow[t]{4}{*}{ Cuhort 2} & \multicolumn{5}{|c|}{ Grade 10} & \multicolumn{5}{|c|}{ Grade 11} & & & & \\
\hline & 1 year & 100 & 101 & 5 & 5 & 1 year & 201 & 11 & 0 & 1 & & & & \\
\hline & 2 ycars & $42 !$ & 11 & 7 & 4 & 2 ycars & $42 i$ & 111 & 7 & 4 & & & & \\
\hline & 1.2 & 1421 & 211 & 12 & 9 & 1,2 & $62 !$ & $12 !$ & 7 & 5 & & & & \\
\hline \multirow[t]{4}{*}{ Colwort 3} & & & & & & \multicolumn{5}{|c|}{ Grade 9} & \multicolumn{4}{|c|}{ Grade 10} \\
\hline & & & & & & 1 year & 225 & 211 & 8 & 16 & 1 year & -. & -. & $\cdot-$ \\
\hline & & & & & & 2 years & 0 & 22 & 16 & 6 & 2 years & 22 & 16 & 6 \\
\hline & & & & & & 1,2 & $225 !$ & $43 !$ & 24 & 19 & 1,2 & 22 & 16 & 6 \\
\hline
\end{tabular}

Example:

* "I year" denotes that these students took the QSL the first year, in Cohort 1.

** "2 years" denules that these sludenls look the QSL over a two-year period of lime and were either in the CAKE program or not assigned a mentor

*** "3 years" denoles that lhese students were still in the CAKE program for lhree years 
This survey was a cross-sectional design as participants were surveyed just once; the design provided a portrait of things as they were at a single point on the continuum in the CAKE program.

Initially, informal interviews were conducted with the program initiators and the vice-principal of the high school, to gather initial perceptions of the mentoring process and the CAKE program. A questionnaire draft was developed, comprised of questions gleaned from the informal interviews, research on effective mentoring, and the program design.

A pilot group consisting of three mentees and three mentors was formed with the intent of gaining insight on survey design and content. One survey was found to be user friendly, and directions were clear for the mentor group. Since many of the students were unclear as to what the CAKE program was and what their involvement was exactly, the mentee group felt that the survey should be given orally instead of requiring written responses. Many of the mentees were not told exactly why a staff member had suddenly taken such an interest in them or were told that they had a "mentor," but did not explain that it was specifically called the CAKE program.

The final questionnaire was self-administered to the mentors and orally given by the researcher to the mentees. 
In both cases, care was taken to explain the purpose of the questionnaire, including aims and the participants involved. Participants were told that feedback would be given at a staff meeting in an attempt to improve the CAKE program. A booklet form was chosen for ease of handling and readability. Page breaks were monitored so that the respondent did not have to turn the pages to complete any portions of the questions. The length of time estimated to complete the questionnaire was 15 minutes. All questionnaires were given directly back to the researcher since most of the respondents could be found in the same building. Those respondents who had moved were given a self-addressed envelope with which to reply. The CAKE surveys for mentors are in Appendix B and for mentees in Appendix $C$.

\section{Procedures}

In the spring of Year 0 , counselors in three junior high schools were given criteria by which they were to identify students from the 8 th grade who would be 9 th graders in the fall and were at risk of dropping out of school within the next four years. These names were given to the counselors at the high school. Students who were on an IEP were deleted from this list due to the fact that they were already receiving services. In the fall, 83 
staff members volunteered to participate in a mentoring program (CAKE). Each was given the name of a student at risk and any known information surrounding the student's circumstances that led to that student's 8 th grade counselor identifying him or her as at-risk. This group of 9 th graders became cohort 1 .

These volunteer staff mentors were given one-hour inservice after school on the mentoring process, legal issues, possibilities for activities, and possible times to meet together. They were instructed to participate as much as they felt comfortable. It was felt that, since these staff members were volunteers, the extent of their participation in the mentoring program should be up to then. At the same time, a group of the staff volunteered to oversee the program. This included one counselor and three teachers.

In october of the first year of the mentor program, a survey of student attitudes (QSL) was administered to all 9th and 10th graders in the school. These were to assess the general climate of the school and were numbered with the student's identification to be used as data in the evaluation of the mentoring program. Also in October, sophomores who were identified as at-risk were also matched with mentors. These 10th graders then became Cohort 2. During the year, staff was given a few 
opportunities to get together and talk about the successes as well as the frustrations they felt with their mentoring experience. No additional inservice was given, and any advice was given by other staff mentors through these meetings.

The following year, the fall of year 2, another group of 9 th graders identified as at-risk by their 8 th grade counselors were matched with mentors. These students became cohort 3. The staff was given the option of adding a second mentee or simply staying with the first student with which they had been matched in year 1. sixty-three staff members agreed to mentor another student from this newest group of 9 th graders. The QSL was given again to all students in the freshman and sophomore classes, and the students from Cohort 2 now in their junior year.

The students in all three cohorts who were matched with a staff mentor became the treatment group (at-risk with mentors) and the students who were identified as atrisk but not matched with mentors became the control group (at-risk without mentors). This group of at-risk students without mentors existed because there were more at-risk students than staff members available to mentor them at the beginning of year 1 . It is interesting to note that approximately half of those students identified as at-risk in year 1 left school within the first four months, 
leaving some mentors without mentees. Many waited until Year 2 to pick up another at-risk student (see Table 1). No special treatment was given to the group without mentors except the monitoring of the same data collected on the students with mentors. The QSI was given to students remaining in cohorts 1 and 3 in the fall of Year 3. No additional students were added since most of the mentors felt they had their hands full with two students. The number of mentors fell to 63 due to retirements, teacher transfer, and dropping from the program. In addition, the teacher primarily responsible for the program retired in the spring of Year 3 . The rest of the staff had added additional responsibilities to their teaching which took away from the mentor program. This researcher systematically collected data on attendance and GPA information through grade 12 for cohorts 1,2 , and 3 . The attendance and GPA data was gathered from records generated in the high school's counseling office at the end of each semester. Social Studies teachers were given the QSL and asked to administer the 20 minute surveys on a set date. Each teacher told students the surveys were confidential and would be scored to determine students' general satisfaction in this high school. Students were instructed to put thei:- student number in the upper right 
hand corner of the surveys in order to distinguish between groups of students. (In this case, students identified as at-risk and not at-risk, with mentors and without mentors.) All surveys were returned to the researcher for scoring.

The disadvantage to a longitudinal study is that the samples tend to shrink in size as time goes by (see Table 3). This was particularly true in this research because of the nature of the subjects being at-risk. For this reason, Cohorts 1,2 , and 3 were compared, using data on attendance and GPA records from their 8 th grade year, and attitudes (as measured by the QSL) from the fall of their 9 th grade year prior to any treatment, to determine if it would be appropriate to merge all three cohorts to increase the numbers for analysis purposes.

Baseline data were needed to see if the students were equivalent as far as the types of data to be analyzed, i.e., attendance, GPA, and attitudes toward school. For at-risk students, attendance and GPA data from their 8 th grade records for cohorts 1,2 , and 3 were compared (Eighth grade GPA for cohort 2 was unavailable). For not at-risk students, attendance and GPA data from the 9 th grade records of cohorts 1, 2, and 3 were compared, since district data was available and this group was not affected by contamination of any treatment. The QSL 
scores prior to treatment were also compared to see if the students identified as at-risk were equivalent groups.

\section{Overview of the Data}

A summary of the schedule for data collection is presented in Table 4. It shows the data collected in the fall and spring of each year of the study, starting with the baseline data collected in the spring of the year prior to the beginning of the study.

In the fall of Year 4, a CAKE survey was given to all 83 mentors and a random sampling of mentees to gather additional qualitative information on the assessment of participants' opinions on the characteristics of this mentoring program that were successful or detracted from its success. This questionnaire was designed to gather descriptive data. Likert-like scales were used to describe respondents' perceptions of the CAKE program, its value in helping at-risk students, factors concerning placement of the mentee in the mentor's class, and time available to mentor. Respondents were asked to respond to questions concerning the match between expectations at the outset of program participation and at the end of their program activities. Nominal questions such as frequency of contacts between the mentor and mentee were included. Respondents were also asked to rank order program 
attributes and program activities in terms of personal value in the mentoring program. The final question was open-ended to encourage free response.

Table 4

Overview of Data Collected from Year 0 through Year 5

\begin{tabular}{|c|c|c|c|c|c|c|c|c|c|c|c|c|}
\hline \multirow[b]{2}{*}{ Cohon } & \multicolumn{2}{|c|}{ Year 0} & \multicolumn{2}{|c|}{ Year I } & \multicolumn{2}{|c|}{ Year 2} & \multicolumn{2}{|c|}{ Year 3} & \multicolumn{2}{|c|}{ Year 4} & \multicolumn{2}{|c|}{ Year 5} \\
\hline & Fall & Spring & Fall & Spring & Fall & Spring & Fall & Spring & Fall & Spring & Fall & Spring \\
\hline 1 & $\begin{array}{l}\text { Grade } 8 \\
\text { Pre }\end{array}$ & $\begin{array}{l}\text { Grade } 8 \\
\text { Pre } \\
\text { attend0 } \\
\text { GPA1, } \\
\text { GPA2 }\end{array}$ & $\begin{array}{l}\text { Grade } 9 \\
\text { Group } \\
I \\
\text { QSL-1 }\end{array}$ & $\begin{array}{l}\text { Grade } 9 \\
\text { Group I } \\
\text { attend ! } \\
\text { GPA1, } \\
\text { GPA2 }\end{array}$ & $\begin{array}{l}\text { Grade } \\
10 \\
\text { Group } \\
2 \\
\text { QSL-2 }\end{array}$ & $\begin{array}{l}\text { Grade } \\
10 \\
\text { Group ? } \\
\text { allend? } \\
\text { GPAI. } \\
\text { GPA2 }\end{array}$ & $\begin{array}{l}\text { Grade } \\
11 \\
\text { Group } \\
3 \\
\text { QSL-3 }\end{array}$ & $\begin{array}{l}\text { Grade } \\
11 \\
\text { Group } 3 \\
\text { attend3 } \\
\text { GPA1. } \\
\text { GPA? }\end{array}$ & $\begin{array}{l}\text { Grade } \\
12 \\
\end{array}$ & $\begin{array}{l}\text { Grade } \\
12 \\
\text { attend4 } \\
\text { GPA1. } \\
\text { GPA2 }\end{array}$ & - & --.- \\
\hline 2 & $\begin{array}{l}\text { Grade } 9 \\
\text { Pre }\end{array}$ & $\begin{array}{l}\text { Grade } 9 \\
\text { Pre } \\
\text { attend0 } \\
\text { GPA1. } \\
\text { GPA2 }\end{array}$ & $\begin{array}{l}\text { Grade } \\
10 \\
\text { Group } \\
1 \\
\text { QSL-1 }\end{array}$ & $\begin{array}{l}\text { Grade } \\
10 \\
\text { Group I } \\
\text { attend! } \\
\text { GPAI. } \\
\text { GPA? }\end{array}$ & $\begin{array}{l}\text { Grade } \\
11 \\
\text { Group } \\
2 \\
\text { QSL-2 }\end{array}$ & $\begin{array}{l}\text { Grade } \\
11 \\
\text { Group } 2 \\
\text { attend2 } \\
\text { GPA1. } \\
\text { GPA2 }\end{array}$ & $\begin{array}{l}\text { Grade } \\
12 \\
\text { Group } \\
3\end{array}$ & $\begin{array}{l}\text { Grade } \\
12 \\
\text { Group } 3 \\
\text { attend3 } \\
\text { GPA1. } \\
\text { GPA? }\end{array}$ & - & - & - & $\longrightarrow$ \\
\hline 3 & & & $\begin{array}{l}\text { Grade } 8 \\
\text { Pre }\end{array}$ & $\begin{array}{l}\text { Grade } 8 \\
\text { Pre } \\
\text { attend0 } \\
\text { GPAI. } \\
\text { GPA? }\end{array}$ & $\begin{array}{l}\text { Grade } 9 \\
\text { Group } \\
l \\
\text { QSL-1 }\end{array}$ & $\begin{array}{l}\text { Grade } 9 \\
\text { Group I } \\
\text { attend I } \\
\text { GPAI. } \\
\text { GPA2 }\end{array}$ & $\begin{array}{l}\text { Grade } \\
10 \\
\text { Group } \\
2 \\
\text { QSL-2 }\end{array}$ & $\begin{array}{l}\text { Grade } \\
10 \\
\text { Group } 2 \\
\text { attend2 } \\
\text { GPA! } \\
\text { GPA2 }\end{array}$ & $\begin{array}{l}\text { Grade } \\
11 \\
\text { Group } \\
3\end{array}$ & $\begin{array}{l}\text { Grade } \\
11 \\
\text { Group } 3 \\
\text { attend3 } \\
\text { GPA1. } \\
\text { GPA? }\end{array}$ & $\begin{array}{l}\text { Grade } \\
12 \\
\text { Group } \\
4\end{array}$ & $\begin{array}{l}\text { Grade } \\
12 \\
\text { Group } 4 \\
\text { attendt } \\
\text { GPA1. } \\
\text { GPA2 }\end{array}$ \\
\hline
\end{tabular}

Pre $=$ Pretreatment data

Altend = attendance or days present

GPA = grades average 1 st and 2nd semester

QSL $=$ Quality of School Life

Data Analysis Procedures

Various analyses were planned, using the statistical treatments most suitable for the data collected.

The questions presented in this chapter were tested by use of the $t$-test, chi-square, analysis of variance, and analysis of covariance. In addition, frequency tables 
and other graphic representations were used in reporting data. These were chosen for the following:

The t-test is used to see if there is a significant difference between the means of two groups. The chisquare test compares frequencies of occurrences within groups to see if one condition occurs more often in one group than in another. Analysis of variance (ANOVA) looks for variance within and between groups to ascertain if there is more variance between two or more means at a selected probability level than is attributable to chance. For the purpose of this study, the researcher is comparing the means of two groups of at-risk students with an intent to examine their similarities or differences. Analysis of covariance (ANCOVA) is a statistical method for equating groups on one or more variables and for increasing the power of a statistical test (Gay, 1987, p. 541). Tukey's test was used for post hoc mean comparisons when comparing three groups that were reported as significant. However, since the sampling distribution with a covariate differs from the studentized range statistic used for one-way analysis comparisons, the generalized studentized range distribution was used and the Bryant-Paulson procedure followed (see Appendix E).

Concerning the qualitative analysis for the questions with written responses, the researcher recognizes there 
are several methods from which to choose. Patton (1990) suggests that insight, creativity, and experience will play a major role when choosing a particular methodology to describe and analyze data, and that applying both quantitative and qualitative methods to a particular research question may be appropriate. Qualitative analysis has emerged as an important and essential means of research and program evaluation in many fields, including education.

It is the researcher's belief that all methodologies have limitations and that in conjunction, appropriate quantitative and qualitative methodology may be a powerful approach to research. Both methodologies were used in this research project to determine the effectiveness of this mentoring program.

The following questions were formulated to evaluate the staff mentor program:

1. Are there significant differences on the subscales and total scale of the quality of School Life Scales (QSL), attendance rates, and GPA between students identified as at-risk and students not at risk?

2. Are there significant differences on the subscales and total scale of the quality of School Life Scales (QSL), attendance rates, and 
GPA between students identified as at risk with mentors, at-risk without mentors, and not atrisk?

3. Are there significant differences in attitudes as measured by the QSL between at-risk students with mentors and at-risk students without mentors?

4. Are there significant differences regarding attendance rates and GPA for at-risk students with mentors and at-risk students without mentors?

5. Are there significant differences in the enrollment status for at-risk students with mentors and at-risk students without mentors?

6. What are the participants' perceptions of the effectiveness and characteristics concerning the CAKE program?

Prior to any analysis of the mentor program, the researcher felt it was necessary to compare data prior to treatment to see if the experimental cohorts were equivalent. If so, the cohorts could be merged for data analysis, since some of the sample sizes were small. Table 5 demonstrates this form of analysis. 
Table 5

Analysis of Variance with Respect to Pretreatment Comparisons: Cohorts 1, 2, and 3, At-Risk and Not At-Risk

\begin{tabular}{|c|c|c|c|c|c|c|}
\hline \multirow{2}{*}{$\begin{array}{l}\text { At-Risk } \\
\text { Status }\end{array}$} & Cohor 1 & Cohor 2 & Cohor 3 & \multirow{2}{*}{ F-value } & \multirow{2}{*}{ Prob } & \multirow{2}{*}{$\begin{array}{l}\text { Significant } \\
\text { Differenies }\end{array}$} \\
\hline & Mean S.D. $\quad \mathrm{N}$ & Mean S.D. N & Mean S.D. N & & & \\
\hline \multicolumn{7}{|c|}{ Rates of Attendance (at-risk: 8th, 8th, 8th: not at-risk: $9 \mathrm{th}, 9 \mathrm{th}, 9 \mathrm{th}$ ) } \\
\hline \multicolumn{7}{|l|}{ at-risk } \\
\hline \multicolumn{7}{|l|}{$\begin{array}{l}\text { not } \\
\text { at-risk }\end{array}$} \\
\hline \multicolumn{7}{|c|}{ GPA* (at-risk: 8th. NA, 8th: not at-risk: 9th. 9th. 9th) } \\
\hline \multicolumn{7}{|l|}{ at-risk } \\
\hline \multicolumn{7}{|l|}{$\begin{array}{l}\text { not } \\
\text { at-risk }\end{array}$} \\
\hline \multicolumn{7}{|c|}{ Satisfaction with School (QSL) } \\
\hline \multicolumn{7}{|l|}{ at-rist } \\
\hline \multicolumn{7}{|l|}{$\begin{array}{l}\text { not } \\
\text { at-risk }\end{array}$} \\
\hline \multicolumn{7}{|c|}{ Commitment to Sehoolwork (QSL) } \\
\hline \multicolumn{7}{|l|}{ at-risk } \\
\hline \multicolumn{7}{|l|}{$\begin{array}{l}\text { not } \\
\text { at-risk }\end{array}$} \\
\hline \multicolumn{7}{|c|}{ Reactions to Teachers (QSL) } \\
\hline \multicolumn{7}{|l|}{ at-rist: } \\
\hline $\begin{array}{l}\text { not } \\
\text { at-risk }\end{array}$ & & & & & & \\
\hline \multicolumn{7}{|c|}{ Total QSL Score } \\
\hline \multicolumn{7}{|l|}{ al-risk } \\
\hline $\begin{array}{l}\text { not } \\
\text { at-risk: }\end{array}$ & & & & & & \\
\hline
\end{tabular}

- Average GPA for two semesters 
Question 1. Are there significant differences on the subscales and total scale of the quality of School Life Scales (QSL), attendance rates, and GPA between students identified as at-risk and not at-risk?

In order to establish a framework from which to have an understanding of the possible effects of any program on a student population, it is necessary to identify how the subgroups differ and are alike. For purposes of this evaluation, the student population given the QSL is divided into those identified as at-risk, and those not at-risk. Students from both groups were given the QSL in the fall of the 9 th grade year in high school, and again in the fall of their loth grade year for cohorts 1 and 3 . For Cohort 2, the QSL was given the fall of their loth grade year, and again in the 11th grade. In addition, attendance and GPA data was compared from Pretreatment to year 1 (Pretreatment data for cohorts 1 and 3 are from 8 th grade records and for cohort 2, from 9 th grade records). The models for these analyses are shown in Tables 6 through 8 . 
Table 6

Analysis of Covariance with Respect to Quality of School Life Scales (QSL)

At-Risk versus Not At-Risk Combined Cohorts

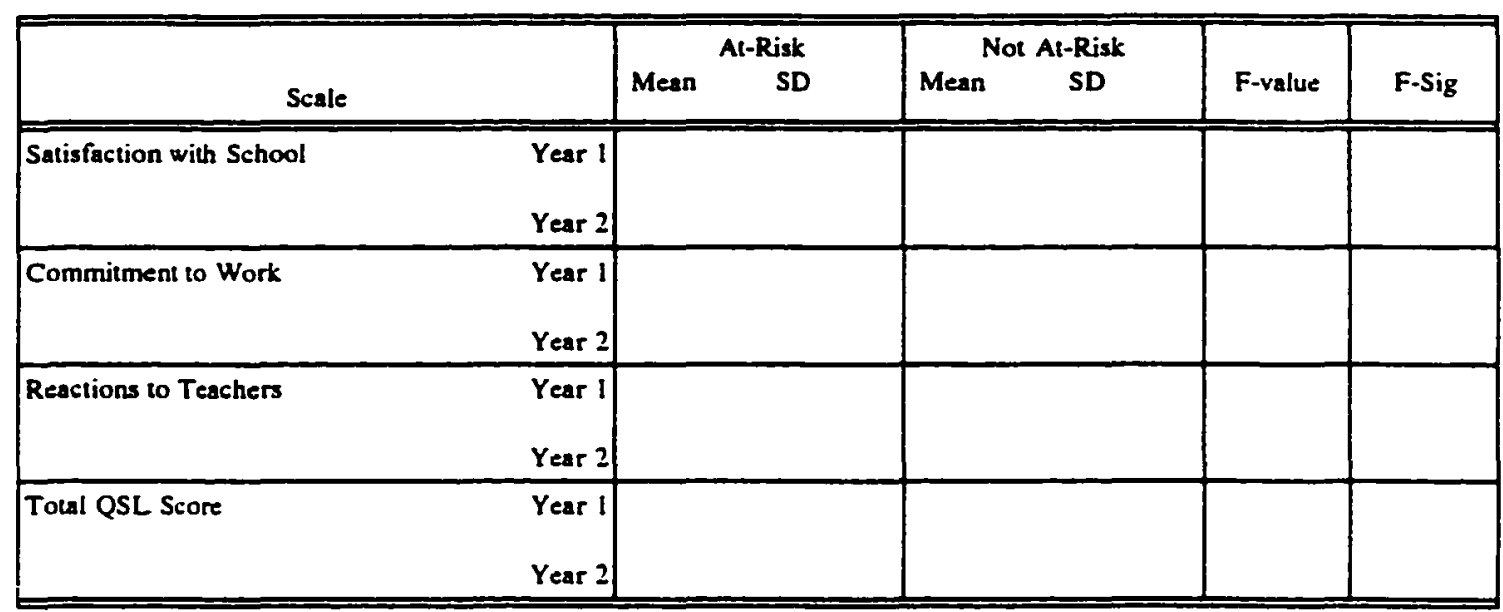

The Year 1 values were uses as the covariate for each analysis.

Table 7

Analysis of Covariance with Respect to Attendance Rates At-Risk versus not At-Risk Combined Cohorts

\begin{tabular}{|c|c|c|c|c|c|c|c|c|c|}
\hline Subjects & Trealment & Mean & $\begin{array}{l}\text { Al-Risk: } \\
\text { S.D. }\end{array}$ & $N$ & Mean & $\begin{array}{l}\text { At-R } \\
\text { S.D. }\end{array}$ & $\mathbf{N}$ & F-value & F-Sig \\
\hline $\begin{array}{l}\text { At-Risk Students } \\
\text { (2 yrs of QSL) }\end{array}$ & $\begin{array}{c}\text { Pre-trtmt } \\
\text { Year } 1\end{array}$ & & & & & & & & \\
\hline All Students & $\begin{array}{c}\text { Pre-trumt } \\
\text { Year } 1\end{array}$ & & & & & & & & \\
\hline
\end{tabular}

Pretreatment served as the covariate. 
Table 8

Analysis of Covariance with Respect to Average Annual GPA At-Risk versus Not At-Risk Combined Cohorts

\begin{tabular}{|c|c|c|c|c|c|c|c|c|c|}
\hline Subjects & Treatment & Mean & $\begin{array}{l}\text { At-Risk } \\
\text { S.D. }\end{array}$ & $\mathbf{N}$ & Mean & $\begin{array}{l}\text { Al-R } \\
\text { S.D. }\end{array}$ & $\mathbf{N}$ & F-value & F-Sig \\
\hline $\begin{array}{l}\text { Al-Rist Students } \\
\text { (2 yrs of QSL) }\end{array}$ & $\begin{array}{l}\text { Pre-trimt } \\
\text { Year } 1\end{array}$ & & & & & & & & \\
\hline All Students & $\begin{array}{r}\text { Pre-trtmt } \\
\text { Year } 1\end{array}$ & & & & & & & & \\
\hline
\end{tabular}

Pretreatment served as the covariate.

Question 2. Are there significant differences on the subscales and total scale of the quality of School Life Scales (QSL), attendance rates, and GPA between students identified as at-risk with mentors, at-risk without mentors and not at-risk?

Table 9 models an analysis of at-risk students with mentors, at-risk without mentors, and not at-risk in the QSL, and Table 10 models this same analysis for attendance and GPA.

Question 3. Are there significant differences in attitudes as measured by the QSL between at-risk students with mentors and at-risk students without mentors?

This analysis used an analysis of covariance which takes into consideration where each student started. The dependent variable = SAT 2 (Year 2), independent variable = mentor, covariate = SAT 1 (Year 1$)$. This procedure was 
followed for the other two scales and the total score on the QSL. Table 11 models an analysis of covariance with respect to the QSL for at-risk students with and without mentors.

Table 9

Analysis of Covariance with Respect to Quality of School Life Scales; At-Risk With Mentors, At-Risk Without Mentors, and Not At-Risk Combined Cohorts

\begin{tabular}{|c|c|c|c|c|c|c|c|c|c|}
\hline \multirow[t]{2}{*}{$\begin{array}{l}\text { Treatronen } \\
\text { Year }\end{array}$} & Al-Rist: Mentor & \multicolumn{2}{|c|}{$\begin{array}{l}\text { Al-Risk: } \\
\text { No Mentor }\end{array}$} & \multicolumn{3}{|c|}{ Nox Al-Risk } & \multirow[b]{2}{*}{ F.value } & \multirow[b]{2}{*}{ F.Sis } & \multirow[t]{2}{*}{$\begin{array}{l}\text { Sienificanx } \\
\text { Differences }\end{array}$} \\
\hline & Mean S.D. & Mean & S.D. & \begin{tabular}{l|l}
$N$ & Mean \\
\end{tabular} & S.D. & $\mathbf{N}$ & & & \\
\hline \multicolumn{10}{|l|}{ Year 1} \\
\hline \multicolumn{10}{|l|}{ Year: } \\
\hline \multicolumn{10}{|c|}{ Cocemituen to Sctwootwork } \\
\hline \multicolumn{10}{|l|}{ Year: } \\
\hline \multicolumn{10}{|c|}{ Reactions to Teachers } \\
\hline \multicolumn{10}{|l|}{ Year 1} \\
\hline \multicolumn{10}{|l|}{ Year: } \\
\hline \multicolumn{10}{|c|}{ Toul QSL Score } \\
\hline
\end{tabular}

Table 10

Analysis of Covariance with Respect to Attendance Rates for students At-Risk with Mentors, At-Risk Without Mentors, and Not At-Risk Combined Cohorts

\begin{tabular}{|c|c|c|c|c|c|c|c|c|c|c|c|c|}
\hline \multirow[t]{2}{*}{$\begin{array}{l}\text { Treatment } \\
\text { Yeat }\end{array}$} & \multicolumn{3}{|c|}{ Al-Risk: Memor } & \multicolumn{3}{|c|}{$\begin{array}{l}\text { At-Risk: } \\
\text { No Mentor }\end{array}$} & \multicolumn{3}{|c|}{ Nod Al-Rist } & \multirow[b]{2}{*}{$F$-salue } & \multirow[b]{2}{*}{ F-Sis } & \multirow[t]{2}{*}{$\begin{array}{l}\text { Sienificane } \\
\text { Differenoes }\end{array}$} \\
\hline & Mean & S.D. & $\therefore$ & Mean & S.D. & $\mathbf{x}$ & Mean & 5.D. & $v$ & & & \\
\hline \multicolumn{13}{|l|}{ Pre-crum } \\
\hline \multicolumn{13}{|l|}{ Year 1} \\
\hline \multicolumn{13}{|l|}{ GPA } \\
\hline Year 1 & & & & & & & & & & & & \\
\hline
\end{tabular}


Table 11

Analysis of Covariance with Respect to the Quality of School Life Questionnaire for At-Risk students With and without Mentors -- Year 1 to Year 2, Cohorts 1, 2, 3

\begin{tabular}{|c|c|c|c|c|c|c|c|c|c|}
\hline \multirow[b]{2}{*}{ Scale } & \multirow[b]{2}{*}{ Year } & \multicolumn{3}{|c|}{ Mentor } & \multicolumn{3}{|c|}{ No Mentor } & \multirow{2}{*}{\multicolumn{2}{|c|}{ F-value }} \\
\hline & & Mean & S.D. & $\mathbf{N}$ & Mean & S.D. & $\mathbf{N}$ & & \\
\hline SAT & $\begin{array}{l}\text { Year } 1 \\
\text { Year } 2\end{array}$ & & & & & & & & \\
\hline COM & $\begin{array}{l}\text { Year } 1 \\
\text { Year } 2\end{array}$ & & & & & & & & \\
\hline $\mathrm{TCH}$ & $\begin{array}{l}\text { Year } 1 \\
\text { Year } 2\end{array}$ & & & & & & & & \\
\hline $\begin{array}{l}\text { Total } \\
\text { QSL }\end{array}$ & $\begin{array}{l}\text { Year } 1 \\
\text { Year } 2\end{array}$ & & & & & & & & \\
\hline
\end{tabular}

Question 4. Are there significant differences regarding attendance rates and GPAs for at-risk students with mentors and at-risk students without mentors? Table 12 models an analysis of at-risk students with mentors versus at-risk students without mentors regarding attendance rates for cohorts 1 and 3 . Table 13 models the same analysis for GPAs. Data from Cohort 2 was excluded for this analysis due to the maturity factor, and can be found in the Appendices. 
Table 12

\section{Analysis of Variance for Attendance by At-Risk students with Mentors versus No Mentors \\ (All Possible Subjects)}

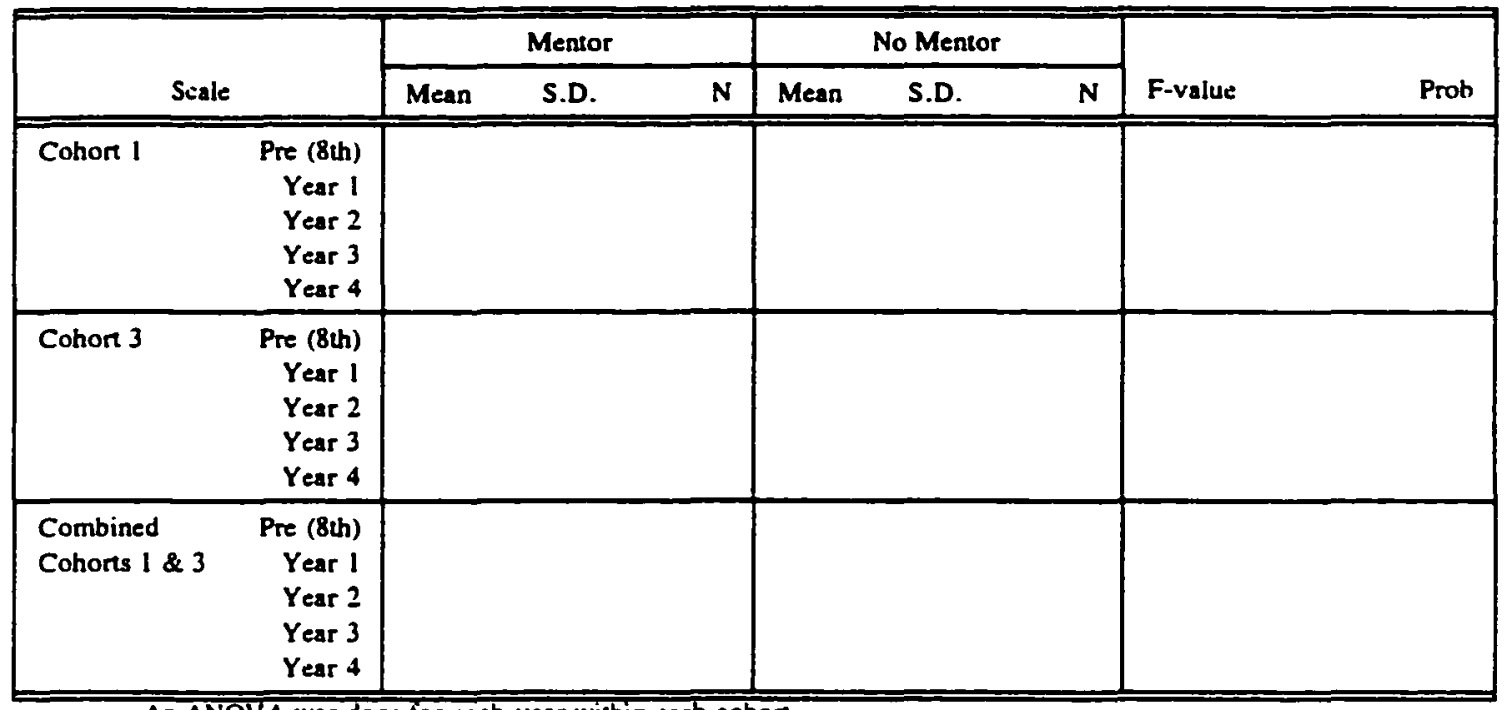

An ANOVA was done for each year within each cohor.

Cohor 2 was omitted since 8 th grade data was not available for many at-risk students.

Table 13

\section{Analysis of Variance for GPA (Average) by Mentors versus No Mentors Cohorts 1 and 3}

\begin{tabular}{|c|c|c|c|c|c|c|c|c|c|}
\hline \multirow{2}{*}{\multicolumn{2}{|c|}{ Scale }} & \multicolumn{3}{|c|}{ Mentor } & \multicolumn{3}{|c|}{ No Mentor } & \multirow{3}{*}{\multicolumn{2}{|c|}{ F-value }} \\
\hline & & \multirow[t]{2}{*}{ Mean } & \multirow[t]{2}{*}{ S.D. } & \multirow[t]{2}{*}{$N$} & \multirow[t]{2}{*}{ Mean } & \multirow[t]{2}{*}{ S.D. } & \multirow[t]{2}{*}{$\mathbf{N}$} & & \\
\hline Cohon I & $\begin{array}{r}\text { Pre }(8 \mathrm{ch}) \\
\text { Year } 1 \\
\text { Year } 2 \\
\text { Year } 3 \\
\text { Year } 4\end{array}$ & & & & & & & & \\
\hline Cohor 3 & $\begin{array}{r}\text { Pre }(8 \mathrm{ch}) \\
\text { Year } 1 \\
\text { Year } 2 \\
\text { Year } 3 \\
\text { Year } 4\end{array}$ & & & & & & & & \\
\hline $\begin{array}{l}\text { Combined } \\
\text { Cohons } 1 \text { \& } 3\end{array}$ & $\begin{array}{r}\text { Pre }(8 \mathrm{th}) \\
\text { Year } 1 \\
\text { Year } 2 \\
\text { Year } 3 \\
\text { Year } 4\end{array}$ & & & & & & & & \\
\hline
\end{tabular}

An ANOVA was done for each year within each cohon.

Cohor 2 was omitted since 8 th grade dals was not available. 
Question 5. Are there significant differences in the enrollment status of at-risk students with mentors and atrisk students without mentors? Status was listed in rank order of the findings. Analyses using percentages and Chi-Squares may be found in Table 14 .

Question 6. What are the participants' perceptions of the effectiveness and characteristics concerning the CAKE program? The format for data analysis is shown in Table 15 .

Table 14

Percentiles and Chi-Square Analysis of Enrollment Status After Year 4 for

All At-Risk Students

\begin{tabular}{|c|c|c|c|c|c|c|c|}
\hline \multirow[t]{2}{*}{ Status } & \multicolumn{2}{|c|}{$\begin{array}{l}\text { At-Risk: } \\
\text { Mentor }\end{array}$} & \multicolumn{2}{|c|}{$\begin{array}{c}\text { At-Risk: } \\
\text { No Mentor }\end{array}$} & \multicolumn{2}{|c|}{ Total } & \multirow[t]{2}{*}{ Chi-Square } \\
\hline & $\mathbf{N}$ & $\%$ & $N$ & x & $\mathbf{N}$ & $\%$ & \\
\hline & & & & & & & \\
\hline & & & & & & & \\
\hline & & & & & & & \\
\hline & & & & & & & \\
\hline & & & & & & & \\
\hline Toual & & & & & & & \\
\hline
\end{tabular}

A separati anaiysis was done for each row (status calegory). 
Table 15

\section{Selected Survey Questions: Comparisons Between Mentor and Mentee Responses}

\begin{tabular}{|c|c|c|c|c|c|c|}
\hline \multirow[b]{2}{*}{ Question } & \multicolumn{3}{|c|}{ Mentors (Staff) } & \multicolumn{3}{|c|}{ Mentees (Students) } \\
\hline & $\mathbf{N}$ & $\%$ & $\begin{array}{c}\text { valid } \\
\mathscr{x}\end{array}$ & $\mathbf{N}$ & 7 & $\begin{array}{c}\text { valid } \\
\pi\end{array}$ \\
\hline \multicolumn{7}{|l|}{ Questions 2, 3, 5, 6, 7} \\
\hline \multicolumn{7}{|l|}{ agree/satisfied (1-2) } \\
\hline \multicolumn{7}{|l|}{ neutral (3) } \\
\hline \multicolumn{7}{|l|}{ disagree/dissatisfied (4-5) } \\
\hline \multicolumn{7}{|l|}{ missing } \\
\hline \multicolumn{7}{|c|}{ Questions 1. 4.8. 16. 17, 20} \\
\hline \multicolumn{7}{|l|}{ yes $(1-2)$} \\
\hline \multicolumn{7}{|l|}{ neutral (3) } \\
\hline \multicolumn{7}{|l|}{ no (t-5) } \\
\hline \multicolumn{7}{|l|}{ missing } \\
\hline \multicolumn{7}{|l|}{ Question 10} \\
\hline \multicolumn{7}{|l|}{ mentor } \\
\hline \multicolumn{7}{|l|}{ menlee } \\
\hline \multicolumn{7}{|l|}{ both } \\
\hline missing & & & & & & \\
\hline
\end{tabular}


CHAPTER IV

\section{RESULTS}

Chapter IV contains the description of the investigative results of the six questions outlined in Chapter III. Pretreatment comparisons were conducted with analysis of variance. Questions 1 through 4 were conducted with the use of a t-test, an analysis of variance, and an analysis of covariance. Question 5 was conducted with a chi-square analysis and Question 6 used percentages. The results of these tests may be seen in Tables 16 through 39.

The pages comprising the remainder of this chapter present the statistical analyses with respect to Questions 1 through 6. A brief discussion preceeds each table. A few students chose to write comments on the back of the QSL. Examples of these comments are included following Question 6 .

\section{Pretreatment Analyses}

The lack of significant differences found among cohorts 1,2 , and 3 strengthened the ability to combine students from all three cohorts to increase the sample 
size for this study. The following results were found in the pretreatment analyses as seen in Table 16.

Table 16

\section{Analysis of Variance with Respect to Pretreatment Comparisons by Cohort for At-Risk and Not At-Risk}

\begin{tabular}{|c|c|c|c|c|c|c|c|c|c|c|c|c|}
\hline \multirow{2}{*}{$\begin{array}{c}\text { Al-Risk } \\
\text { Slatus }\end{array}$} & \multicolumn{3}{|c|}{ Cohon 1} & \multicolumn{3}{|c|}{ Cohon 2} & \multicolumn{3}{|c|}{ Cohon 3} & \multirow{2}{*}{ F-value } & \multirow{2}{*}{ Prob } & \multirow{2}{*}{ - Tukey'sq. } \\
\hline & Mean & S.D. & $\mathbf{N}$ & Mean & S.D. & $\mathbf{N}$ & Mean & S.D. & $\mathbf{N}$ & & & \\
\hline \multicolumn{13}{|c|}{ Rates of Altendince (Al-Risk: 8th-NA-8th: Not Al-Risk: 9th-9th-9th) } \\
\hline at-risk & 154.4 & 22.8 & 56 & 161.8 & 8.2 & 15 & 151.7 & 32.3 & 38 & 0.86 & .4273 & n.s. \\
\hline $\begin{array}{l}\text { not } \\
\text { at-risk }\end{array}$ & 164.3 & 22.6 & 190 & 165.0 & 22.8 & 125 & 166.8 & 18.1 & 207 & 0.79 & .4558 & n.s. \\
\hline \multicolumn{13}{|c|}{ GPA** (At-Risk: 8th-NA-8th: Nol At-Risk: 9th-9th-9th) } \\
\hline at-risk & 2.24 & 0.72 & 55 & - & - & - & 2.16 & 0.91 & 30 & 0.18 & .6698 & n.s. \\
\hline $\begin{array}{l}\text { not } \\
\text { at-risi }\end{array}$ & 2.81 & 0.84 & 185 & 2.65 & 0.74 & 120 & 2.75 & 0.94 & 206 & 1.23 & .2934 & n.s. \\
\hline \multicolumn{13}{|c|}{ Satisfaction with School (QSL**») } \\
\hline at-risk & 1.88 & 1.72 & 64 & 1.92 & 1.77 & 21 & 2.53 & 1.63 & 43 & 2.03 & .1360 & n.s. \\
\hline $\begin{array}{l}\text { not } \\
\text { at-risk }\end{array}$ & 2.69 & 1.72 & 196 & 2.58 & 1.74 & 142 & 2.97 & 1.68 & 226 & 2.70 & .0682 & n.s. \\
\hline \multicolumn{13}{|c|}{ Commitment to Schoolwork (QSL) } \\
\hline at-risk & 2.88 & 2.95 & 64 & 3.87 & 3.18 & 21 & 4.86 & 2.61 & 43 & 1.68 & .1906 & n.s. \\
\hline $\begin{array}{l}\text { not } \\
\text { at-risk }\end{array}$ & 5.47 & 2.94 & 196 & 4.71 & 2.71 & 142 & 5.84 & 2.85 & 226 & 6.75 & .0013 & $\operatorname{coh} 3.1>\operatorname{coh} 2$ \\
\hline \multicolumn{13}{|c|}{ Reactions to Teachers (QSL) } \\
\hline at-risk & $4.7 \overline{3}$ & 2.66 & 64 & 5.41 & 3.45 & 21 & 5.05 & 2.98 & 43 & 0.25 & .7801 & n.s. \\
\hline $\begin{array}{l}\text { not } \\
\text { at-risk }\end{array}$ & 6.19 & 2.69 & 196 & 6.31 & 2.84 & 142 & 6.48 & 2.53 & 226 & 0.62 & .5398 & n.s. \\
\hline \multicolumn{13}{|c|}{ Tolal QSL Score } \\
\hline at-risk & 10.65 & 6.40 & 64 & 11.20 & 7.59 & 21 & 12.44 & 5.99 & 43 & 0.99 & .3746 & n.s. \\
\hline $\begin{array}{l}\text { not } \\
\text { at-risk }\end{array}$ & 14.35 & 6.21 & 196 & 13.61 & 6.16 & 142 & 15.29 & 6.04 & 226 & 3.43 & .0331 & $\operatorname{coh} 3>\operatorname{coh} 2$ \\
\hline
\end{tabular}

- Referenced in Appendix E

- Average GPA for two semesters. 8th grade GPA for Cuhon 2 was not available

-.* Quality of School Life questionnaire

Refer to Appendix D for further information coneeming data analysis on pretreatment cumparisons for each cohor. For the purpose of answering questions I through $S$, the possibility of merging all three cohorts will be examined. 
Pretreatment

1. Pretreatment comparison of attendance using analysis of variance revealed no significant difference between cohorts 1,2 , and 3 for students identified as atrisk.

2. Pretreatment comparison of attendance using the analysis of variance revealed no significant difference between cohorts 1,2 , and 3 for students identified as not at-risk.

3. Pretreatment comparison of GPA from 8th grade data using analyses of variance revealed no significant difference between cohorts 1 and 3 for students identified as at-risk. (GPA data for cohort 2 were not retained by the school district as students exited the 8 th grade during the year this information was requested.) When GPA data from the 9 th grade was used in this comparison, there was no significant difference (see Appendix D).

4. Pretreatment comparison of GPA using analyses of variance revealed no significant difference between Cohorts 1, 2, and 3 for students identified as not atrisk. (The 9th grade year was selected when GPA data were available for this group since treatment was not an issue.)

5. Pretreatment comparisons of the Quality of School Life ouestionnaire revealed no significant 
difference between Cohorts 1, 2, and 3 for at-risk students, but revealed a difference between cohorts 1 and 3 when compared to cohort 2 for not at-risk students. Two variables could account for these differences. First, the "Ns" are much larger for not at-risk students, decreasing the difference needed for tests of significance, and these students were one year older than those in cohorts 1 and 3. If the scores are analyzed from a practical point of view, there is very little difference between the actual scores of all three cohorts.

The small differences found between the three cohorts, as well as the use of analysis of covariance, supported combining cohorts for further data analysis in this research.

\section{Question 1. Comparison of At-Risk and Not At-Risk Students}

The first research question examined differences between at-risk and not at-risk students on selected variables. The question was: Are there significant differences on the subscales and total scale of the Quality of School Life Scales (QSL), attendance rates, and GPA between students identified as at-risk and students not at risk?

In order to determine if there was a difference initially between students at-risk and students not at- 
risk, an analysis of variance was performed prior to treatment on the total scale of the Quality of School Life Survey (QSL). A t-test analysis was performed on attendance and GPA data for all three cohorts.

The statistical hypothesis was rejected for the total score of the QSI for cohorts $1(\underline{p}<.01)$ and $3(\underline{p}<.01)$, but not for cohort 2 (p>.106). As can be seen in Table 17 , the first year means for the QSL (prior to treatment) were significantly lower for at-risk students in cohorts 1 and 3. The QSL means for cohort 2 were lower for at-risk students, but not significantly. The students in cohort 2 were a year older than the other two cohorts. (See Appendix E for all QSL scale scores.)

\section{Table 17}

Analysis of Variance Prior to Treatment Total Quality of School Life scale At-Risk versus Not At-Risk Combined Cohorts

\begin{tabular}{|c|c|c|c|c|}
\hline \hline Total QSL & $\begin{array}{c}\text { At-Risk } \\
\text { Mean }\end{array}$ & $\begin{array}{c}\text { Not At-Risk } \\
\text { Mean }\end{array}$ & F Value & P \\
\hline \hline $\begin{array}{c}\text { Cohort 1 } \\
\text { (Grade 9) }\end{array}$ & 10.65 & 14.35 & 16.91 & .0001 \\
\hline $\begin{array}{c}\text { Cohort 2 } \\
\text { (Grade 10) }\end{array}$ & 11.20 & 13.61 & 2.63 & .1068 \\
\hline $\begin{array}{c}\text { Cohort 3 } \\
\text { (Grade 9) }\end{array}$ & 12.44 & 15.29 & 8.05 & .0049 \\
\hline
\end{tabular}

Using a t-test, a significant difference in attendance rates and GPA was found for students at-risk 
and not at-risk. The statistical hypothesis was rejected for attendance rates in cohort 1 ( $p<.01)$, cohort 2 $(\underline{p}<.05)$, and cohort $3(\underline{p}<.01)$. As can be seen on Table 18, the attendance rates prior to treatment for the students at-risk was significantly lower than those not at-risk (in all three cohorts). The statistical hypothesis was also rejected for GPA in cohort 1 ( $2<.01)$, Cohort $2(p<.01)$, and cohort $3(\underline{p}<.01)$. Prior to treatment, the GPA means for all three cohorts was significantly lower for students at-risk when compared to students not at-risk. These analyses established an initial difference prior to treatment between the at-risk and not at-risk groups studied. 
Table 18

T-test Analysis Prior to Treatment on Attendance and GPA At-Risk versus Not At-Risk Combined Cohorts

\begin{tabular}{|c|c|c|c|c|}
\hline Cohort & $\begin{array}{c}\text { At-Risk } \\
\text { Mean }\end{array}$ & $\begin{array}{c}\text { Not At-Risk } \\
\text { Mean }\end{array}$ & t-Value & $P$ \\
\hline \multicolumn{5}{|l|}{ Attendance } \\
\hline $\begin{array}{l}\text { Cohort } 1 \\
\text { (Grade 8) }\end{array}$ & 156.5 & 170.2 & 5.22 & .001 \\
\hline $\begin{array}{l}\text { Cohort } 2 \\
\text { (Grade 9) }\end{array}$ & 145.9 & 165.3 & 2.56 & .018 \\
\hline $\begin{array}{l}\text { Cohort } 3 \\
\text { (Grade 8) }\end{array}$ & 156.2 & 173.5 & 4.92 & .001 \\
\hline \multicolumn{5}{|l|}{ GPA } \\
\hline $\begin{array}{l}\text { Cohort } 1 \\
\text { (Grade 8) }\end{array}$ & 2.25 & 3.05 & 6.91 & .001 \\
\hline $\begin{array}{l}\text { Cohort } 2 \\
\text { (Grade 9) }\end{array}$ & 1.42 & 2.68 & 5.96 & .001 \\
\hline $\begin{array}{l}\text { Cohort } 3 \\
\text { (Grade 8) }\end{array}$ & 2.16 & 2.97 & 5.44 & .001 \\
\hline
\end{tabular}

The Quality of School Life scales

An analysis of covariance was performed separately on each of the scales and the total scale of the Quality of School Life Survey (QSL), using the scale scores of the first year as the covariate and the corresponding scale scores of the second year as the dependent variable. The levels of the independent variable were: (a) the combined cohorts (1, 2, and 3 ) of at-risk students and (b) the combined cohorts $(1,2$, and 3$)$ of the not at-risk students. The statistical hypotheses were rejected for Commitment to Work ( $\underline{p}<.01)$, Reaction to Teachers $(\underline{p}<.01)$, 
and Total QSL ( $\mathrm{p}<.01)$; it was not rejected for

Satisfaction with the School (p>.32).

As can be seen in Table 19, the first year means on all scales were less for the at-risk students than for the not at-risk students. However, with the exception of the Satisfaction with school scale, the second year means were higher for at-risk students than for the not at-risk students. When the adjusted means are examined, the differences were even greater: (a) on commitment to work, 6.1 for at-risk and 4.6 for not at-risk; (b) on Reaction to Teachers, 7.2 for at-risk and 6.2 for not at-risk; and (c) on the Total QSL scale, 16.3 for at-risk and 13.4 for not at-risk.

Table 19

Analysis of Covariance with Respect to Quality of School Life Scales (QSL) At-Risk versus Not At-Risk Combined Cohorts

\begin{tabular}{|c|c|c|c|c|c|c|c|c|c|}
\hline \multirow{2}{*}{ QSL Scale } & \multirow{2}{*}{$\begin{array}{c}\text { Treatment } \\
\text { Year }\end{array}$} & \multicolumn{3}{|c|}{ - At-Risk $(N=90)$} & \multicolumn{3}{|c|}{$\cdots$ Not At-Risk $(N=\| 13)$} & \multirow[b]{2}{*}{ F-value } & \multirow[b]{2}{*}{$P$} \\
\hline & & Mean & $\begin{array}{l}\text { (Adj. } \\
\text { Mean) }\end{array}$ & S.D. & Mean & $\begin{array}{l}\text { (Adj. } \\
\text { Mean) }\end{array}$ & S.D. & & \\
\hline Satisfaction with School & $\begin{array}{l}\text { Year } 1 \\
\text { Year } 2\end{array}$ & $\begin{array}{l}2.15 \\
2.76\end{array}$ & (2.93) & $\begin{array}{l}1.71 \\
1.90\end{array}$ & $\begin{array}{l}2.77 \\
2.83\end{array}$ & $(2.70)$ & $\begin{array}{l}1.66 \\
1.64\end{array}$ & 0.99 & .322 \\
\hline Commitment to Work & $\begin{array}{l}\text { Year } 1 \\
\text { Year } 2\end{array}$ & $\begin{array}{l}4.38 \\
5.76\end{array}$ & (6.05) & $\begin{array}{l}2.88 \\
3.47\end{array}$ & $\begin{array}{l}5.36 \\
4.86\end{array}$ & $(4.62)$ & $\begin{array}{l}2.57 \\
2.98\end{array}$ & 12.12 & .001 \\
\hline Reactions to Teachers & $\begin{array}{l}\text { Year } 1 \\
\text { Year } 2\end{array}$ & $\begin{array}{l}5.11 \\
6.93\end{array}$ & (7.19) & $\begin{array}{l}2.80 \\
3.00\end{array}$ & $\begin{array}{l}6.32 \\
6.41\end{array}$ & $(6.20)$ & $\begin{array}{l}2.69 \\
2.70\end{array}$ & 6.83 & .010 \\
\hline Tolal QSL Score & $\begin{array}{l}\text { Year } 1 \\
\text { Year } 2\end{array}$ & $\begin{array}{l}11.64 \\
15.45\end{array}$ & (16.32) & $\begin{array}{l}6.37 \\
7.57\end{array}$ & $\begin{array}{l}12.45 \\
14.09\end{array}$ & $(13.39)$ & $\begin{array}{l}5.66 \\
6.19\end{array}$ & 11.40 & .001 \\
\hline
\end{tabular}

- Cohorts 1, 2, 3 combined

Students in study for at least two years/Analysis of Variance is in Appendix $E$

- Cohorts 1 \& 2 combined (no 2nd year QSL scores for Cohor 3 for nol al-risk: 


\section{Attendance}

An analysis of covariance was performed on the attendance variable (total number of days in attendance), using the attendance of the year prior to treatment (pretreatment) as the covariate and the attendance of the first year of the program as the dependent variable. The levels of the independent variable were: (a) the combined cohorts (1, 2, and 3) of at-risk students and (b) the combined cohorts $(1,2$, and 3 ) of the not at-risk students. This analysis was performed twice:

(a) restricting the analysis to those students who had QSL scores for both years; and (b) all students in the cohorts, whether or not they had taken the QSL. The statistical hypothesis that the adjusted attendance means are equal was rejected in both cases $(\underline{p}<.01)$. (See Table 20.) In both analyses, the pretreatment and first year means (unadjusted and adjusted) were lower for the at-risk than for the not at-risk cohorts. For the at-risk with QSL scores, the adjusted mean was 157.3 ; for the not atrisk, the adjusted mean was 166.8 . For all students atrisk (including those without QSL), the adjusted mean was 156.5; for all students not at-risk, the adjusted mean was 165.6 .

As can be seen in Table 20, a significant difference was found between at-risk students and not at-risk 
students on attendance rates $(\mathrm{g}<.01)$ as measured from pretreatment data to post treatment data or Year 1.

Table 20

Analysis of Covariance with Respect to Attendance Rates At-Risk versus Not At-Risk Combined Cohorts

\begin{tabular}{|c|c|c|c|c|c|c|c|c|c|c|c|}
\hline \multirow[b]{2}{*}{ Subjects } & \multirow[b]{2}{*}{$\begin{array}{c}\text { Treatment } \\
\text { Year }\end{array}$} & \multicolumn{4}{|c|}{ At-Risk } & \multicolumn{4}{|c|}{ Not At-Risk } & \multirow[b]{2}{*}{ F-value } & \multirow[b]{2}{*}{$\mathbf{P}$} \\
\hline & & Mean & $\begin{array}{l}\text { (Adj. } \\
\text { Mean) }\end{array}$ & S.D. & $\mathbf{N}$ & Mean & $\begin{array}{l}\text { (Adj. } \\
\text { Mean) }\end{array}$ & S.D. & $\mathbf{N}$ & & \\
\hline \multirow[t]{2}{*}{ with QSL } & Pre-trtmt & 154.9 & & 24.1 & 80 & 169.7 & & 13.6 & 90 & & \\
\hline & Yearl & 154.5 & (157.3) & 26.3 & 80 & 169.3 & (166.8) & 13.7 & 90 & 8.71 & .004 \\
\hline \multirow[t]{2}{*}{ all students } & Pre-trmt & 152.8 & & 26.6 & 113 & 170.3 & & 13.1 & 426 & & \\
\hline & Year I & 150.8 & (156.5) & 28.9 & 113 & 167.2 & (165.6) & 17.1 & $\$ 26$ & 17.7 & .001 \\
\hline
\end{tabular}

Aralysis of Variance is in Appendix $E$

\section{Grade Point Average}

An analysis of covariance was performed on GPA, using the GPA of the year prior to treatment (pretreatment) as the covariate and the GPA of the first year of the program as the dependent variable. The levels of the independent variable were: (a) the combined cohorts $(1,2$, and 3) of at-risk students and (b) the combined cohorts (1, 2, and 3) of the not at-risk students. This analysis was perfomed twice: (a) restricting the analysis to those students who had QSL scores for both years; and (b) all students in the cohorts, whether or not they had taken the QSL. The statistical hypothesis that the adjusted GPA means are equal was rejected in both cases $(\underline{p}<.05$ and $\mathrm{p}<.01$, respectively). In both analyses, the pretreatment 
and first year means (unadjusted and adjusted) were lower for the at-risk than for the not at-risk cohorts. For the at-risk with QSL scores, the adjusted mean was 2.1; for the not at-risk, the adjusted mean was 2.8. For all students at-risk (without some QSI scores), the adjusted mean was 2.4; for all students not at-risk, the adjusted mean was 2.7 .

As can be seen in Table 21, a significant difference was found between at-risk students and not at-risk students on their GPA rate ( $p>.05)$ as measured from pretreatment data to post treatment data or Year 1 .

\section{Table 21}

Analysis of Covariance with Respect to Average Annual GPA At-Risk versus Not At-Risk Combined Cohorts

\begin{tabular}{|c|c|c|c|c|c|c|c|c|c|c|c|}
\hline \multirow[b]{2}{*}{ Subjects } & \multirow[b]{2}{*}{$\begin{array}{c}\text { Trealment } \\
\text { Year }\end{array}$} & \multicolumn{4}{|c|}{ At-Risk } & \multicolumn{4}{|c|}{ Not At-Risk } & \multirow[b]{2}{*}{ F-value } & \multirow[b]{2}{*}{$\mathbf{P}$} \\
\hline & & Mean & $\begin{array}{l}\text { (Adj. } \\
\text { Mean) }\end{array}$ & S.D. & $\mathbf{N}$ & Mean & $\begin{array}{l}\text { (Adj. } \\
\text { Mean) }\end{array}$ & S.D. & $\mathbf{N}$ & & \\
\hline with QSL & $\begin{array}{l}\text { Pre-trimt } \\
\text { Yearl }\end{array}$ & $\begin{array}{l}2.25 \\
1.96\end{array}$ & 2.07 & $\begin{array}{l}0.83 \\
0.91\end{array}$ & $\begin{array}{l}68 \\
68\end{array}$ & $\begin{array}{l}2.84 \\
2.68\end{array}$ & $(2.47)$ & $\begin{array}{l}0.65 \\
0.85\end{array}$ & $\begin{array}{l}89 \\
89\end{array}$ & 4.46 & .036 \\
\hline all students & $\begin{array}{l}\text { Pre-trimt } \\
\text { Year ! }\end{array}$ & $\begin{array}{l}2.13 \\
1.82\end{array}$ & (2.35) & $\begin{array}{l}0.81 \\
0.92\end{array}$ & $\begin{array}{l}96 \\
96\end{array}$ & $\begin{array}{l}2.91 \\
2.83\end{array}$ & $(2.71)$ & $\begin{array}{l}0.73 \\
0.87\end{array}$ & $\begin{array}{l}423 \\
+23\end{array}$ & 22.1 & .001 \\
\hline
\end{tabular}

Analysis of Variance is in Appendix $E$ 
Question 2. Comparison of At-Risk Students with Mentors, At-Risk Students without Mentors, and Not At-Risk students

The second research question examined differences between at-risk students with and without mentors, and not at-risk students on the same selected variables as in Question 1, to ascertain if having a mentor lessened the severity of being at-risk when compared to students not at-risk. The question was: Are there any significant differences on the subscales and total scale of the Quality of School Life Scales (QSL), attendance rates, and GPA between students identified as at-risk with mentors, at-risk without mentors, and not at-risk?

\section{The Quality of School Life scales}

An analysis of covariance was performed separately on each of the scales and the total scale of the quality of School Life Survey (QSL), using the scale scores of the first year as the covariate and the corresponding scale scores of the second year as the dependent variable. The levels of the independent variable of the combined cohorts (1, 2, and 3) were: (a) at-risk students with mentors, (b) at-risk students without mentors, and (c) not at-risk students. The statistical hypotheses were rejected for all four covariate analyses ( $\mathrm{p}<.01$ ). 
As can be seen in Table 22 , the first year means on all scales were less for the at-risk students with and without mentors than for the not at-risk students. However, the second year means for all scales were higher for at-risk students with a mentor, and lower for at-risk students without a mentor and not at-risk students. When adjusted means were examined, the differences were even greater: (a) on Satisfaction with School, 3.2 for at-risk with a mentor, 2.7 for not at-risk, and 2.1 for at-risk without a mentor; (b) on Commitment to School Work, 6.6 for at-risk with a mentor, 4.6 for not at-risk, and 4.4 for at-risk without a mentor; (c) on Reactions to Teachers, 7.7 for at-risk with a mentor, 6.2 for not atrisk, and 5.8 for at-risk without a mentor; and (d) on the Total QSL scale, 17.7 for at-risk with a mentor, 13.4 for not at-risk, and 12.3 for at-risk without a mentor.

Tukey's test for post hoc mean comparisons from this analysis of covariance was performed separately on each of the scales and the total QSL scale using the mean of Year 1 as the covariate and the corresponding adjusted mean of Year 2 as the dependent variable. However, since the sampling distribution with a covariate differs from the studentized range statistic used for 1-way analysis comparisons, the generalized range distribution was used and the Bryant-Paulson procedure followed. (See 
Table 22

Analysis of Covariance with Respect to Quality of School

Life Scales, At-Risk With Mentors, At-Risk without Mentors, and Not At-Risk Combined Cohorts

\begin{tabular}{|c|c|c|c|c|c|c|c|c|c|c|c|c|c|c|c|}
\hline \multirow{2}{*}{$\begin{array}{l}\text { Trumnt } \\
\text { Year }\end{array}$} & \multicolumn{4}{|c|}{$\begin{array}{l}\text { Al-Risk: Mentor } \\
\text { (1) }\end{array}$} & \multicolumn{4}{|c|}{$\begin{array}{l}\text { At-Risk: No Mentor } \\
\text { (2) }\end{array}$} & \multicolumn{4}{|c|}{$\begin{array}{l}\text { Not At-Risk } \\
\text { (3) }\end{array}$} & \multirow[b]{2}{*}{$\begin{array}{c}\text { F- } \\
\text { value }\end{array}$} & \multirow[b]{2}{*}{$\mathbf{P}$} & \multirow{2}{*}{$\begin{array}{l}\text { Tukey's q } \\
\text { Significant } \\
\text { Differences }\end{array}$} \\
\hline & Mean & S.D. & $\begin{array}{l}\text { (Adj. } \\
\text { Mean) }\end{array}$ & N. & Mean & S.D. & $\begin{array}{l}\text { (Adj. } \\
\text { Mean) }\end{array}$ & N. & Mean & S.D. & $\begin{array}{l}\text { (Adj. } \\
\text { Mean) }\end{array}$ & N. & & & \\
\hline \multicolumn{16}{|c|}{ Satisfaction with School } \\
\hline ye 1 & 2.99 & 1.67 & $(3.20)$ & 68 & 2.05 & 1.99 & $(2.09)$ & 22 & 2.83 & 1.65 & $(2.70)$ & 113 & 14.79 & .009 & $\begin{array}{l}(1)>(2) \\
(1)>(3) \\
(3)>(\text { (2) }\end{array}$ \\
\hline \multicolumn{16}{|c|}{ Commitment to Schookwork } \\
\hline $\begin{array}{l}y<1 \\
y<2\end{array}$ & $\begin{array}{l}4.42 \\
6.31\end{array}$ & $\begin{array}{l}2.90 \\
3.23\end{array}$ & (6.58) & 68 & $\begin{array}{l}4.27 \\
4.05\end{array}$ & $\begin{array}{l}2.88 \\
3.72\end{array}$ & (4.39) & $\begin{array}{l}22 \\
22\end{array}$ & $\begin{array}{l}5.36 \\
4.86 \\
\end{array}$ & $\begin{array}{l}2.57 \\
2.98\end{array}$ & (4.62) & $\begin{array}{l}113 \\
113\end{array}$ & 11.40 & .001 & $\begin{array}{l}(1)>(2) \\
(1)>(3)\end{array}$ \\
\hline \multicolumn{16}{|c|}{ Reactions to Teachers } \\
\hline $\begin{array}{l}\text { yr } 1 \\
y r 2\end{array}$ & $\begin{array}{l}4.92 \\
7.32\end{array}$ & $\begin{array}{l}2.79 \\
2.77\end{array}$ & (7.68) & $\begin{array}{l}68 \\
68 \\
\end{array}$ & $\begin{array}{l}5.73 \\
5.73\end{array}$ & $\begin{array}{l}2.80 \\
3.41\end{array}$ & (5.75) & $\begin{array}{l}22 \\
22\end{array}$ & $\begin{array}{l}6.32 \\
6.41 \\
\end{array}$ & $\begin{array}{l}2.69 \\
2.70\end{array}$ & (6.19) & $\begin{array}{l}113 \\
113\end{array}$ & 8.16 & .001 & $\begin{array}{l}(1)>(2) \\
(1)>(3)\end{array}$ \\
\hline \multicolumn{16}{|c|}{ Total QSL Score } \\
\hline $\begin{array}{l}\text { yr } 1 \\
\text { yr } 2\end{array}$ & $\begin{array}{l}11.40 \\
16.63\end{array}$ & $\begin{array}{l}6.37 \\
6.97\end{array}$ & (17.66) & 68 & $\begin{array}{l}12.41 \\
11.82\end{array}$ & 8.35 & $(12.27)$ & $\begin{array}{l}22 \\
22\end{array}$ & $\begin{array}{l}14.45 \\
14.09\end{array}$ & 6.19 & (13.38) & $\begin{array}{l}113 \\
113\end{array}$ & 13.26 & .001 & $\begin{array}{l}(1)>(2) \\
(1)>(3)\end{array}$ \\
\hline
\end{tabular}

Students in at least two years of the study

- Referenced in Appendix E

Appendix E.) The independent variables were: (a) AtRisk:Mentor > At-Risk:No Mentor; (b) At-Risk:Mentor > Not At-Risk; and (C) Not At-Risk > At-Risk: No Mentor.

Using Tukey's $g$, the means for the at-risk with mentors group were significantly greater $(\underline{D}<.01)$ than the means for the at-risk with no mentor and the not at-risk group on all scales: Satisfaction with school, commitment to School Work, Reactions to Teachers, and Total QSL. on 
the Satisfaction with School scales, the mean for the not at-risk group was significantly greater than the mean for the at-risk group without a mentor.

As can be seen from the Tukey's $g$ analyses and the adjusted means, having a mentor lessened the severity of being at-risk when compared to students not at-risk. For all QSL scales, at-risk students with mentors scored significantly higher than at-risk students without mentors and higher than not at-risk students. With the exception of Satisfaction with school scale, there was no significant difference between how students scored who were not at-risk and those at-risk without mentors.

\section{Attendance}

An analysis of covariance was performed on the attendance variable (total number of days in attendance), using the attendance of the year prior to treatment (pretreatment) as the covariate and the attendance of the first year of the program as the dependent variable. The levels of the independent variable were: (a) the combined cohorts (1, 2, and 3) of at-risk students with a mentor; (b) the combined cohorts $(1,2$, and 3$)$ of at-risk students without a mentor; and (c) the combined cohorts (1, 2, and 3) of not at-risk students. As can be seen in Table 23, the pretreatment year attendance mean was lowest for atrisk students without mentors (146.8), next for at-risk 
students with mentors (156.1), and highest for the not atrisk students $(170.3)$. The attendance for Year 1 deteriorated for the students at-risk without mentors (139.9) and the not at-risk students (167.2), but remained unchanged for the students at-risk with mentors (156.4).

As can be seen in Table 23, there was no significance between any of these independent variables for attendance. The variable of a student at-risk having a mentor did not significantly increase (p>.09) the attendance rate when compared to either those students not at-risk, or those students at-risk without a mentor.

Table 23

Analysis of Covariance with Respect to Attendance Rates for students At-Risk with Mentors, At-Risk without Mentors, and Not At-Risk Cohorts 1 and 3

\begin{tabular}{|c|c|c|c|c|c|c|c|c|c|c|c|c|c|c|}
\hline \multirow{2}{*}{$\begin{array}{l}\text { Trtmnt } \\
\text { Year }\end{array}$} & \multicolumn{4}{|c|}{$\begin{array}{c}\text { At-Risk: Mentor } \\
\text { (1) }\end{array}$} & \multicolumn{4}{|c|}{$\begin{array}{l}\text { At-Risk: No Mentor } \\
\text { (2) }\end{array}$} & \multicolumn{4}{|c|}{$\begin{array}{c}\text { Not At-Risk } \\
\text { (3) }\end{array}$} & \multirow[b]{2}{*}{$\begin{array}{c}\text { F- } \\
\text { value }\end{array}$} & \multirow[b]{2}{*}{$\mathbf{P}$} \\
\hline & Mean & S.D. & $\begin{array}{l}\text { (Adj. } \\
\text { Mean) }\end{array}$ & N. & Mean & S.D. & $\begin{array}{l}\text { (Adj. } \\
\text { Mean) }\end{array}$ & N. & Mean & S.D. & $\begin{array}{l}\text { (Adj. } \\
\text { Mean) }\end{array}$ & N. & & \\
\hline pre & 156.1 & 16.9 & - & 75 & 146.8 & 39.2 & - & 38 & 170.3 & 13.1 & - & 426 & & \\
\hline yr 1 & 156.4 & 23.6 & $(160.6)$ & 75 & 139.9 & 35.6 & $(147.8)$ & 38 & 167.2 & 17.1 & $(165.7)$ & 426 & 4.79 & .09 \\
\hline
\end{tabular}

All possible students

\section{GPA}

An analysis of covariance was performed on GPA, using the GPA of the year prior to treatment (pretreatment) as the covariate and the GPA of the first year of the program as the dependent variable. The levels of the independent variable were: (a) the combined cohorts (1, 2, and 3) of 
at-risk students with a mentor; (b) the combined cohorts $(1,2$, and 3$)$ of at-risk students without a mentor; and (c) the combined cohorts (1, 2, and 3) of not at-risk students. In the pretreatment year, the mean GPA was lowest for the at-risk without mentors (2.0), next for atrisk with mentors (2.2), and highest for the not at-risk group (2.9). In Year 1, the GPA means were actually lower than for the pretreatment year for all three groups: atrisk with no mentor (1.6), at-risk with a mentor (1.9), and not at-risk (2.8). (See Table 24.) The statistical hypotheses for the analysis of covariance was rejected $(\underline{p}<.01)$.

Tukey's $g$ post hoc pairwise comparison of adjusted means was performed. The statistical hypothesis was rejected ( $\underline{p}<.01)$ for all three comparisons. The adjusted mean GPA for the at-risk with mentors group (2.4) was significantly greater than the adjusted mean GPA of the at-risk without mentors group (2.3). The adjusted mean GPA for the not at-risk group (2.7) was greater than the adjusted mean GPAs for both at-risk groups. 
Table 24

Analysis of Covariance with Respect to GPA for students At-Risk With Mentors, At-Risk Without Mentors, and Not At-Risk Cohorts 1 and 3

\begin{tabular}{|c|c|c|c|c|c|c|c|c|c|c|c|c|c|c|c|}
\hline \multirow{2}{*}{$\begin{array}{l}\text { Tmnt } \\
\text { Year }\end{array}$} & \multicolumn{4}{|c|}{$\begin{array}{l}\text { At-Risk: Mentor } \\
\text { (1) }\end{array}$} & \multicolumn{4}{|c|}{$\begin{array}{l}\text { At-Risk: No Mentor } \\
\text { (2) }\end{array}$} & \multicolumn{4}{|c|}{$\begin{array}{l}\text { Not At-Risk } \\
\text { (3) } \\
\end{array}$} & \multirow{2}{*}{\multicolumn{2}{|c|}{$\begin{array}{c}\text { F- } \\
\text { value }\end{array}$}} & \multirow{2}{*}{$\begin{array}{l}\text { - Tukey's q. } \\
\text { Significant } \\
\text { Differences }\end{array}$} \\
\hline & Mean & S.D. & $\begin{array}{l}\text { (Adj. } \\
\text { Mean) }\end{array}$ & N. & Mean & S.D. & $\begin{array}{l}\text { (Adj. } \\
\text { Mean) }\end{array}$ & N. & Mens & S.D. & $\begin{array}{l}\text { (Adj. } \\
\text { Mean) }\end{array}$ & N. & & & \\
\hline pre & 2.18 & 0.78 & - & 65 & 2.02 & 0.88 & - & 31 & 2.91 & 2.57 & - & 423 & & & $\begin{array}{l}(1)>(\text { () } \\
\text { (3) }>\text { (1) } \\
\text { (3) }>(\text { (2) }\end{array}$ \\
\hline$y+l$ & 1.88 & 0.81 & $(2.37)$ & 65 & 1.64 & 1.10 & $(2.27)$ & 31 & 2.83 & 0.87 & $(2.71)$ & 423 & 11.40 & .001 & \\
\hline
\end{tabular}

Reterenced in Appendix $E$

Question 3. Comparison of At-Risk with Mentoring and At-Risk without Mentoring: Quality of School Life Scales

The third research question examined differences on selected variables between at-risk with mentoring (CAKE students) and at-risk students without mentoring. The question was: Are there any significant differences in attitudes as measured by the QSL between at-risk students with mentors and at-risk students without mentors?

An analysis of covariance was performed separately on each of the scales and the total scale of the quality of School Life Survey (QSL), using the scale scores of the first year as the covariate and the corresponding scale scores of the second year as the dependent variable. The levels of the independent variable were: (a) the combined cohorts $(1,2$, and 3 ) of at-risk students with mentors and (b) the combined cohorts $(1,2$, and 3) of at-risk students 
without mentors. The statistical hypotheses were rejected for all dependent variables: Satisfaction with the School $(\mathrm{p}<.01)$; Commitment to Work $(\underline{p}<.01)$, Reaction to Teachers $(\underline{p}<.01)$, and Total QSL $(\underline{p}<.01)$.

In contrast with the non-mentored student group, the first year means of the mentored group of at-risk students were less on Satisfaction with school, Reaction to Teachers, and the Total QSL; the mean was greater on the Commitment to Work scale. However, the second year means on all scales (both unadjusted and adjusted) were higher for at-risk with mentors than for the at-risk without mentors. When the adjusted means were examined, the differences tended to be greater: (a) on Satisfaction with school, 3.0 for mentored students and 1.9 for nonmentored; (b) on commitment to work, 6.3 for mentored and 4.1 for non-mentored; (c) on Reactions to Teachers, 7.4 for the mentored group and 5.5 for non-mentored group; and (d) on the Total QSL scale, 16.8 for the mentored group and 11.5 for the non-mentored group. A significant difference $(\underline{p}<.01)$ on the subscales and total scale of the QSL was found using an analysis of covariance from Year 1 to Year 2 between at-risk students with mentors and atrisk students without mentors (see Table 25). 
Table 25

Analysis of Covariance with Respect to the Quality of School Life Survey (QSL) for students At-Risk:

Mentor versus No Mentor Combined Cohorts

\begin{tabular}{|c|c|c|c|c|c|c|c|c|c|c|c|}
\hline \multirow[b]{2}{*}{ Scale } & \multirow[b]{2}{*}{$\begin{array}{c}\text { Treatment } \\
\text { Yeat }\end{array}$} & \multicolumn{4}{|c|}{ Mentor } & \multicolumn{4}{|c|}{ No Mentor } & \multirow[b]{2}{*}{ F-value } & \multirow[b]{2}{*}{$\mathbf{P}$} \\
\hline & & Mean & S.D. & $\begin{array}{l}\text { (Adj. } \\
\text { Mean) }\end{array}$ & N. & Mean & S.D. & $\begin{array}{l}\text { (Adj. } \\
\text { Mean) }\end{array}$ & N. & & \\
\hline \multirow[t]{2}{*}{ SAT } & Year 1 & 2.06 & 1.67 & & 68 & 2.41 & 1.84 & & 22 & & \\
\hline & Year 2 & 2.99 & 1.82 & $(3.03)$ & 68 & 2.04 & 1.99 & (1.92) & 22 & 7.07 & .009 \\
\hline \multirow[t]{2}{*}{ COM } & Year I & 4.42 & 2.90 & & 68 & 4.27 & 2.88 & & 22 & & \\
\hline & Year 2 & 6.31 & 3.23 & $(6.30)$ & 68 & 4.05 & 3.72 & $(4.10)$ & 22 & 8.17 & .005 \\
\hline \multirow[t]{2}{*}{ TCH } & Year I & 4.92 & 2.79 & & 68 & 5.73 & 2.80 & & 22 & & \\
\hline & Year 2 & 7.32 & 2.77 & $(7.39)$ & 68 & 5.72 & 3.41 & $(5.50)$ & 22 & 7.58 & .007 \\
\hline \multirow[t]{2}{*}{ QSL } & Year I & 11.40 & 6.37 & & 68 & 12.41 & 6.46 & & 22 & & \\
\hline & Year 2 & 16.63 & 6.97 & (16.75) & 68 & 11.82 & 8.35 & (11.45) & 22 & 10.45 & .002 \\
\hline
\end{tabular}

Question 4. Comparison of At-Risk with Mentoring and At-Risk without Mentoring: Attendance and GPA

The fourth research question examined differences on selected variables between at-risk students with mentoring (CAKE students) and at-risk students without mentoring. The question was: Are there any significant differences regarding attendance rates and GPA for at-risk students with mentors and at-risk students without mentors?

\section{Attendance}

For each of the four years of the study, an analysis of covariance for attendance was performed separately for Cohorts 1, 3, and combined Cohorts 1 and 3, with data for the 8 th grade year or pretreatment as the covariate and 
attendance data for the following year as the dependent variable, beginning with Year 1. Thus, twelve separate analyses were performed. (There was not sufficient attendance data from 8 th grade available for those students in Cohort 2 to add to this analysis.) For each analysis, the levels of the independent variable were:

(a) the at-risk students with mentors and (b) at-risk students without mentors.

For both cohort 1 and the combined cohorts 1 and 3 , the statistical hypothesis that the attendance adjusted means of the at-risk mentored group and the at-risk nonmentored group are equal was rejected for Year 1; it was also rejected for Cohort 1 in Year 2 .

The attendance adjusted means for students with mentors in Cohort 1 were significantly higher ( $\underline{p}<.01$ ) for the first two years in the CAKE program (159 for year 1 and 149 for Year 2) than the adjusted means for students without mentors (138 for Year 1 and 103 for Year 2). There were no significant differences between the adjusted means for Years 3 and 4 , with the adjusted means continuing to fall for the mentored group (142 for Year 3 and 131 for Year 4), but increasing for the non-mentored group ( 110 for Year 3 and 132 for Year 4). However, it should be noted that the percentage of remaining students 
was much higher for those students with mentors, $75 \%$ (Year 4), than for those without mentors, 25\% (Year 4). The attendance adjusted means for students with and without mentors in Cohort 3 were not significantly different ( $p>.09$ and $p>.39$ ) for the first two years in the CAKE program, unlike cohort 1 . At the end of the first year, the adjusted mean for the mentored group was 158 , and the non-mentored group 146. The adjusted mean in Year 2 for the mentored group was lower (143) than the nonmentored group (157). Similar to cohort 1 , the differences were also not significant for Years 2 through 4. The adjusted means for the mentored group was lower (149 for Year 3 and 133 for Year 4) than the nonmentored group (155 for Year 3 and 149 for Year 4). However, it should be noted that the percentage of students remaining was much higher for those students with mentors, $74.2 \%$ (Year 4), than those without mentors, $32.1 \%$ (Year 4).

When examining the combined cohorts 1 and 3 , for Year 1 , the attendance adjusted mean was significantly greater $(\underline{p}<.01)$ for the at-risk students with mentors (159) than the attendance adjusted means for at-risk students without mentors (143); no significant difference was found for Years 2, 3, and 4. Again, the adjusted means were lower for the mentored group in Year 4 (132) than the non- 
mentored group (144). However, it should be noted that the percentage of remaining students was higher for those students with mentors (74.2\%, Year 4) than for those students without mentors (32.1\%, Year 4) (see Table 26).

Table 26

Analysis of Covariance with Respect to Attendante for students At-Risk Mentor versus No Mentor

Cohorts 1 and 3

\begin{tabular}{|c|c|c|c|c|c|c|c|c|c|c|c|c|c|}
\hline \multirow[b]{2}{*}{ Cohon } & \multirow[b]{2}{*}{$\begin{array}{c}\text { Trumm } \\
\text { Year }\end{array}$} & \multicolumn{5}{|c|}{ Mentor } & \multicolumn{5}{|c|}{ No Mentor } & \multirow[b]{2}{*}{ F-value } & \multirow[b]{2}{*}{$\mathbf{P}$} \\
\hline & & Mean & S.D. & $\begin{array}{l}\text { (Adj. } \\
\text { Mean) }\end{array}$ & N. & $\begin{array}{c}\% \\
\text { Change }\end{array}$ & Mean & S.D. & $\begin{array}{l}\text { (Adj. } \\
\text { Mean) }\end{array}$ & N. & $\begin{array}{c}\text { \% } \\
\text { Change }\end{array}$ & & \\
\hline $\begin{array}{c}\text { Cobont } \\
1\end{array}$ & $\begin{array}{c}\text { Pre(8lh) } \\
\text { Year } 1 \\
\text { Year } 2 \\
\text { Year } 3 \\
\text { Year } 4\end{array}$ & $\begin{array}{l}156.8 \\
159.8 \\
148.8 \\
144.2 \\
131.1\end{array}$ & $\begin{array}{l}17.0 \\
19.2 \\
37.8 \\
44.3 \\
46.5\end{array}$ & $\begin{array}{l}(159.3) \\
(148.8) \\
(141.6) \\
(130.8)\end{array}$ & $\begin{array}{l}44 \\
44 \\
41 \\
38 \\
33\end{array}$ & $\begin{array}{l}-\overline{93.2} \\
86.4 \\
75.0\end{array}$ & $\begin{array}{c}153.2 \\
136.5 \\
101.6 \\
96.0 \\
128.7\end{array}$ & $\begin{array}{l}21.9 \\
40.5 \\
55.8 \\
75.9 \\
61.2\end{array}$ & $\begin{array}{l}(138.2) \\
(102.6) \\
(110.4) \\
(132.1)\end{array}$ & $\begin{array}{l}12 \\
12 \\
10 \\
7 \\
3\end{array}$ & $\begin{array}{l}-\overline{83.3} \\
58.3 \\
25.0\end{array}$ & $\begin{array}{l}8.37 \\
8.90 \\
2.19 \\
0.01\end{array}$ & $\begin{array}{l}.006 \\
.004 \\
.147 \\
.964\end{array}$ \\
\hline $\begin{array}{c}\text { Cohort } \\
3\end{array}$ & $\begin{array}{c}\text { Pre(8th) } \\
\text { Year } 1 \\
\text { Year } 2 \\
\text { Year } 3 \\
\text { Year } 4\end{array}$ & $\begin{array}{l}155.1 \\
158.5 \\
144.8 \\
149.0 \\
133.3\end{array}$ & $\begin{array}{l}15.9 \\
14.6 \\
40.9 \\
30.1 \\
47.3\end{array}$ & $\begin{array}{l}(157.7) \\
(143.2) \\
(148.7) \\
(133.0)\end{array}$ & $\begin{array}{l}22 \\
22 \\
21 \\
16 \\
16\end{array}$ & $\begin{array}{l}\overline{95.5} \\
72.7 \\
72.7\end{array}$ & $\begin{array}{l}147.0 \\
144.7 \\
152.5 \\
154.3 \\
148.8\end{array}$ & $\begin{array}{l}46.7 \\
29.1 \\
33.5 \\
24.4 \\
30.0\end{array}$ & $\begin{array}{l}(145.8) \\
(156.5) \\
(154.9) \\
(149.4)\end{array}$ & $\begin{array}{l}16 \\
16 \\
9 \\
7 \\
6\end{array}$ & $\begin{array}{l}56.3 \\
43.8 \\
37.5\end{array}$ & $\begin{array}{l}3.03 \\
0.74 \\
0.21 \\
0.53\end{array}$ & $\begin{array}{l}.091 \\
.396 \\
.655 \\
.476\end{array}$ \\
\hline $\begin{array}{c}\text { Cohort } \\
1,3\end{array}$ & $\begin{array}{c}\text { Pre(8th) } \\
\text { Year } 1 \\
\text { Year } 2 \\
\text { Year } 3 \\
\text { Year } 4\end{array}$ & $\begin{array}{l}156.3 \\
159.4 \\
147.4 \\
145.6 \\
131.8\end{array}$ & $\begin{array}{l}16.5 \\
17.7 \\
38.6 \\
40.4 \\
46.3\end{array}$ & $\begin{array}{l}(158.6) \\
(146.6) \\
(144.0) \\
(131.5)\end{array}$ & $\begin{array}{r}66 \\
666 \\
62 \\
54 \\
49\end{array}$ & $\begin{array}{l}- \\
93.9 \\
81.8 \\
74.2\end{array}$ & $\begin{array}{l}149.6 \\
141.2 \\
125.7 \\
125.1 \\
142.1\end{array}$ & $\begin{array}{l}37.6 \\
34.0 \\
52.3 \\
62.0 \\
40.0\end{array}$ & $\begin{array}{l}(142.9) \\
(128.4) \\
(131.6) \\
(144.1)\end{array}$ & $\begin{array}{c}28 \\
28 \\
19 \\
14 \\
9\end{array}$ & $\begin{array}{l}\overline{67.9} \\
50.0 \\
32.1\end{array}$ & $\begin{array}{l}9.99 \\
2.57 \\
0.76 \\
0.54\end{array}$ & $\begin{array}{l}.002 \\
.113 \\
.358 \\
.467\end{array}$ \\
\hline
\end{tabular}

- all possible subjects

Attendance data from 9 th grade records for cohort 2 was omitted from this analysis due to the fact that these students were one year older than cohorts 1 and 3 . The analysis of variance for cohort 3 can be found in Appendix E, using 9 th grade data as Pretreatment. 
GPA

For each of the four years of the study, an analysis of covariance for GPA was performed separately for cohort 1, Cohort 3, and combined cohorts 1 and 3 , using the GPA from the 8 th grade year (pretreatment) as the covariate and the GPA of subsequent years, beginning with year 1 as the dependent variable. Thus, twelve separate analyses were performed. (There was no GPA data available for students in the 8 th grade year for Cohort 2. Analysis using 9 th grade GPAs can be found in Appendix c.) For each analysis, the levels of the independent variable were: (1) at-risk students with mentors and (2) at-risk students without mentors. With two exceptions, the statistical hypothesis that the adjusted GPA means of atrisk students with and without mentors was not rejected for all years and cohorts.

For Cohort 1, the statistical hypothesis for Year 1 was rejected $(\underline{p}<.05)$, with the adjusted mean for the atrisk group with mentors (1.9) being higher than the atrisk group without mentors (1.5). For cohort 1, the GPA means and adjusted means decreased during Year 1 and 2 , increased during Year 3, and for the mentored group only increased during Year 4. For Cohort 3, the GPA means dropped during Year 1, increased during Year 2 and 3, and 
stabilized for the mentored group during Year 4, but dropped for the non-mentored group. (See Table 27.)

A partial explanation for the tendency for GPA means to increase in Years 3 and 4 can be found in the loss of students in both groups. However, the differences in the percentages of students who have dropped out, when comparing mentored groups with unmentored, is noteworthy. The percentage of at-risk students with mentors in Year 4 is about four times higher in cohort 1 (65.1\%) and 1.5 times as high in cohort $3(64.7 \%)$ than at-risk students without mentors in Cohort 1 (16.7\%), and cohort 3 (38.5\%). It should be noted that the percentage of retained students for Cohorts 1, 2, and combined cohorts in the GPA analysis was different from the percentage of retained students in the attendance analysis. This was due to the fact that GPAs were not available for some students in the eighth grade, which modified the percentages. However, the percentage of at-risk students with mentors remaining in Year 4 in both attendance and GPA analysis was much greater than those students without mentors. 
Table 27

Analysis of Covariance with Respect to GPA for students At-Risk

Mentor versus No Mentor

Cohorts $1 \& 3$

\begin{tabular}{|c|c|c|c|c|c|c|c|c|c|c|c|c|c|}
\hline \multirow[b]{2}{*}{ Cohort } & \multirow[b]{2}{*}{$\begin{array}{c}\text { Trtmnt } \\
\text { Year }\end{array}$} & \multicolumn{5}{|c|}{ Menior } & \multicolumn{5}{|c|}{ No Mentor } & \multirow[b]{2}{*}{ F-value } & \multirow[b]{2}{*}{$\mathbf{P}$} \\
\hline & & Menn & S.D. & $\begin{array}{l}\text { (Adj. } \\
\text { Mean) }\end{array}$ & $\mathbf{N}$. & $\stackrel{\$}{\text { Change }}$ & Mean & S.D. & $\begin{array}{l}\text { (Adj. } \\
\text { Mean) }\end{array}$ & N. & $\begin{array}{c}x \\
\text { Change }\end{array}$ & & \\
\hline $\begin{array}{c}\text { Cobort } \\
1\end{array}$ & $\begin{array}{l}\text { Pre(8th) } \\
\text { Year } 1 \\
\text { Year } 2 \\
\text { Year } 3 \\
\text { Year } 4\end{array}$ & $\begin{array}{l}2.32 \\
1.99 \\
1.87 \\
1.96 \\
2.03\end{array}$ & $\begin{array}{l}0.75 \\
0.77 \\
1.07 \\
0.92 \\
0.91\end{array}$ & $\begin{array}{l}(1.93) \\
(1.83) \\
(1.97) \\
(2.03)\end{array}$ & $\begin{array}{l}43 \\
43 \\
38 \\
31 \\
28\end{array}$ & $\begin{array}{l}- \\
88.4 \\
72.1 \\
65.1\end{array}$ & $\begin{array}{l}1.93 \\
1.24 \\
1.18 \\
2.82 \\
2.23\end{array}$ & $\begin{array}{l}0.57 \\
0.95 \\
1.39 \\
1.49 \\
1.03\end{array}$ & $\begin{array}{l}(1.47) \\
(1.46) \\
(2.65) \\
(2.21)\end{array}$ & $\begin{array}{c}12 \\
12 \\
5 \\
3 \\
2\end{array}$ & $\begin{array}{l}\overline{41.7} \\
25.0 \\
16.7\end{array}$ & $\begin{array}{l}5.08 \\
0.81 \\
1.81 \\
0.11\end{array}$ & $\begin{array}{l}.028 \\
.375 \\
.188 \\
.747\end{array}$ \\
\hline $\begin{array}{c}\text { Cohort } \\
3\end{array}$ & $\begin{array}{l}\text { Pre(8ch) } \\
\text { Year } 1 \\
\text { Year } 2 \\
\text { Year } 3 \\
\text { Year } 4\end{array}$ & $\begin{array}{l}1.96 \\
1.67 \\
1.81 \\
2.07 \\
1.86\end{array}$ & $\begin{array}{l}0.77 \\
0.90 \\
0.95 \\
0.89 \\
1.08\end{array}$ & $\begin{array}{l}(1.83) \\
(2.03) \\
(2.18) \\
(1.97)\end{array}$ & $\begin{array}{l}17 \\
17 \\
13 \\
11 \\
11\end{array}$ & $\begin{array}{l}- \\
76.5 \\
64.7 \\
64.7\end{array}$ & $\begin{array}{l}2.42 \\
2.04 \\
2.73 \\
3.11 \\
3.11\end{array}$ & $\begin{array}{l}1.04 \\
1.27 \\
1.28 \\
0.86 \\
0.86\end{array}$ & $\begin{array}{l}(1.83) \\
(2.26) \\
(2.89) \\
(2.87)\end{array}$ & $\begin{array}{c}13 \\
13 \\
6 \\
5 \\
5\end{array}$ & $\begin{array}{l}-\overline{46.2} \\
38.5 \\
38.5\end{array}$ & $\begin{array}{l}0.00 \\
0.22 \\
2.27 \\
2.60\end{array}$ & $\begin{array}{l}1.00 \\
.648 \\
.156 \\
.131\end{array}$ \\
\hline $\begin{array}{c}\text { Cohort } \\
1,3\end{array}$ & $\begin{array}{c}\text { Pre(8th) } \\
\text { Year } 1 \\
\text { Year } 2 \\
\text { Year } 3 \\
\text { Year } 4\end{array}$ & $\begin{array}{l}2.22 \\
1.90 \\
1.85 \\
1.98 \\
1.98\end{array}$ & $\begin{array}{l}0.76 \\
0.81 \\
1.03 \\
0.90 \\
0.95\end{array}$ & $\begin{array}{l}(1.89) \\
(1.90) \\
(2.03) \\
(2.02)\end{array}$ & $\begin{array}{l}60 \\
60 \\
51 \\
42 \\
39\end{array}$ & $\begin{array}{l}\overline{85.0} \\
70.0 \\
65.0\end{array}$ & $\begin{array}{l}2.19 \\
1.66 \\
2.03 \\
3.00 \\
2.86\end{array}$ & $\begin{array}{l}0.87 \\
1.18 \\
1.50 \\
1.04 \\
0.92\end{array}$ & $\begin{array}{l}(1.68) \\
(1.79) \\
(2.77) \\
(2.02)\end{array}$ & $\begin{array}{l}25 \\
25 \\
11 \\
8 \\
7\end{array}$ & $\begin{array}{c}- \\
44.0 \\
32.0 \\
28.0\end{array}$ & $\begin{array}{l}1.79 \\
0.13 \\
6.36 \\
3.70\end{array}$ & $\begin{array}{l}.185 \\
.717 \\
.025 \\
.061\end{array}$ \\
\hline
\end{tabular}

- all possible subjects

Question 5. Comparison of Enrollment status of At-Risk with Mentoring and At-Risk without Mentoring

The fifth research question examined the enrollment status of at-risk students with mentors and at-risk students without mentors over a four-year period of time in school. The question was: Are there significant differences in the enrollment status of at-risk students with mentors and at-risk students without mentors?

The results in the form of percentages are listed in rank order on five variables found in Table 28: Graduated, GED, dropped out, transferred, and returning 
for a fifth year. The statistical hypothesis was rejected $(\mathfrak{p}<.01)$. The percentage of at-risk students with a mentor who graduated was twice as high, $43.7 \%$, as those at-risk without a mentor, 21.3\%. Likewise, the percentage of atrisk students with a mentor who received a GED (General Equivalency Exam) was twice as high, 26.4\%, as those atrisk without a mentor, 10.6\%. In comparison, those students without a mentor dropped out more than twice as much at $44.7 \%$ as those with a mentor at $17.2 \%$. Both transfering and returning students with and without a mentor were approximately the same.

Table 28

Chi Square and Percentage with Respect to Enrollment Status After Year 4 for All Students At-Risk Mentor versus No Mentor

\begin{tabular}{|c|c|c|c|c|c|c|c|c|}
\hline \multirow[t]{2}{*}{ Status } & \multicolumn{2}{|c|}{$\begin{array}{l}\text { At-Riak: } \\
\text { Mentor }\end{array}$} & \multicolumn{2}{|c|}{$\begin{array}{l}\text { At-Risk: } \\
\text { No Mentor }\end{array}$} & \multicolumn{2}{|c|}{ Toual } & \multirow[b]{2}{*}{ Chi-Sq } & \multirow[b]{2}{*}{ Prob } \\
\hline & $\mathbf{N}$ & $x$ & $\mathbf{N}$ & * & $\mathbf{N}$ & $\boldsymbol{x}$ & & \\
\hline Graduated & 38 & 43.7 & 10 & 21.3 & 48 & 35.8 & \multirow[t]{6}{*}{19.97} & \multirow[t]{6}{*}{.0005} \\
\hline GED & 23 & 26.4 & 5 & 10.6 & 28 & 20.9 & & \\
\hline Dropped Out & 15 & 17.2 & 21 & 44.7 & 36 & 26.9 & & \\
\hline Transferred & 8 & 9.2 & 10 & 21.3 & 18 & 13.4 & & \\
\hline Retuming & 3 & 3.4 & 1 & 2.1 & 4 & 3.0 & & \\
\hline Toul & 87 & $(64.1)$ & 47 & $(35.1)$ & 134 & 100.0 & & \\
\hline
\end{tabular}


Question 6. Perceptions of the Mentor Program: Results of the CARE Survey

The sixth research question examined the perceptions and characteristics of the CAKE program with the staff mentors and a random sample of the mentees. The question was: What are the participants' perceptions of the effectiveness and characteristics concerning the CAKE program?

The results of the survey can be found in Tables 29 through 39, and are grouped together according to topic. Results are listed in percentages and include the number of respondents and valid percentages (taking into account any missing data). Chapter $v$ contains a discussion of these findings.

Results indicated both mentors (53\%) and mentees (60\%) felt satisfied as to their participation in the CAKE program. (See Table 29.)

As can be seen in Table 30, both mentors (74\%) and mentees (75\%) felt satisfied as to the CAKE program's value for at-risk students in developing a positive attitude toward school. 
Table 29

\section{CAKE Survey - Selected Questions: \\ Rate of Participation for both \\ Mentors and Mentees}

\begin{tabular}{|c|c|c|c|c|c|c|}
\hline \multirow[t]{2}{*}{ Question } & \multicolumn{3}{|c|}{ Mentors (Staf) } & \multicolumn{3}{|c|}{ Mentees (Sudents) } \\
\hline & $\mathbf{N}$ & $\Phi$ & Valid $\%$ & $\mathbf{N}$ & $\mathscr{x}$ & Valid $\%$ \\
\hline \multicolumn{7}{|c|}{ 2. How would you rate your participation in the CAKE mentorship program? } \\
\hline very satisfied & 9 & 13.6 & 13.6 & 7 & 35.0 & 35.0 \\
\hline satisfied & 26 & 39.4 & 39.4 & 5 & 25.0 & 25.0 \\
\hline neutral & 17 & 25.8 & 25.8 & 4 & 20.0 & 20.0 \\
\hline discakisfied & 14 & 21.2 & 21.2 & 3 & 15.0 & 15.0 \\
\hline very dissutisfied & 0 & 0.0 & 0.0 & 1 & 5.0 & 5.0 \\
\hline
\end{tabular}

Table 30

CAKE Survey - Selected Questions:

Program's Value for both

Mentors and Mentees

\begin{tabular}{|c|c|c|c|c|c|c|}
\hline \multirow[t]{2}{*}{ Question } & \multicolumn{3}{|c|}{ Mentors (Staff) } & \multicolumn{3}{|c|}{ Mentees (Students) } \\
\hline & $\mathbf{N}$ & \% & Valid $\%$ & $\mathbf{N}$ & $\Phi$ & Valid \% \\
\hline \multicolumn{7}{|c|}{ How would you rate the program's value in helping students develop a positive attitude towards school? } \\
\hline very satisfied & 19 & 28.8 & 28.8 & 6 & 30.0 & 30.0 \\
\hline satisfied & 30 & 45.5 & 45.5 & 9 & 45.0 & 45.0 \\
\hline neutral & is & 22.7 & 22.7 & 3 & 15.0 & 15.0 \\
\hline dissatisfied & 0 & 0.0 & 0.0 & 1 & 5.0 & 5.0 \\
\hline very dissatisfied & 0 & 0.0 & 0.0 & 1 & 5.0 & 5.0 \\
\hline
\end{tabular}

As can be seen in Table 31, mentor expectations of the CAKE program were rank ordered as follows: (a) help atrisk students stay in school (34\%); (b) understand at-risk students better $(24 \%)$; (c) increase personal satisfaction 
(16\%); (d) improve job satisfaction (14\%); and

(e) increase professional commitment (12\%).

Table 31

CAKE Survey - Selected Questions: Expectations of the Program Mentors

\begin{tabular}{|l||c|c|}
\hline \multicolumn{2}{|c|}{ Quextion } & \multicolumn{2}{|c|}{ Mentors (Suft) } \\
\hline \hline 15.a. Mentor expectations of CAKE mentorahip program: & median & \\
\hline to help at-risk students stay in school & & 34 \\
\hline to have an opportunity to underutand at-risk students better & 1 & 24 \\
\hline $\begin{array}{l}\text { to increase my personal satisfaction by showing concern for at-risk } \\
\text { students }\end{array}$ & 2 & 16 \\
\hline to improve my job satisfaction & 3 & 14 \\
\hline to increase my commitmens as a profeasional & 4 & 13 \\
\hline
\end{tabular}

Results in Table 32 indicated that, of the respondents who chose to answer these questions, both mentors (85\%) and mentees (67\%) agreed that having the mentee in a class taught by the staff mentor was helful. (Approximately half of the mentors (45.5\%) and mentees (40\%) did not answer question 5.a.) Only half of the mentees were actually in a class taught by their mentor.

As indicated in Table 33, mentors who replied in this question were split as to being well matched with their mentee (agree: 428; undecided: 398). Mentees who responded, however, felt they were well matched $(74 \%)$ with mentors. 
Table 32

\section{CAKE Survey - Selected Questions: Mentee in Mentor's Class}

\begin{tabular}{|c|c|c|c|c|c|c|}
\hline \multirow[t]{2}{*}{ Question } & \multicolumn{3}{|c|}{ Mentors (Staff) } & \multicolumn{3}{|c|}{ Mentees (Students) } \\
\hline & $\mathbf{N}$ & 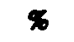 & Valid $\%$ & $\mathbf{N}$ & $x$ & Valid $x$ \\
\hline \multicolumn{7}{|c|}{ Was mentee in a class laught by the mentor? } \\
\hline yes & 34 & 51.5 & 51.5 & 10 & 50 & 50.0 \\
\hline yes \& no & 2 & 3.0 & 3.0 & 0 & 0.0 & 0.0 \\
\hline no & 30 & 45.5 & 45.5 & 10 & so.0 & 50.0 \\
\hline \multicolumn{7}{|c|}{ 5.a. Was the fact that the mentec was in one or more classes taught by the mentor helpful? } \\
\hline arongly agree & 23 & 34.8 & 56.1 & 3 & 15.0 & 25.0 \\
\hline agree & 12 & 18.2 & 29.3 & 5 & 25.0 & 41.7 \\
\hline undecided & 5 & 7.6 & 12.2 & 2 & 10.0 & 16.7 \\
\hline disagree & 0 & 0.0 & 0.0 & 2 & 10.0 & 16.7 \\
\hline stongly disagree & 1 & 1.5 & 2.4 & 0 & 0.0 & 0.0 \\
\hline missing & 30 & 45.5 & - & 8 & 40.0 & - \\
\hline \multicolumn{7}{|c|}{ 5.b. Was the fact that the mentee was NOT in a class taught by the mentor helpful? } \\
\hline strongly agree & 2 & 3.0 & 7.7 & 1 & 5.0 & 11.1 \\
\hline agree & 1 & 1.5 & 3.8 & I & 5.0 & 11.1 \\
\hline undecided & 6 & 9.1 & 23.1 & 4 & 20.0 & 44.4 \\
\hline disagree & 8 & 12.1 & 30.8 & 2 & 10.0 & 22.2 \\
\hline strongly disagree & 9 & 13.6 & 34.6 & 1 & 5.0 & 11.1 \\
\hline missing & 40 & 60.6 & - & 11 & 55.0 & - \\
\hline
\end{tabular}

Table 33

CAKE Survey - Selected Questions: Interest Match between Mentor and Mentee

\begin{tabular}{|c|c|c|c|c|c|c|}
\hline Question & \multicolumn{3}{|c|}{ Mentors (Staff) } & \multicolumn{3}{|c|}{ Mentees (Students) } \\
\hline \multicolumn{7}{|c|}{ Were the mentor and mentee well-matched with respect to interests? } \\
\hline strongly agree & 4 & 6.1 & 6.2 & 6 & 30.0 & 31.6 \\
\hline agree & 23 & 34.8 & 35.4 & 8 & 40.0 & 42.1 \\
\hline disagree & 9 & 13.6 & 13.8 & 1 & 5.0 & 5.3 \\
\hline strongly disagree & 4 & 6.1 & 6.2 & 0 & 0.0 & 0.0 \\
\hline missing & 1 & 1.5 & - & 1 & 5.0 & - \\
\hline
\end{tabular}


As indicated in Table 34, responding mentors reported that there wasn't enough time available during the day to meet with mentees $(62 \%) ; 44 \%$ of the mentees were undecided. Mentors $(77 \%)$ and mentees (75\%) agreed that they met at least monthly, with $34 \%$ and $20 \%$, respectively, indicating that they met daily. Over half of the mentors (70\%) said that they initiated the meetings; $44 \%$ of the mentees agreed. Mentors indicated that most of the activities listed in the questionnaire (64\%) were not activities pursued by CAKE participants. (See Table 34 for additional activities.)

As reported in Table 35 , results concerning communication in the CAKE mentoring program indicated the following. (a) Half of the mentors (56\%) explained the mentor program to his/her mentee; $65 \%$ of the mentees agreed; (b) Two-thirds of the mentors (59\%) used written communication of some kind with the mentee; (c) Most mentors (69\%) indicated that they did not communicate with the mentee's parents or guardians; mentees (63\%) tended to agree; (d) Mentors reported that progress in classes was the most frequent topic discussed in meetings with mentees (71\%); mentees agreed (65\%). Most participants agreed (81\% mentors; $75 \%$ mentees) that meetings involved feedback on performance at school. 
Table 34

\section{CAKE Survey - Selected Questions: Meetings/Activities with Mentor and Mentee}

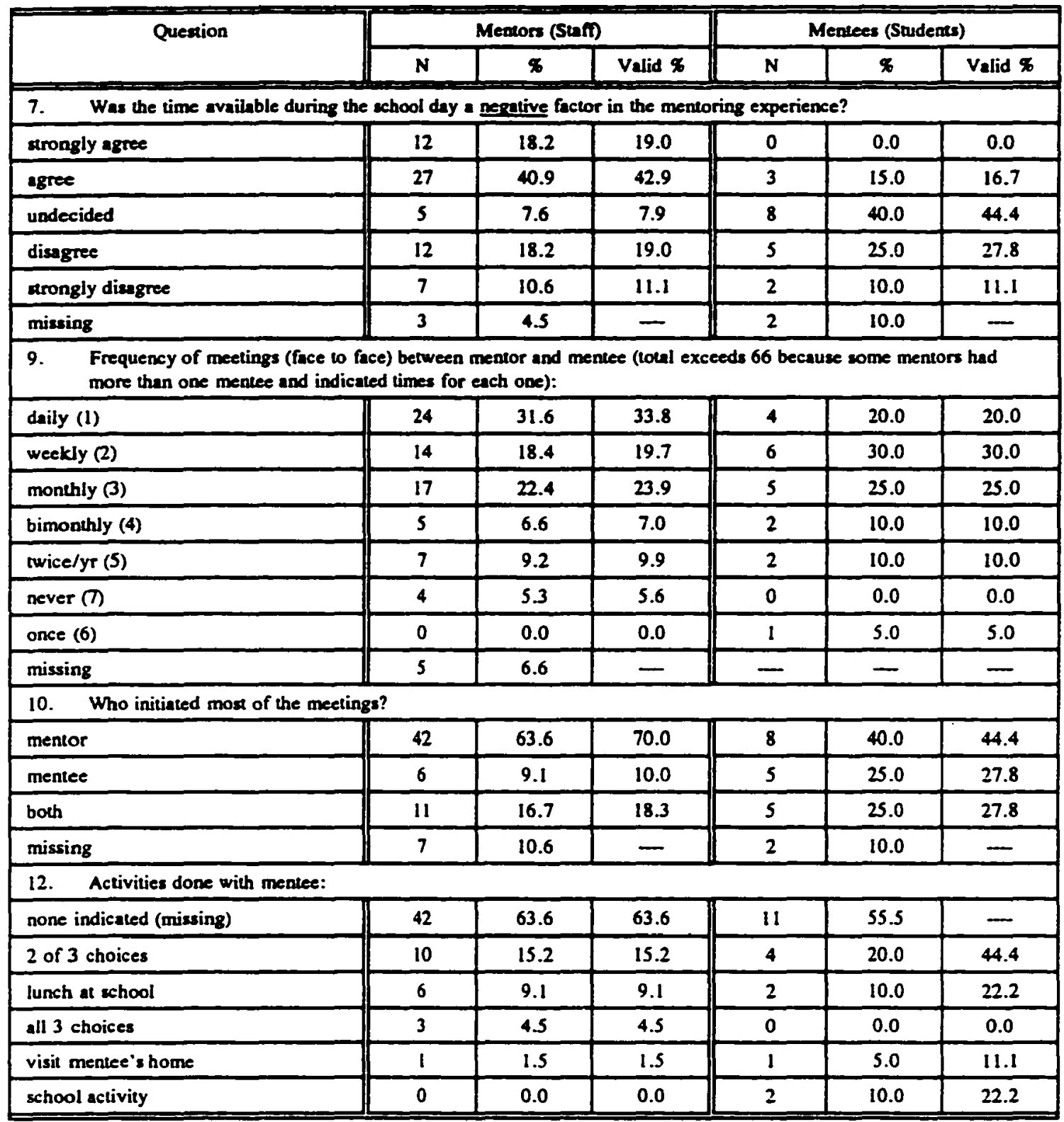


Table 35

\section{CAKE Survey - Selected Questions: communication between Mentor and Mentee}

\begin{tabular}{|c|c|c|c|c|c|c|}
\hline \multirow[t]{2}{*}{ Quextion } & \multicolumn{3}{|c|}{ Menors (Senfi) } & \multicolumn{3}{|c|}{ Memees (Sudents) } \\
\hline & $\mathbf{N}$ & $x$ & Valid $\%$ & $\mathbf{N}$ & x & Valid $\%$ \\
\hline \multicolumn{7}{|c|}{ 8. Did the mentor explain the CAKE mentorship program to the mentee? } \\
\hline yes & 36 & 54.5 & 56.3 & 13 & 65.0 & 65.0 \\
\hline yes \& no & $\mathbf{I}$ & 1.5 & 1.6 & 0 & 0.0 & 0.0 \\
\hline no & 27 & 40.9 & 42.2 & 7 & 35.0 & 35.0 \\
\hline missing & 2 & 3.0 & - & 0 & 0.0 & 一 \\
\hline \multicolumn{7}{|c|}{ 11. Type of communication between mentor and mentee: } \\
\hline notes of encourngement & 3 & 4.5 & 4.5 & 1 & 5.0 & 5.0 \\
\hline congratulations: grades/attendance & 3 & 4.5 & 4.5 & 4 & 20.0 & 20.0 \\
\hline special occasion cand & 2 & 3.0 & 3.0 & 1 & 5.0 & 5.0 \\
\hline birthday card & 1 & 1.5 & 1.5 & 1 & 5.0 & 5.0 \\
\hline all 4 choices (all 4 of the above) & 6 & 9.1 & 9.1 & 0 & 0.0 & 0.0 \\
\hline 2-3 out of 4 choices & 24 & 36.4 & 36.4 & 0 & 0.0 & 0.0 \\
\hline none indicated & 11 & 16.7 & 16.7 & 0 & 0.0 & 0.0 \\
\hline other communication & 16 & 24.2 & 24.2 & 13 & 65.0 & 65.0 \\
\hline \multicolumn{7}{|c|}{ 13. Did the mentor have communication with the mentee's guardian/parent(s)? } \\
\hline yes & 19 & 28.8 & 30.6 & 7 & 35.0 & 38.8 \\
\hline no & 43 & 65.2 & 69.4 & 12 & 60.0 & 63.2 \\
\hline missing & 4 & 6.1 & - & $\mathbf{I}$ & 5.0 & - \\
\hline \multicolumn{7}{|c|}{ 14. Topics discussed in mentor/mentee meetings: } \\
\hline progress in class(es) & 1 & 47 & 71.2 & I & 13 & 65.0 \\
\hline leacher issues & 3 & 17 & 25.8 & 5 & 4 & 20.0 \\
\hline help with homework & 4 & 10 & 15.2 & 6 & 4 & 20.0 \\
\hline family issues & 2 & 20 & 30.3 & 4 & 3 & 15.0 \\
\hline friends & 4 & 10 & 15.2 & 4.5 & 4 & 20.0 \\
\hline other issues outside school & - & - & - & 3 & 5 & 25.0 \\
\hline involvement in activities & 4 & 7 & 10.6 & 3 & 1 & 5.0 \\
\hline \multicolumn{7}{|c|}{ 16. Did student receive feedback from mentor about performance in school? } \\
\hline yes & 52 & 78 & 81.3 & 15 & 75.0 & 75.0 \\
\hline no & 12 & 18.2 & 18.8 & $\mathbf{S}$ & 25.0 & 25.0 \\
\hline missing & 2 & 3.0 & - & - & - & - \\
\hline
\end{tabular}


Results concerning staff development/training for mentors was mixed, with about half of the mentors (59\%) actually participating in staff development focused on mentoring students (see Table 36 ). Of the training components listed, staff ranked the behavior of at-risk students, and laws surrounding activities with their mentees as most important. Substance abuse information, goal-setting strategies, and other mentorship programs were ranked as least important as part of inservice training (see Table 37).

Results from students involved in the CAKE program indicated the following: (a) Most mentees (60\%) did not feel having a mentor made a positive difference in performance at school although compared to last year; these mentees $(708)$ thought that they were doing better in school this year and over half (55\%) believed school now had value; (b) most mentees (70\%) felt they could talk with their mentors when needed and that the most important attribute of the program was the fact that they had an adult to discuss problems with (45\%), followed closely with a better understanding of the school (30\%), get better grades (30\%), and discussing issues at home (30\%). Getting help on homework ranked last with $25 \%$ (see Table 38). 
Table 36

CAKE Survey - Selected Questions:

Training/Inservice for Mentors

\begin{tabular}{|c|c|c|c|c|}
\hline \multirow{2}{*}{\multicolumn{2}{|c|}{ Quextion }} & \multicolumn{3}{|c|}{ Mentors (Staft) } \\
\hline & & $\mathbf{N}$ & $\Phi$ & Valid $x$ \\
\hline 17. & \multicolumn{4}{|c|}{$\begin{array}{l}\text { Did you receive training/inservice on mentoring prior to participation in } \\
\text { the program? }\end{array}$} \\
\hline yes & & 30 & 57.6 & 59.4 \\
\hline no & & 26 & 39.4 & 40.6 \\
\hline missing & & 2 & 3.0 & - \\
\hline
\end{tabular}

Table 37

CAKE Survey - Average Ranking of Mentor Expectations/ Needs for Inservice Training

\begin{tabular}{|l|c|c|}
\hline \multicolumn{1}{|c|}{ Question } & \multicolumn{2}{c|}{ Mentors (Stufi) } \\
\cline { 2 - 3 } & $N$ & $\%$ \\
\hline $18 . \quad$ Mentor expectstions/needs as part of inservice training: \\
\hline at-risk student behavior & $\frac{\text { Ranking }}{2}$ & 11 \\
\hline $\begin{array}{l}\text { laws surrounding student/teacher } \\
\text { activities }\end{array}$ & 2 & 11 \\
\hline tirst meeting tips & 3 & 11 \\
\hline motivation techniques & 3 & 7 \\
\hline counseling techniques & 5 & 8 \\
\hline community resources available & 5 & 11 \\
\hline substance abuse information & 6 & 5 \\
\hline goal seuting arategies & 6.5 & 12 \\
\hline other mentorahip programs & 9 & 24 \\
\hline \hline
\end{tabular}


Table 38

\section{CAKE Survey - Selected Questions: Outcomes from CAKE Program Mentees}

\begin{tabular}{|c|c|c|c|}
\hline \multirow[t]{2}{*}{ Quextion } & \multicolumn{3}{|c|}{ Mentees (Swdents) } \\
\hline & $\mathbf{N}$ & $\boldsymbol{s}$ & Valid $\%$ \\
\hline \multicolumn{4}{|c|}{ 17. Having a mentor made a positive difference in how I perform in school: } \\
\hline agree $(1-2)$ & 8 & 40.0 & - \\
\hline disagree (4-5) & 12 & 60.0 & - \\
\hline \multicolumn{4}{|c|}{ 18. I feel as though I can go to my mentor any time I need help: } \\
\hline agree $(1-2)$ & 13 & 65.0 & $\longrightarrow$ \\
\hline disagree (4-5) & 6 & 30.0 & - \\
\hline miscing & 1 & 5.0 & - \\
\hline \multicolumn{4}{|c|}{ 19. I was able to talk to my mentor most of the time I needed to: } \\
\hline agree $(1-2)$ & 14 & 70.0 & - \\
\hline disagree (4-5) & 5 & 25.0 & $\longrightarrow$ \\
\hline missing & 1 & 5.0 & - \\
\hline \multicolumn{4}{|c|}{ 20. Compared to lat year. I am doing better this year: } \\
\hline agree $(1-2)$ & 14 & 70.0 & $\longrightarrow$ \\
\hline disagree $(4-5)$ & 5 & 25.0 & - \\
\hline missing & 1 & 5.0 & - \\
\hline \multicolumn{4}{|l|}{ 21. Coming to school has value for me: } \\
\hline agree $(1-2)$ & 11 & 55.0 & - \\
\hline disagree (4-5) & 9 & 45.0 & 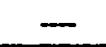 \\
\hline \multicolumn{4}{|c|}{ 22. I feel having an adult mentor in school is important because: } \\
\hline help with homework & 0 & 0.0 & - \\
\hline I have someone to Galk to & 10 & 50.0 & - \\
\hline someone cares about me & 2 & 10.0 & - \\
\hline 2 or more of the above & 7 & 35.0 & - \\
\hline missing & 1 & 5.0 & - \\
\hline \multicolumn{4}{|c|}{ 15.b. Student outcomes of CAKE mentorship program: } \\
\hline $\begin{array}{l}\text { to better understand the workings of a } \\
\text { large high school }\end{array}$ & 5 & 6 & 30.0 \\
\hline $\begin{array}{l}\text { to have an adult friend to diecuas } \\
\text { problems with }\end{array}$ & 1 & 9 & 45.0 \\
\hline $\begin{array}{l}\text { to get better grades and increase my } \\
\text { aftendance }\end{array}$ & 2 & 6 & 30.0 \\
\hline $\begin{array}{l}\text { to discuss issues outside of school } \\
\text { such as family, job, etc. }\end{array}$ & 2.5 & 6 & 30.0 \\
\hline to get help on homework & 4 & 5 & 25.0 \\
\hline
\end{tabular}


The following attributes, as seen by mentors regarding the success of a mentorship program, were ranked in the following order: (a) availability of time to meet (52\%); (b) training for mentors (23\%); (c) support from administration (13\%). Ranked 4 th and 5 th were the assignment of a mentee to his/her mentor's class (11\%) and selection process for mentees ( $9 \%)$. There seemed to be little or no need for get-togethers with mentors/mentees (4\%), parents (0z), or support groups (4\%) (see Table 39).

Table 39

CAKE Survey - Selected Questions: Ranking of Attributes for success of CAKE Mentoring Program Mentors

\begin{tabular}{|c|c|c|c|c|c|c|c|c|c|}
\hline $\begin{array}{l}\text { Attributes important } \\
8=\text { lowest): }\end{array}$ & the succe & of any $m$ & corship pr & ram, ranke & by mentor & (ranked 1 - & with $\mathrm{l}=\mathrm{h}$ & hest and & \\
\hline & & Rankng & Jue ( $\%$ inc & des only th & sece suff $m$ & abers who & sponded) & & \\
\hline Attributes & $\begin{array}{c}\text { (1) } \\
\text { highest }\end{array}$ & (2) & (3) & (4) & (5) & (6) & $(7)$ & $\begin{array}{l}\text { (8) } \\
\text { lowes }\end{array}$ & \\
\hline & N $\%$ & N $\%$ & N $\%$ & $\mathbf{N} \%$ & N $\%$ & $N \quad \%$ & N $\%$ & $\mathbf{N}$ & ж \\
\hline availability of time to meet & $30 \quad 52$ & 1424 & 14 & 3 & 3 & 0 & 0 & 1 & 2 \\
\hline $\begin{array}{l}\text { mentorship training for } \\
\text { mentors }\end{array}$ & 1323 & 3 & $10 \quad 18$ & 4 & 9 & $15 \quad 26$ & 7 & 1 & 2 \\
\hline $\begin{array}{l}\text { support from } \\
\text { administration }\end{array}$ & $7 \quad 13$ & 916 & $10 \quad 18$ & $7 \quad 13$ & 1323 & $6 \quad 11$ & 2 & & 5 \\
\hline $\begin{array}{l}\text { mentees assigned to a } \\
\text { mentor's class }\end{array}$ & $6 \quad 11$ & $12 \quad 22$ & $7 \quad 13$ & $8 \quad 15$ & $7 \quad 13$ & $7 \quad 13$ & 6 & & 4 \\
\hline $\begin{array}{l}\text { selection process for } \\
\text { mentees }\end{array}$ & 9 & 5 & 6 & $6 \quad 11$ & 9 & 5 & 2343 & & 3 \\
\hline $\begin{array}{l}\text { formal "get-logethers" for } \\
\text { mentor/mentees }\end{array}$ & 4 & $7 \quad 13$ & $9 \quad 17$ & 1222 & $9 \quad 17$ & $6 \quad 11$ & 11 & & 4 \\
\hline $\begin{array}{l}\text { existence of an informal } \\
\text { suppon group }\end{array}$ & 24 & 5 & $11 \quad 20$ & 1324 & 1120 & 815 & 7 & & 0 \\
\hline $\begin{array}{l}\text { formal meeting with } \\
\text { mentee's parents }\end{array}$ & 0 & 0 & & & 2 & 4 & 5 & 40 & \\
\hline
\end{tabular}


student comments - QSL

A few students chose to write comments on the back of the QSL. Examples included the following (reproduced as written by students):

overall, I don't like school. But I know its nessessary to get any were in life. I think its possible to have a life with out a full education, because my cousin dropped out and he is doing fine. I don't like school.

I hate school because it's to much work I wish I could just take one class at a time (one class for half of a year).

School is okay but sometimes it gets very repetitive and $I$ cant seem to get my mind focused correctly on my daily agenda, therefore, I usually don't apply myself to many of my verious assignments.

I like the game's dance's the day off's this school is oK but if it was my choise I wouldnt go.

I would say school all right at the first of the year. But teachers start to get more strict towards the end of the year. And you lose privilages. And it starts to get boring so it's not even worth going to school. I wish all the teachers were like Mr. Carle and Mr. Wilkins. The school would be a lot better.

I like school better than most places in the world. There are people and friends here who can really understand the way I feel about certain issues. I mainly solve my problems in school.

I hate school because often times the teachers treat you like dirt. You are always overpowered like, "me teacher, you kid. Kid know nothing."

I like coming to school just to see my friends. Most of my teachers are a real pain especially English, Math. 
The reason I hate school is because of: Some of the teachers act like they know everything about the world. Teachers give the students to much home work during weekends. Teachers want us to do projects their way not our way. Some of the kids in this school are stuck up or they need their "ass" kicked badly. I hate going to school five days a week and I think school is a waste of my $t$ ime. Some teachers are nerds and some act their better than anyone else. THE END!

The comments reinforced the findings of the CAKE survey and is in agreement with the body of literature surrounding the reasons often cited by students who have dropped out of school: the lack of relevance between school and the students' life outside school, irrelevant course work, teaching techniques that did not match learning styles, feeling a part of the school that the electives and activities provide, and the importance of relationships, primarily with teachers. (Beck \& Muia, 1980; Benson et al., 1987; Boyer, 1995; Hershaff, 1980; oregon Department of Education, 1997) 
CHAPTER V

DISCUSSION OF FINDINGS AND RECOMMENDATIONS

Anthropologist Loren Eiseley chronicled the perhaps apocryphal story of how we can each make a difference in our personal and professional lives. He relates a time he was walking on the beach and saw, in the distance, the figure of a man repeatedly throwing something into the surf, one at a time. As Eiseley drew closer, he saw a young man throwing starfish from a large pile into the ocean. He asked the young man why he was engaged in this practice, to which the man cited the probable dismal future of the starfish due to human incursions on the starfish habitat and the mollusk as a species. Eiseley replied that single effort was not likely to alter the probable outcome for this species. The young man replied as he threw yet another into the sea, "Well, it certainly makes a difference to that one!"

(Paraphrased from Eiseley, 1978) 
The mentees were this researcher's "starfish."

This study examined the effect of a staff mentoring program with students at risk of leaving school prior to graduation. The study consisted of five components: (a) a comparison of at-risk students and those not at-risk prior to the start of the program, using indicators of school achievement (grades and attendance data) and attitudes toward school; (b) the same indicators were analyzed over time, comparing not at-risk, at-risk with mentors, and atrisk without mentors; (c) the same indicators were analyzed over time comparing at-risk students with mentors and at-risk without mentors; (d) enrollment status after four years was analyzed for students at-risk with and without mentors, and (e) results from surveys given to mentors and mentees were analyzed for activities and characteristics contributing to the success of a staff mentoring program.

This final chapter is divided into three sections. The first section is devoted to the discussion and interpretations of the statistical results obtained and reported in chapter IV. These findings relate to the ANOVAs, ANCOVAs, chi-square, and percentage analyses performed. The second section consists of conclusions drawn from the study with implications and recommendations for practice. The final section concludes with 
recommendations to others who may wish to pursue this topic in further research.

\section{Statistical Findings: Interpretations}

\section{Question 1}

The purpose of the first research question was to ascertain if there was a difference between the two groups of students identified for purposes of this study, at-risk and not at-risk. Prior to treatment, the students at-risk were found to have significantly lower means on the total QSL scores (with the exception of cohort 2), attendance rates, and GPA when compared to those students not atrisk. This established an initial difference prior to treatment between the two groups studied, at-risk and not at-risk.

Using an analysis of covariance, a difference was found not only prior to treatment between at-risk students and students not at-risk, but these two groups of students continued to respond differently after one year in the study.

The first year means on all QSL scales were less for the at-risk students than for the not at-risk. However, with the exception of the Satisfaction with School scale, the second year QSL mean scores were reported as higher for at-risk students than not at-risk. In each case the 
adjusted mean was also higher for the at-risk student group. Using an analysis of covariance, significant differences were found between all groups, except with the Satisfaction of School scale.

Using analysis of covariance, a significant

difference was also found between students at-risk and students not at-risk in attendance and GPA. In both cases, the actual attendance and GPA means for at-risk groups were lower prior to treatment than for the not atrisk. For each group, the attendance means remained about the same at the end of Year 1 as they were at the beginning of the study. When examining the adjusted attendance means, the attendance rates remained lower for the at-risk groups when compared with the not at-risk groups. When examining the adjusted GPA means, the GPA means of the at-risk groups were significantly lower than the adjusted means for the not at-risk groups. It is interesting to note that the GPA for at-risk and not atrisk within their groups dropped from pretreatment to Year 1; this relationship held true for both the QSL group and for all students.

\section{Question 2}

The second research question examined differences between at-risk students with mentors, at-risk students without mentors, and not at-risk students. The purpose of 
these comparisons was to determine if having a mentor lessened the severity of being at-risk when compared to students not at-risk.

The first year means on all scales of the QSL were less for at-risk students with or without mentors than for those not at-risk; however, there were differences between those with mentors and those without mentors. Students not at-risk reported better attitudes toward school the first year of the study, and had a slightly lower total QSL score the following year. This contrasted with atrisk students with or without mentors. The first year of the study, those with mentors had lower means on all scales, except the commitment to school work, than those without mentors. Using analysis of covariance, in the fall of the second year of the study the means were significantly higher for at-risk students with mentors than without mentors on all scales. It is noteworthy that the means of the mentored group in Year 2, before any adjustments were made, were greater on all scales than the not at-risk students. When adjusted means using the analysis of covariance were examined, these differences were even greater when compared to the unmentored group and not at-risk students.

The attendance means were the lowest for the at-risk student group without mentors, next for those with 
mentors, and highest for the not at-risk group. This same relationship occurred at the end of Year 1 . But, it is interesting to note that the at-risk student group with mentors had the same attendance rate in Year 1 as it did in the pretreatment year, whereas the attendance rate dropped for both the unmentored group and not at-risk student group. The statistical hypothesis was not rejected; differences observed between the three groups were not significant.

The initial GPA means were the lowest for the at-risk without mentors, next for at-risk with mentors, and the highest for the not at-risk group. The same patterns existed at the end of Year 1, with the GPA means actually being lower for all three groups. Following the rejection of the statistical hypothesis using an analysis of covariance, the adjusted means for GPA were examined. As expected, the adjusted means for the not at-risk was higher than the other two groups. However, the GPA mean for the at-risk student group with mentors was also higher than the unmentored group.

Significant differences in GPA, attendance rates, and attitudes toward school over a year's period of time were found between students at-risk and not at-risk. The addition of a mentor with at-risk students resulted in a significant improvement in their attitudes toward school 
as compared with those without mentors and students not at-risk. The addition of a mentor resulted in improved GPAs, as compared with those without mentors. students not at-risk maintained significantly higher GPAs from Year 1 to Year 2 than either of the at-risk student groups. In terms of rates of absence, it would appear that the addition of a mentor did not impact the attendance rate of at-risk students. This lack of significant difference could be due to the difference in sample size and the variances in the variable itself.

The remainder of the study focused on the effects of staff mentoring on the group of students identified as atrisk since differences between at-risk students and not at-risk students has been established.

\section{Question 3}

The third research question examined differences on selected variables between at-risk students with mentoring and at-risk students without mentoring. The analysis of the quality of school Life data, using an analysis of covariance, established significant differences on the subscales and total score of the QSL between at-risk students with mentors and at-risk students without mentors. The mentored at-risk students actually scored lower prior to treatment on two of the subscales and the total scale of the QSL than those without mentors. The 
exception was commitment to Teachers. One year later, they actually scored higher on all scales. The differences were even greater when comparing the adjusted means, with the mentored students scoring significantly higher on all scales. Thus, the mentored group demonstrated an increased positive attitude toward school, whereas those without mentors were less enthusiastic about school. This is even more important when, as Epstein and McPartland (1978) note, students consistently report lower scores on the QSL as they get older. "There is a consistent pattern of decreasing satisfaction with school life for the same students in two surveys, one year apart" (p. 21)

\section{Question 4}

The fourth research question examined differences on the selected variables (attendance and GPA) between atrisk students with mentors and at-risk students without mentors. Examining the attendance for the combined Cohorts 1 and 3 , the mentored group began at 156 days and increased to a mean of 159 days at the end of the first year. Attendance for the unmentored group began at 150 days; the mean decreased to 141 days. At the end of the first year, the attendance rate of the mentored group (combined Cohorts 1 and 3) increased from 156 to 159 days, with an adjusted mean of 159 days. For the non-mentored 
group, attendance decreased from 150 to 141 days, with an adjusted mean of 143. There was a significant difference between the adjusted means (159 for mentored and 143 for non-mentored) .

The attendance rate for the mentored group continued to decline during Years 2, 3, and 4. A similar pattern occurred in the non-mentored group across Year 2 and 3 , but the rate increased in Year 4. In comparing the attendance rate for Years 2, 3, and 4, in these two groups there were no significant differences. It is important to note that the mentored group had $94 \%$ of its students left, and the non-mentored group had $68 \%$ left at the end of two years.

It is also important to note here the dramatic decline in the group numbers from Year 1 to Year 4 in the unmentored group. At the end of Year 2, those with mentors had 93\%, without mentors 68\%; at the end of Year 3, the difference was much greater with those with mentors at $82 \%$ and without mentors at 50\%; and at the end of Year 4, the difference increased again, with those students with mentors at $74 \%$ and without mentors at $32 \%$. This could explain the lack of significant difference from Year 2 to Year 4 in that the dramatic decline in the nonmentored group left students with the skills to attend school comparable to those in the mentored group. 
The analyses of GPAs revealed the same trend for these students. Grades for mentored at-risk students actually worsened at the end of the four years, whereas those students without mentors showed an actual increase. At the end of the first year, the adjusted mean of the GPAs of at-risk students with mentors dropped, and those without mentors was lower still. GPA for the combined Cohorts 1 and 3 mentored groups began at 2.2 and decreased to the adjusted mean of 1.9 at the end of the first year. GPA for the unmentored groups began at 2.2 and decreased to the adjusted mean of 1.7 . This was not a significant difference. There continued to be no significant difference in Year 1 to Year 2, with the mentored group's adjusted GPA mean at 1.9 and the unmentored group at 1.8 . From Year 2 to Year 3, there was a significant difference between the mentored group and the unmentored group; the adjusted mean for the mentored group rose to 2.0 while the unmentored group rose to 2.8. Year 3 to Year 4, both groups had an adjusted mean of 2.0 .

As in the attendance data, a partial explanation for this phenomenon can be found in the actual number of students left in each year's study. Again, there was a dramatic decline in the unmentored group over the four year period. Although their grades fell, greater percentages of students with mentors continued in school 
after four years than those without mentors. This

phenomena also supports the results in question $5, i . e .$, mentored students graduated at a greater rate than nonmentored students.

From the data analysis, it would appear that having a mentor did not make a difference in such indicators of school success as rates of attendance and GPA. However, it is noteworthy that more students left school in those four years in the group without mentors than those with mentors, leaving those that maintained their attendance and GPA over time in the unmentored group. This could explain the unexpected trend. The influence of mentor status versus an unmentored status and its relationship to students' enrollment status in school at graduation is examined in the following section.

\section{Question 5}

The fifth research question examined the enrollment status of at-risk students with mentors and at-risk students without mentors over a four year period in school. An analysis of student enrollment status after Year 4 of the study found a statistically significant difference, indicating that having a mentor positively influenced at-risk students. Approximately twice as many at-risk students with mentors graduated from high school (44\%) versus those without mentors (21\%). Nearly half of 
those students without mentors dropped out of school (45\%) prior to graduation, versus only a fifth (17\%) dropping out from at-risk students with mentors. Approximately one quarter of those mentored at-risk students passed their High School Equivalency exam (GED) (26\%) or planned on returning to high school as "5th year seniors" (3\%). This compares to only one tenth of those at-risk students without mentors (11\%) receiving GEDs or returning for a "5th year" (2\%). Both groups of at-risk students had approximately the same transfer rate, which would not necessarily be influenced by mentor status.

In summary, at-risk students with mentors graduated or received GEDs at much higher rates and demonstrated better attitudes toward school than those without mentors.

\section{Question 6}

The sixth research question examined the perceptions and characteristics of the CAKE program with the staff mentors and a random sample of the mentored students. The analysis of the survey given to both students and staff examined the mentor and mentees' perceptions of the effectiveness and characteristics concerning the mentorship program and its effect on at-risk students. The survey was primarily given to mentors because of the limited sampling of mentees available (see Limitations). Therefore, this study is likely to report findings based 
on mentor responses in assessing the characteristics contributing to program effectiveness.

Students (75\%) and staff (74\%) agreed that they were "satisfied" that the mentor program helped at-risk students develop positive attitudes toward school, but about half were satisfied concerning their participation in the program ( $60 \%$ students; $53 \%$ staff). While $40 \%$ of the mentors were neutral or dissatisfied with their participation, $70 \%$ of the students surveyed felt they were doing better in school, but $60 \%$ did not attribute their improved performance to having a mentor. Most students surveyed felt that they could go to their mentor if they needed help (65\%), that their mentor was available when needed $(70 \%)$, and that having a mentor provided them with an adult to talk to (50\%).

Mentors were unsure as to whether the mentees and mentors were well matched with respect to interests $(39 \%$ undecided). Approximately half the staff (54\%) and students (50\%) agreed they met either daily or weekly. staff mentors $(70 \%)$ felt they were responsible for organizing meetings with their mentees. Respondents reported topics most often discussed in meetings included mentees' progress in classes (mentors, 71\%; mentees, 65\%) and, to some extent, family and teacher issues. Help with homework and involvement with activities was the least 
likely to be discussed. Mentors (69\%) and mentees (63\%) agreed that mentors did not communicate with the parents of the students. Slightly over half (59\%) of the staff reported receiving inservice on mentoring prior to participation in the program. The two top needs identified by those who attended the inservice were information concerning the behavior of at-risk students and information regarding legal issues surrounding student/teacher activities. The least needed topics as reported in this inservice included substance abuse, goalsetting strategies, and other mentorship programs.

The mentors were divided in their perceptions of the degree to which mentors explained program facets to mentees. Many staff members (42\%) did not reveal to their mentees that they were students identified as at-risk and were assigned a mentor as part of the CAKE program; 65\% of the mentees reported that the program was explained to them. This reporting coincides with many of the mentees' surprise upon learning they were part of this program when asked by the researcher to fill out the CAKE survey. Consequently, fewer mentees were given the survey. This researcher believes the mentoring program would have provided greater assistance to these students had there been communication concerning the purpose of the mentor. This is a "planned" mentor program versus a "natural" 
mentor relationship. To pretend this was anything else could infuse this mentor relationship with less integrity, purpose, true communication, and trust than was the case. Staff ranked their expectations of the CAKE mentoring program. They rated the opportunity to learn more about at-risk $(24 \%)$ students and helping those students stay in school (34\%) as their highest expectation from participation in the program. An unexpected outcome for some proponents of mentoring was increased job satisfaction (14\%) and commitment as professionals (12\%) as the two lowest expectations of the program. It is the researcher's opinion these staff volunteers in the mentor program were already professionally committed and satisfied with their jobs as teachers.

Most mentors with mentees in their classes agreed having the at-risk student assigned to them in class was beneficial ( $85 \%)$; only $15 \%$ of those without their mentees in their classes percieved this as beneficial. This statistic coincides with $62 \%$ of the mentors reporting they did not have enough time to meet with their mentees. Most mentors felt time to meet with their mentee must be provided regularly in addition to time spent in classroom intervention with mentees.

Most of the mentors (90\%) ranked in the top "3" out of a possible ranking of "9," availability of time to meet 
as the most important attribute of successful mentorship programs (52\% ranked "1," $24 \%$ ranked "2," and $14 \%$ ranked "3"). They ranked a formal meeting with the mentee's parents as least important $(74 \%)$. Formal get-togethers or support groups for mentors, along with the selection process for mentees, were also listed as less important attributes to the success of the program. Staff split evenly on the need for inservice training, probably due to the $40 \%$ of staff who reported earlier that they had not attended the inservice!

Consistent administrative support is crucial to program success. This is needed in order to provide availability of time and organization of planned activities. In this case, a new principal entered the high school the second year of the mentor program. Although this new leadership supported the existing program, subtle changes and less emphasis during staff meetings on the mentor program had a dampening effect overall. The ultimate result became evident in the third year of the program. New leadership for the high school, with the retirement of the staff members responsible for recruiting mentors and organization of the initial program, led to the eventual decline of the program during the third year and final dissolution in the fourth year. Mentors continued to meet with mentees assigned to them 
during the first two years, but did not add any additional mentees the third.

This event seemed to coincide with the decline of GPA and attendance data. There were no significant differences in achievement data the third and fourth years between at-risk students with or without mentors. When the program was at its zenith the first year, a more significant difference was reported between those with and without mentors. It is the writer's belief that, if there had been additional leadership and support for the program, new mentors could have been recruited, organizational concerns addressed, and the program revitalized.

This survey, although limited, gave valuable additional insight into participants' perceptions of the program. Survey responses added additional weight to the research data and helped explain some of the phenomena. Respondents in general were satisfied with mentoring atrisk students as one tool to increase their chances of successfully completing high school.

\section{Conclusions}

The qualitative and quantitative findings of this study supported the recommendations imbedded in the review of literature surrounding mentoring at-risk students. As 
current research literature suggested, educators can do little to influence the environmental factors placing students at-risk, but they can take active roles in responding to fundamental needs unmet by contemporary schools, i.e., developing positive teacher-student relationships which in turn affect the students' attitudes toward school and, ultimately, a student's decision to stay in school.

The qualitative findings of this study found that satisfaction in school may be the major intervening factor concerning the holding power of schools. This perception from the survey is supported by the quantitative findings reported in Chapter IV. At-risk students with mentors demonstrated significant improvement in attitudes toward school. The at-risk students with mentors scored significantly higher on all scales of the QSL than both at-risk students without mentors and students not at-risk. They did not, however, improve in other measures of school success, e.g., attendance and grades. However, over the four years that attendance and GPA were reported, more atrisk students with mentors remained in school than those without mentors, perhaps explaining the difference. In fact, approximately twice as many at-risk students in this study with mentors graduated or made positive choices toward their education than did those without mentors 
(i.e., obtaining a GED and returning fifth-year seniors). The fact that mentored at-risk students displayed no improvement in attendance and GPA paled in comparison to their increased ability to stay in school.

staff mentors reported in the CAKE survey that their preparation to be a mentor, along with varied frequency and quality of contacts with their mentee, had little effect on the outcome involving the holding power of the school on at-risk students. On the same survey both mentors and mentees felt that this mentoring program did have a positive effect on the mentees' attitudes toward school. Perhaps the mere presence of an adult who showed interest in and caring for these at-risk students was the most important factor in the change in attitude toward school, independent of any quantitative factors. What was important was the fact that these at-risk students had an adult who cared about them during their secondary school experience.

The CAKE survey also found that most students felt that their mentor was available when needed, and that having a mentor provided them with an adult to talk to. These findings, along with quotes that students wrote on the back of the QSL, coincided with studies cited on reasons students leave school early in the review of the literature. Students who dropped out of high school in 
previous studies most frequently cited irrelevant coursework and teaching techniques that did not match their learning styles, along with the impersonal educational system, as the major causes for leaving school (Boyer, 1995; Brendtro et al., 1990; Hershaff, 1980; Kovalik \& Olson, 1994; Meier, 1995). Current research involving the study of resilient children stressed the importance of children being connected to a teacher or other adult during adolescence. This research demonstrated that having an adult that students at-risk could turn to and trust built resiliency, which in turn made school for them a refuge from society's ills (Bushweller, 1995; Wolin \& Wolin, 1993).

The findings of this study, along with previous research, suggest that, even though educators can do little to influence environmental factors that place students at-risk, they can respond to one fundamental need unmet by contemporary schools, i.e., having an adult who cares! It appears from both qualitative and quantitative findings in this study, in conjunction with previous studies, that mentoring programs matching at-risk students with adult staff members can have a positive effect on students' attitudes which in turn helps prevent these students from dropping out of school. 


\section{Implications for Practice}

The issues facing education today are many and complex. Secondary educators in Oregon are faced with the reality of the oregon Education Act for the 21 st Century, with its concomitant expectations. For the first time, the graduating class of 1998 will have to "measure up" to the standards set by the Oregon Department of Education. These standards with little fidelity to the reality of public schools now charged with education for all students, not just the academically able, those with more of the world's goods, or those with the personal resilience to stay the course. Compounding the problem, the amount of funds available to educate students is declining.

It is the opinion of this researcher that the move toward "rigorous" academics and higher standards with less funding will tend to reinforce the already blessed, and provide even less help to those with the least ability to survive and prosper under the present expectations. It remains to be seen whether mandating certain levels of proficiency in the absence of systemic change to benefit all students will result in higher levels of student achievement. Without systemic change, it may result in producing even greater numbers of dropouts. Students may perceive that they have even less chance to graduate. We 
must address the issue of how the new system will respond to the concomitantly partitioned students of ethnic and racial groups, those "low average" students at the 16 th to 40 th percentiles of intelligence, the handicapped and disabled, all of whom have been invited to the banquet we offer. Unfortunately, it is likely they will find tables with insufficient room for all invited to take part. While attempting to fight battles on many grounds, public schools have to choose how to direct their available energies. It is probable that the choice will be to work with the students that we have, and depend on others to deal with the remainder of the agenda facing us. That being the case, it is this researcher's belief that mentoring programs, such as the one described in this study, may be one way to encourage the discouraged and help the alienated remain in school

Based on the findings of this study, coupled with the review of the literature, the following recommendations are listed concerning staff mentoring programs for students at risk:

\section{Recommendations for Practice}

1. Mentoring programs need to begin prior to the transition of the middle school student to the high school. This study found almost half of the at-risk 
students identified in the 8th grade dropped out within the first few months in high school (see Table 1).

2. Planned mentorship programs may be enhanced by a formal selection process for both mentees and mentors. commitment and expectations need to be established and communicated at the beginning of the program for all participants. There seemed to be a lack of clarity of mission. In this case, staff mentors did not have specific expectations involved with their participation.

3. A mentoring program must establish an organized system of matching mentors with students. Even in a "planned" mentorship program, there must be an effort to minimize the problems between participants. As indicated in the literature review and student survey, the need to match/communicate with both mentors and mentees is necessary for the program's success.

4. A formal communication link should be consistently established between the mentee's home and the staff mentor. Information on outside social agencies, resources available, and modeling positive adult behaviors which enhance the learning process may assist behaviors in the mentee's home.

5. Staff mentors should be inserviced, using the guidelines of mentor programs outlined in the Literature Review (p. 27) and adjusted for local needs. 
6. The progress of the program should be highlighted with every opportunity, using staff and district meetings, newsletters, and other forms of communication.

7. A staff mentor program must be supported at the highest levels. A program of this type is doomed if its continuance is based on the "cult of the personality," or the leadership of one or two people. The program's leadership should be part of that staff member's job description and time made available during the day to manage the program. It would be reasonable to infer that the CAKE program deteriorated due to the perception that it was no longer important to the new principal. Partial evidence may be found in the deterioration of attendance and GPA figures from the first year of the program to its last year (see pp. 141-146).

8. A system should be devised for ongoing formulative and summative evaluation to drive necessary changes as the program grows and matures.

9. Staff mentors need to establish short- and longrange goals that can be measured, using both qualitative and quantitative data. This is crucial feedback as to the effectiveness of the program.

10. Each mentee should be asked to keep a log to document his or her activities, concerns, and thoughts; 
this would greatly enhance learning and the mentoring process. Credit for such an activity should also be considered as motivation to complete such a task. This provides valuable feedback in any adjustments needed to make the mentoring program viable.

11. Additional documentation/emphasis needs to be made on those students who actually leave school early. Surveys/interviews should be conducted as to the circumstances leading to that student dropping out. This provides valuable information to counselors when advising students who drop out as to other educational avenues available to them. This will also add to the assessment of the mentoring program and provide valuable information for adjustments.

\section{Recommendations for Research}

1. Additional research is needed to clearly identify current reasons students drop out of school, and to compare these to earlier findings. This will add more information available to assist educators in developing appropriate programs to help students remain in school.

2. Research replicating this study should be conducted in urban and rural settings and with other mixes of student populations. 
3. Longitudinal studies that describe the progress of at-risk students involved in mentoring programs before high school graduation and years following are needed.

4. Research studies are needed that describe mentoring programs that include the middle school years and their effect on at-risk students' completion of high school.

5. Research on the level of participation in a mentoring program of staff participants and the at-risk students' success in school is needed.

6. Studies are needed comparing the effects of different types of staff mentoring programs and their effects on targeted student populations.

7. Studies using additional quantitative methods of research on the effects of staff mentoring of at-risk students will add to our knowledge base.

\section{Final Remarks}

Schools that emphasize keeping students in school, including the isolated and less capable, while providing assistance to the disaffected, are demonstrating at worst enlightened self interest and, at best, fulfilling the goal of an education appropriate to each student. The findings of this dissertation, with respect to the mentor program upon which it is based, may help provide a partial 
answer of how to provide education to more students. The ostensible goal of equity spurring tax cuts is spurious. Genuine equity does not lie in seeing that districts are funded at the same level. Equity is far more likely to lie in the quality of our work with students and their educational outcomes. It is for this reason that we must continue to replicate best practices when they are seen. Mentor programs offer a tool that requires little additional funding but depends on a personal and professional commitment to do the best we can for all our students. 


\section{REFERENCES}

Abcug, L. (1991). Teachers achieving success with kids (TASK), Practicum, Nova University (ERIC Document Reproduction Service No. ED 330 974).

Alleman, E., Cochran, J., Doverspike, J., \& Newman, I. (1984, February). Enriching mentoring relationships. The Personnel and Guidance Journal, 62 (16), 329-332.

Applegate, J. (1981, September/October). Perceived problems of secondary students. Journal of Educational Research, 75(1), 49-55.

Arkansas State Department of Education. (1980). Career awareness and job placement for early school leavers and adults. Iittle Rock, AR: Author. (ERIC Document Reproduction Service No. ED 201 755)

Ary, D., Jacobs, L.C., \& Razavieh, A. (1985). Introduction to research in education. New York: CBS college Publishing.

Association of Supervision and Curriculum Development (1992). Curriculum report. Alexandria, VA: Author.

Astin, A.W. (1985, July/August). Involvement: The cornerstone of excellence. Change, 17(4), 24-38.

Beardon, L., Spencer, W., \& Moracco, J. (1989). A study of high school dropouts. The School counselor, 37(2), 113-120.

Beck, L., \& Muia, J.A. (1980, November). A portrait of a tragedy: Research findings on the dropout. The High School Journal, 64(2), 65-72.

Benson, P., Williams, D., and Johnson, A. (1987). The quicksilver years: The hopes and fears of early adolescence. San Francisco: Harper and Row.

Berkowitz, L. (1971). Staying in school: An evaluation of a program to prevent school dropouts (Final Report). New York: Educational Alliance. 
Blackwell, J.E. (1989, September/October). Mentoring: An action strategy for increasing minority faculty. Academe, $75(5), 8$.

Blough, T.B. (1956). A critical analysis of selected research literature on the problem of school dropouts. (Doctoral dissertation, University of Pittsburgh) - Dissertation Abstracts International, 17(01), 0058A.

Borman, C., \& Colson, S. (1984, March). Mentoring: An effective career guidance technique. The Vocational Guidance Quarterly, 32(3), 192-197..

Boyer, E.I. (1983) . High school: A report on secondary education in America. New York: Harper and Row.

Boyer, E.L. (1995). The education person. In J.A. Bean (Ed.), ASCD 1995 yearbook: Toward a coherent curriculum (pp. 16-25). Alexandria, VA: Association for Supervision and Curriculum Development.

Brendtro, L.K., Brodcenleg, M., \& Van Bockern, S. (1990). Reclaiming youth at risk: Our hope for the future. Bloomington, IN: National Educational Service.

Bronfenbrenner, U. (1986). Alienation and the four worlds of childhood. Phi Delta Kappan, 67(6), 430-436.

Buckner, M.P. (1976, April 10-13) . Effective dropout prevention programs. Paper presented at the Annual Meeting of the National School Boards Association. San Francisco. (ERIC Document Reproduction Service No. ED 123 730)

Bunzel, J.H. (1985). Challenge to American schools: The case for standards and values. New York: Oxford University Press.

Bushweller, K. (1995). The resilient child. American School Board Journal, 182(5), 18-23.

Camp, C. (1980). School dropouts: A discussion paper, Sacramento: California State Legislative Assembly Office of Research. (ERIC Document Reproduction Service No. ED 191 959)

Campbell, D., \& Stanley, J. (1963). Experimental and guasi-experimental designs for research. Boston: Houghton Mifflin. 
Campbell-Peralta, P.J. (1995, June). Reducing suspensions of minority mates through a group quidance/mentoring intervention program (Master of Science research report). Location: Nova Southeastern University. (ERIC Document Reproduction Service No. ED 394 094)

Carter, S. \& Herzog, B. (1997, February 18). Pupils, parents lobby for education money. The oregonian, pp. A1, A10.

Catterall, L.S. (1987, October/November). On the social costs of dropping out of school. The High School Journat, 20(1), 19-30.

Cave, G. \& quint, J. (1990) Career beginnings impact evaluation: A program for disadvantaged high school students. New York: Development Research Corporation.

CETA -- Education Linkage Unit. (1981). Secondary school dropouts. St. Paul: Minnesota Department of Education.

Clawson, J.G. (1980). Mentoring in managerial careers. In C.B. Derr (Ed.), Work, family and the career (pp. 144-165). New York: Praeger.

Clawson, J.G. (1985). Is mentoring necessary? Training and Development Journal, 39(4), 36-39.

Coleman, J.S. (1966). Equality of educational opportunity. Washington, DC: U.S. Government Printing office.

Cooke, D.R. (1965). A quide to educational research. Boston: Allyn and Bacon.

Cooper, C.C. (1985, spring). Mentors can serve black youth in many ways. The Journal of Negro Education, 54(2), 115-116.

Cox, J., \& Daniel, N. (1985, March-April). The role of the mentor. $\mathrm{G} / \mathrm{C} / \mathrm{T} /, \underline{37}(1), 33-36$.

Cuban, L. (1989, February). At-risk students: what teachers and principals can do. Educational Leadership, $46(5), 29-32$. 
Davis, H. (1988). A mentor program to assist in increasing academic achievement and attendance of at-risk ninth-grade students (Doctoral dissertation, University of Pittsburgh). Dissertation Abstracts International, 50(3), 0580A.

Di Rado, A. (1997, February 16) . Saving Hispanic students. The oregonian, pp. B1-B2.

Duke, D. (1985, June). What is excellence and should we try to measure it?, Phi Delta Kappan, 66 (10), 673.

Edlind, E.P., \& Haensly, P.A. (1985). Gifts of mentorships, Gifted Child ouarterly, 29 (2), 55-60.

Education Commission of the states. (1984). Task force on education for economic growth. Journal of Children in Contemporary society, 16(3-4), 11-47.

Education Commission of the states. (1985). Edu-gram. Salem: Oregon Department of Education.

Education Commission of the states, Business Advisory Commission. (1985). Reconnecting youth: The next stage of reform. Denver: ECS Distribution Center.

Eiseley, L.C. (1978). The star thrower. New York: Times Books.

Ellingson, M.K., Haeger, W.W., \& Feldhusen, J.F. (1986, March/April). The Purdue mentor program: A university-based mentorship experience for $\mathrm{g} / \mathrm{c} / \mathrm{t}$ children. $\mathrm{G} / \mathrm{C} / \mathrm{T}, \underline{9}(2), 2-5$.

Elliot, D.S., \& Voss, H.L. (1968). Delinguency and dropout. Lexington, $\mathrm{KY}$ : Lexington Books.

Epstein, L. , \& McPartland, M. (1978). Administration and technical manual for the QSL. Boston, MA: Houghton Mifflin Co.

Fehr, D.E. (1993, September). When faculty and staff mentor students in inner-city schools. Middle school Journal, 25(1), 65-67.

Ferguson, R. (1990). The case for community-based programs that inform and motivate black male youth. Washington, DC: Urban Institute. (ERIC Document Reproduction Service No. ED 336 458) 
Flaxman, E., \& Ascher, C. (1992). Mentoring in action: The efforts of programs in New York City. New York:

Institute for Urban and Minority Education, Teachers College, Columbia University.

Flaxman, E., Ascher, C., \& Harrington, C. (1988).

Mentoring programs and practices: Analysis of the

literature. New York: Institute for Urban and Minority Education, Teachers College, Columbia University.

Fraser, L.A. (1996, Winter). The Atlanta adopt-a-school program: Innovative interactions. Action in Teacher Education, $\underline{7}(4), 17-22$.

Freedman, M. (1988). Partners in growth: Elder mentors and at-risk youth. Philadelphia: Public/Private Ventures.

Freedman, M. (1991). The kindness of strangers:

Reflections on the mentoring movement. Philadelphia: Public/Private Ventures.

Frymier, J., \& Gansneder, B. (1989, October). The Phi Delta Kappa study of students at-risk. Phi Delta Kappan, 71(2), 142 .

Gadwa, K., Christenson, J., Bryan, E., \& Boeck, D. (1983, June). School dropout study: A final report. Lynnwood, WA: Edmonds School District, student Services Department.

Gay, L.R. (1987) . Educational research: Competencies for analysis and application. Columbus, OH: Merrill Publishing Company.

Gehrke, N.J. ( 1988 , January/February). On preserving the essence of mentoring as one form of teacher leadership. Journal of Teacher Education, $\underline{39}(1), 43-$ 45 .

Glass, R.S. (1991, Spring) - Opening windows for teenagers: How mentors can help. American Educator: The Professional Journal of the American Federation of Teachers, 15(1), 21-26.

Glasser, W. (1969). Schools without failures. New York: Harper and Row.

Goodlad, J.I. (1983). A place called school: Prospects for the future. New York: McGraw-Hill Book Co. 
Gordon, E.W. (1972). Work-study program: Project Stay. Washington, DC: National Center for Educational Communication DHEW/OE.

Gray, W. (1989, Summer). Advice on planning mentoring programs for at-risk youth. Mentoring International, $\underline{3}(3), 18-21$.

Gray, W.A., \& Gray M.M. (1986). Mentoring: An annotated bibliography of important references. Vancouver, BC: International Center for Mentoring.

Green, B.I. (1966). Preventing student dropouts. Englewood Cliffs, NJ: Prentice-Hall.

Green, K. \& Baker, A. (1986, June). Promising practices for high risk youth education and work program. Portland, OR: Northwest Regional Educational Laboratory.

Guba, E.G. (1978). Toward a methodology of naturalist inquiry in educational research. CAE Monograph Series in Evaluation, $\underline{8}(3), 16-21$.

Hahn, A., Danzberger, J., \& Lefkowitz, B. (1987). Dropouts in America: Enough is known for action. Washington, DC: Institute for Educational Leadership.

Hamilton, S.F. (1990). Linking up: Final report on a mentoring program for youth. Ithaca, NY: Cornell University, Dept. of Human Development and Family Studies. (ERIC Document Reproduction Service No. ED 324395 )

Hamilton, S.F., \& Hamilton, M.A. (1992, March). Mentoring programs: Promise and paradox. Phi Delta Kappan, 73 (7), 546-550.

Haring-Hidore, M. (1986, Fall). Developing mentoring programs for retention of high-risk students. Reading Improvement, 23(3), 239-244.

Harris, W. (1973). The early withdrawal of pupils from school: Its causes and its remedies. Addresses and journal of proceedings of the national education association (Vol. 3, pp. 260-271). Peoria: The National Education Association, Washington, DC. 
Harrison, J., \& Klopf, G.J. (1986). Dual perspectives of a mentoring relationship. In W.A. Gray \& M.M. Gray (Eds.), Mentoring: Aid to excellence in career development, business and the professions, Proceedings of the First International Conference on Mentoring. II, (pp. 60-65). Vancouver, BC: International centre for Mentoring.

Hathaway, W., Sheldon C., \& McNamara, P. (1989). The solution lies in the programs that work. In $D$. Capuzzi \&.R. Gross (Eds.), Youth at risk: A resource for counselors, teachers and parents (pp. 367-394). Alexandria, VA: American Association for Counseling and Development.

Henderson, N. (1996). Resiliency in schools: Making it happen for students and educators. Resiliency in action. Thousand Oaks, CA: Corwin Press, Inc.

Hershaff, S. (1980, Fall). Dropouts: A comparison of their general feelings of alienation and attitudes toward school with those of persisters. Southern Journal of Educational Research, 24(4), 274-276.

Hewitt, J.D., \& Johnson, W. (1979, March). Dropping out of "Middletown." High School Journal, 62 (6), 252-256. (ERIC Document Reproduction Service No. ED 215372 )

Higgins, C. (1991, Winter). I have a dream in Washington, DC (Initial Report). Philadelphia: Public/Private Ventures.

Hirschi, T. (1969). Causes of delinquency. Berkeley: University of California Press.

Hunt, N., \& Holt, B. (1979). The dropout report: Numbers of dropouts, current responses, recommendations. New York: New York City Public Schools.

Ianni, F.A.J. (1989). Providing a structure for adolescent development. Phi Delta Kappan, 70(9), 673-682.

Jacobi, M. (1991, Winter). Mentoring and undergraduate academic success: A literature review. Review of Educational Research, 61(4), 505-532.

Jensen, E. (1994). The learning brain. San Diego, CA: Turning Point Publishing. 
Jobs for the Future. (1996). Executive summary: A year of progress in school-to-careers system building. (Brochure). Boston: The Benchmark Communities Initiative, Jobs for the Future.

Jones, R. (1997, August) . [Interview with R. Jones, Director of oregon Department of Corrections, Department of Human Relations].

Kaplan, S. (1985, september). From gifted to general education: Exploring the spill-over effect, NASSP Bulletin, $69(482), 79-82$.

Kaufman, F., Harrel, G., Milam, C., Woolverton, N., \& Miller, J. (1986). The nature, role, and influence of mentors in the lives of gifted adults. Journal of Counseling and Development, 64(9), 576-578.

Kovalik, S., \& Olsen, K. (1994). Integrated thematic instruction: The model. Kent, WA: Susan Kovalik \& Assoc., Publishers.

Krupp, J.A. (1985, October). Mentoring: A means of sparking school personnel. Journal of Counseling and Development, 64(2), 154-155.

Kulik, C.C., \& Kulik, J.A. (1982). Effects of ability grouping on secondary school students: A meta-analysis of evaluation findings, American Educational Research Journal, 19(3), 415-428.

Kushman, J., \& Kinney, P. (1989). Understanding and preventing school dropouts. In D. Capuzzi \& D.R. Gross (Eds.), Youth at risk: A resource for counselors, teachers and parents (pp. 345-365). Alexandria, VA: American Association for Counseling and Development.

Lambert, S.E., \& Lambert, J.W. (1982, November/December) . Mentoring: A powerful learning device. $G / C / T /, 25(1)$, 12-13.

Lanier, P.R. (1986). A mentoring experience in the south Bronx: A successful strategy for conducting an innercity mentoring program. Mentoring: Aid to Excellence, $\underline{1}(2), 40-46$. 
Laughrey, M.C. (1990). The design and implementation of a mentor program to improve the academic achievement of black male high school students (Educational Specialist Practicum Report). Fort Lauderdale, FL: Nova Southeastern University. (ERIC Document Reproduction Service No. ED 328 647)

Lefkowitz, B. (1989). Tough change: Growing up on your own in America. New York: Free Press.

Levin, H. (1972). The costs of the nation of inadequate education (Report to the Select Committee on Equal Educational opportunity, United states Senate). Washington, DC: U.S. Government Printing office.

Levinson, D.J. (1978). The seasons of a man's life. New York: Alfred A. Knopf.

Lugg, C.A., \& Boyd, W.L. (1993) . Leadership for collaboration: Reducing risk and fostering resilience. Phi Delta Kappan, 75(3), 253-256.

MDC, Inc. (1985). The state's excellence in education commissions: Who's looking out for at-risk youth?. Prepared for the Charles stewart Mott Foundation. Chapel Hill, NC: Author.

Mahan, G., \& Johnson, C. (1983, April). Portrait of a dropout: Dealing with academic, social, and emotional problems. NASSP Bulletin, 67(462), 80-83.

Martin, D.L. (1980). A study of the family, personal, and subjective characteristics of school dropouts in Kentucky (Doctoral dissertation, University of Kentucky) . Dissertation Abstracts International, $41(08), 3357 \mathrm{~A}$.

Mayeske, G.W. (1973). A study of the achievement of our nation's students. Washington, DC: U.S. Department of HEW Publication.

MCDill, E., Nafriello, G., \& Pallas, A. (1987). The high cost of high standards: School reform and dropouts, article in hot topic series Dropouts, Pushouts and other Casualties. Bloomington, IN: Center on Evaluation, Development, Research of Phi Delta Kappa, pp. 183-209. 
McPartland, J.M., \& Nettles, S.M. (1991, August). Using community adults and advocates for at-risk middle school students: A two-year evaluation of Project RAISE. The American Journal of Education, 99(4), 568586 .

Meier, D. (1995). The power of their ideas. New York: Beacon Press.

Mernit, S. (1990). Kids today. Instructor, 100(2), 35-36, 41-43.

Mosqueda, P.F. (1990). Mentoring young people makes a difference. Denver, Co: Education Commission of the States. (ERIC Document Reproduction Service No. ED 317 945)

Nafriello, G., McDill, E.L., \& Pallas, A.M. (1985, September). School reform and potential dropouts, Educational Leadership. Journal of the Department of Supervision and Curriculum Development, 43(1), 10-14.

National Association of Secondary school Principals. (1988). The practitioner: A newsletter for the on-line administrator, $15(2), 1-4$.

National Center for Education Statistics. (1995a). The condition of education, 1994. Washington, DC: U.S. Department of Education, office of Educational Research and Improvement. (ERIC Document Reproduction Service No. ED 381 685)

National Center for Education Statistics. (1995b). (Report No: NCES-95-720). Washington, DC. (ERIC Document Reproduction Service No. ED 382 756)

National Center for Education Statistics. (1996). Dropout rates in the United States: 1994. Washington, DC: U.S. Department of Education: Office of Educational Research and Improvement.

National Coalition of Advocates for Students. (1986). Barriers to excellence: Our children at risk. Boston, MA: Author.

National Commission on Excellence in Education. (1983) . A nation at risk: The imperative for educational reform. Washington DC: U.S. Government Printing office. 
National Foundation for the Improvement of Education. (1986). A blueprint for success: Operation rescue. Washington, DC: Author. (ERIC Document Reproduction Service No. ED 274 093)

New York Public Schools. (1979). The dropout report. Brooklyn: Board of Education, City of New York.

Nichols, C.E. (1984). The development of a dropout prediction instrument for an urban high school (Doctoral dissertation, University of Pennsylvania). Dissertation Abstracts International, 44, 3564A.

Ohio State Department of Education. (1983). Reducing dropouts in Ohio schools: Guidelines and promising practices, a quide to drop out prevention, intervention and remediation. Columbus: Ohio state Department of Education. (ERIC Document Reproduction Service No. ED 262316 )

Oregon Department of Education. (1980). Oregon early school leavers study. Salem, OR: Author.

Oregon Department of Education. (1997). Oregon early school leavers study. Salem, OR: Author.

Outen, D. (1989, Summer). The mentor project: Aid for teachers and students. Mentoring International, 3 (3), $35-42$.

Pallas, A. (1986). School dropouts in the United States. In J.D. Stem \& M.F. Williams (Eds.), The condition of education (pp. 158-174). Washington, DC: United States Government Printing office.

Parkay, F.W. (1988, Summer). Reflections of a protege, Theory into Practice, 27(3), 196-200.

Parnell, D. (1985). The neqlected majority. Washington, DC: The Community college Press.

Patton, M.Q. (1990). Qualitative evaluation and research methods (2nd ed.). Newbury Park, CA: Sage Publications, Inc.

Peng, S.S. \& Takai, R.T. (1983, November). High school dropouts: Descriptive information from high school and beyond. National Center for Educational statistics Bulletin, pp. 1-9. (ERIC Document Reproduction Service No. ED 236 366) 
Phillips, L.L. (1977). Mentors and proteges: A study of the career development of women managers and executives in business and industry. Unpublished doctoral dissertation, University of California at Los Angeles.

Phillips-Jones, L. (1983) . Mentors and proteges. New York: Arbor House.

Poole, M.E. (1994, summer). The schools adolescents would like. Adolescence, $19(74), 447-458$.

Portland Leaders Roundtable Planning Project. (1986). Working papers: Ingredients of a comprehensive system for at-risk youth. Portland, OR: Portland Public Schools.

Presseisen, J.L. (1985). Unlearned lessons: Current and past reforms for school improvement. Philadelphia: The Falmer Press.

Research and Policy Committee of the Committee for Economic Development. (1987). Children in need: Investment strategies for educationally disadvantaged. New York: NYNEX Foundation.

Rhodes, D.C., \& McMillan, S.H. (1987). Refocusing schools for dropout prevention: With implications for teacher education. Washington, DC: National Foundation for Improvement of Education. (ERIC Document Reproduction Service No. ED 277 698)

Richardson, H.B. (1987, Fall). Bronx Community College and the student mentor program for at-risk high school students. Community Review, $\underline{8}(1), 33-37$.

Robertson, E. (1991). Neglected dropouts: The gifted and talented. Equity and Excellence, 25(1), 62-74.

Rosenbaum, J.E. (1980). Social implications of educational grouping. Review of Research in Education, $\underline{8}$, 361-401.

Sappington, J.P. (1979). The predictive strength of nine school related indicators for distinquishing potential dropouts (Doctoral dissertation, US International University). Dissertation Abstracts International, 41, $2944 \mathrm{~A}$. 
Schein, E. (1978). Career dynamics: Matching individual and organizational needs. Reading, MA:

Addison-Wesley.

Schonert-Reichl, K.A. (1992). Seeking help and social support in adolescence: The role of non-related adults. New York: Columbia University. (ERIC Document Reproduction Service, No. ED 354 295)

Schrieber, D. (1964). Guidance and the school dropout. Washington, DC: American Personnel and Guidance Association.

Schwartz, w. (1995, August). School dropouts: New information about an old problem. (ERIC/CUE Digest, 109). New York: ERIC Clearinghouse on Urban Education. (ERIC Document Reproduction Service No. ED 386 515)

Self, T.C. (1985, April). Dropouts: A review of literature. Monroe: Project Talent Search, Northeast Louisiana University.

Shavelson, R.J. (1996). Statistical reasoning for the behavioral sciences (3rd ed.). Boston: Allyn and Bacon.

Sheehy, G. (1976). Passages: Predictable crises of adult life. New York: Dutton.

Sizer, T.B. (1984) - Horace's compromise: The dilemma of the American high school today. Boston: Houghton Mifflin.

Slater, G. (1997). Employment and education. Salem: oregon State Department of Labor.

Slicker, E.K., \& Palmer, D.J. (1993, May). Mentoring atrisk high school students: Evaluation of a schoolbased program. School Counselor, 40(5), 327-334.

Smink, J. (1990). Mentoring programs for at-risk youth: A dropout prevention research report. Clemson, SC: National Dropout Prevention Center. (ERIC Document Reproduction Service No. ED 318 931)

Stanwyck, D.J., \& Anson, C.A. (1989). The adopt a student evaluation project final report. Atlanta: Georgia State University, Department of Educational Foundations. 
Stradford, C.W. (1993, June). Implementation of a rural program to reduce the dropout rate of $9 \mathrm{th}$ and $10 \mathrm{th}$ grade at-risk students. Practicum. Fort Lauderdale, FL: Nova Southeastern University. (ERIC Document Reproduction Service No. ED 368 527)

Thesaurus of ERIC Desriptors. (1990). Twelfth Edition. Oryx Press, Phoenix, Az; 161.

Timberlake, C. (1980, June). Why do students dropout of School?: A selected and related literature review. Syracuse: Syracruse University. (ERIC Document Reproduction Service No. ED 189 502)

Torrance, E. (1983). Role of mentors in creative achievement. The Creative Child and Adult Quarterly, $8,(18), 8-15$.

U.S. Department of Education. (1992). One-on-one: A quide for establishing mentor programs. Washington, DC: U.S. Department of Education.

U.S. Department of Labor. (1992). Learning a living: A blueprint for high performance. Washington, DC: Secretary's Commission on Achieving Necessary skilis (SCANS) .

Vaillant, G.E. (1977). Adaptation to life. Boston: Little Brown.

Voss, H.C., Wendling, A., \& Elliot, D.S. (1966, April). Some types of highschool dropouts, The Journal of Educational Research, 59(8), 360-367.

Weber, J.E., \& Silani-Lacey, C. (1983). Building basic skills: The dropout (Research and Development Series No. 236) . Columbus, OH: National Center for Research in Vocational Education. (ERIC Document Reproduction Service No. CE 036 465)

Wehlage, G. (1983). Effective programs for the marginal high school student. Bloomington, IN: Phi Delta Kappa. (ERIC Document Reproduction Service No. ED 235 132)

Wehlage, G. \& \& Rutter, R.A. (1986, Spring) - Dropping out: How much do schools contribute to the problem? Teachers College Record, 87(3), 374-392. 
Wehlage, G., Rutter R.A., \& Turnbaugh, A. (1987, March) . A program model for at-risk high shool students, Educational Leadership, 44(6), 70-73.

Werner, E.E., \& Smith, R.S. (1982). Vulnerable but not invincible: A longitudinal study of resilient children and youth. New York: McGraw-Hill.

Werner, E.E., \& Smith, R.S. (1992) - Overcoming the odds: High risk children from birth to adulthood. New York: Cornell University Press.

Wiersma, w. (1969). Research methods in education. Philadelphia: J.B. Lippincott Company.

Wiles, K. (1963). The changing curriculum of the American high school. New Jersey: Prentice-Hall, Inc.

Wolin, S., \& Wolin, S. (1993). The resilient self: How survivors of troubled families rise above adversity. New York: Random House.

Wrenn, C. (1967). The dropout and the school counselor. In D. Schreiber (Ed.), The school dropout (pp. 192-205). New York: Vantage Books. 
APPENDIX A

QSL ITEM CHARACTERISTICS 
TÄEิLE $\varepsilon$

QSL Item Characteristics

\begin{tabular}{|c|c|c|c|c|}
\hline Item & $\underset{1 / 0^{-S}}{\operatorname{Scoring}}$ & $\begin{array}{l}\text { Mean of } \\
\text { Seored } \\
\text { tiem }\end{array}$ & $\begin{array}{c}\text { Itam-to- } \\
\text { Subscale } \\
\text { Corretation }\end{array}$ & $\begin{array}{l}\text { Iiem-to- } \\
\text { Total Scale } \\
\text { Correlation }\end{array}$ \\
\hline \multicolumn{5}{|l|}{ A. Satistaction with School (SAT) } \\
\hline $\begin{array}{l}\text { I enjoy the work I do in class. (24) } \\
\text { The school and I are like: Good friends: Friends. /Distant relatives. } \\
\text { Strangers: Enemies. (19) }\end{array}$ & $\begin{array}{l}\text { AOISSN } \\
\text { MC }\end{array}$ & .35 & $\begin{array}{l}67 \\
.74\end{array}$ & $\begin{array}{l}62 \\
63\end{array}$ \\
\hline I like school very much (11) & TIF & 42 & .83 & 67 \\
\hline I am very happy when I am in school. (7) & T/F & 42 & 80 & 61 \\
\hline Most of the time I do not want to go to senool. (3) & $T / F$ & 54 & 71 & 57 \\
\hline \multicolumn{5}{|l|}{ B. Commitment to Classwork (COM) } \\
\hline Work in class is just busy work and a waste of lime. (25) & SNAAOS & 50 & .63 & 48 \\
\hline School work is dull and bonng to me. (27) & SN/AOS & .34 & 58 & 56 \\
\hline In class, I ohen count the minutes till it ends. (1) & $\mathbf{F} \pi$ & 40 & .54 & 49 \\
\hline I hardly ever do anything exciting in class. (5) & $\mathbf{F} \pi$ & .48 & .68 & 68 \\
\hline I daydream a lot in class. (9) & $F \pi$ & .68 & 49 & 40 \\
\hline $\begin{array}{l}\text { In my classes I get so interested in an assignment or project that I don't } \\
\text { want to stop work Everyday: quite ohen; mardly ever. never. (17) }\end{array}$ & MC & .42 & .56 & 47 \\
\hline $\begin{array}{l}\text { The work i do in most classes is: Very important to me; tpretry important } \\
\text {...: not too...: not at all important to me. (20) }\end{array}$ & MC & .21 & .53 & 45 \\
\hline $\begin{array}{l}\text { Most of the lopics we study in class can't end soon enough to } \\
\text { suit tme. (13) }\end{array}$ & $F \pi$ & 46 & 50 & 45 \\
\hline $\begin{array}{l}\text { The things I get to work on in most of my classes are: Great stuth-really } \\
\text { interesting io me: Good stuft pretty interesting to me: 1OK-school } \\
\text { work is school work: Dull stuth-not very inleresting to me. } \\
\text { Trasth- total loss lor me. (22) }\end{array}$ & MC & 41 & 71 & 67 \\
\hline $\begin{array}{l}\text { If you could choose to take any courses at all, how many of your present } \\
\text { courses would you take? All; More than hali: IADout half. Fewer than } \\
\text { half: None. (23) }\end{array}$ & MC & 48 & 58 & 57 \\
\hline $\begin{array}{l}\text { This term I am eager to get to: All my classes: Most.. . I Hall... } \\
\text { One or ino...: None of my classes. (15) }\end{array}$ & MC & 53 & 63 & .60 \\
\hline \multicolumn{5}{|l|}{ C. Rexctions to Teachers (TCH) } \\
\hline I wish I could have the same teachers next yeat. (2) & $T / F$ & .38 & 52 & 46 \\
\hline $\begin{array}{l}\text { How would you rate the ability of most of your teachers compared to } \\
\text { teachers in other schools at your grade level? My teachers are. } \\
\text { Far above average: Above average: I Average: Below. } \\
\text { Far below average. (16) }\end{array}$ & MC & 47 & 54 & 51 \\
\hline $\begin{array}{l}\text { Thinking of my teachers this term. I really like. All of them: Most.... } \\
\text { i Hall...: One or two...: None... (18) }\end{array}$ & MC & 53 & 65 & 64 \\
\hline $\begin{array}{l}\text { This term my teachers and I are: On the same wave length. On the } \\
\text { same planet: / Somewhere in the same solar system; in two } \\
\text { diflerent worlds. (21) }\end{array}$ & MC & 62 & 56 & 51 \\
\hline $\begin{array}{l}\text { Most of my teachers want me to do inings their way and } \\
\text { not my own way. (4) }\end{array}$ & $F \pi$ & 34 & .50 & 41 \\
\hline $\begin{array}{l}\text { Most of my teachers do not like me to ask a lot of questions ouring a } \\
\text { lesson. (14) }\end{array}$ & Fr & 60 & 46 & 34 \\
\hline Most of my teachers really listen to what I nave to say $(8)$ & $T / F$ & 67 & 59 & 46 \\
\hline Teachers here have a way with students that makes me like them (12) & $T / F$ & 48 & S5 & 46 \\
\hline I teel I can go to my teacher with the things that ate on my mind (26) & AOISSN & 21 & 41 & .37 \\
\hline $\begin{array}{l}\text { Cenain sudents in my class are favored by my teachers more than the } \\
\text { rest. (10) }\end{array}$ & $F \pi$ & 24 & 38 & 30 \\
\hline $\begin{array}{l}\text { My teachers in this school often ect as it they are atways right and I } \\
\text { am wrong. (6) }\end{array}$ & $F \pi$ & 45 & .57 & 46 \\
\hline $\begin{array}{l}\text { D. Quality of School Lite (OSL) } \\
\text { The total scale is comprised of the } 27 \text { items irom ine inree scales Iisied } \\
\text { above. }\end{array}$ & & & & \\
\hline
\end{tabular}

(Epstein \& McPartland, 1978, p. 15) 
APPENDIX B

MENTOR (STAFF) CAKE SURVEY 
Dear Milwaukie C.A.K.E. Participant,

Your response to this survey is necessary to complete the feedback we have been gathering on the C.A.K.E. mentor program at Milwaukie High School.

The feedback from this survey will give us information on how to improve our mentor program next year.

All questionaires are coded to assist us in the data collection process. However, the information from the questionaires will be compiled in such a way as to not identify any one individual who has completed a form; your response will be confidential and used only for data collection. 


$$
\text { code number }
$$

A QUESTIONAIRE DESIGNED TO GATHER DESCRIPTIVE DATA CONCERNING THE MENTORSHIP PROGRAM AT MILWAUKIE HIGH SCHOOL (CAKE)

DIRECTIONS: PLEASE ANSWER EACH OF THE FOLLOWING QUESTIONS BY MARKING DIRECTLY ONTO THE SURVEY FORM. PLEASE RETURN THIS QUESTIONAIRE TO GAIL HAYES.

APPRECIATE YOUR WILLINGNESS TO SHARE YOUR THOUGHTS CONCERNING THIS MENTOR PROGRAM.

\section{SECTION I}

1. Were you a mentor in the mentorship program, C.A.K.E.?

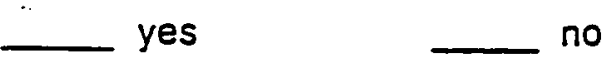

PLEASE CIRCLE THE NUMBER THAT APPLIES FOR EACH OF THE FOLLOWING QUESTIONS BY USING THIS SCALE:
1 = very satisfied
2 = satisfied
$3=$ neutral
4 = dissatisfied
5 = very dissatisfied

2. How would you rate your participation in the CAKE mentorship program?
1
2
3
4
5

3. How would you rate the program's value in helping students develop a positive attitude towards school?
1
2
3
4
5

4. Was your mentee in a class taught by you during your participation in C.A.K.E.? 
PLEASE CIRCLE THE NUMBÉR THAT APPLIES FOR EACH OF THE FOLLOWING QUESTIONS BY USING THIS SCALE:

$$
\begin{array}{ll}
1=\text { strongly agree } & 2=\text { agree } \quad 3=\text { undecided } \\
4=\text { disagree } & 5=\text { strongly disagree }
\end{array}
$$

5. Answer only one: $5 A$ or $5 B$
A. Was the fact that the mentee (student) was in one or more classes taught by the mentor helpful?
12
3
4
5
8. Was the fact that the mentee (student) was not in class taught by the mentor helpful?

$\begin{array}{lllll}1 & 2 & 3 & 4 & 5\end{array}$
Please briefly explain why (optional):

6. Were you and your mentee well-matched with respect to interests? Circle the number that applies.
1
2
3
4
5

7. Was time available during the school day a negative factor in your mentoring experience?

$\begin{array}{lllll}1 & 2 & 3 & 4 & 5\end{array}$

Please explain briefly: 
8. Did you explain the C.A.K.E. mentorship program to your mentee? yes no

Please explain briefly:

9. Which of the following best describes the frequency with which you met (face-to-face) with your mentee? Check the one answer that applies.

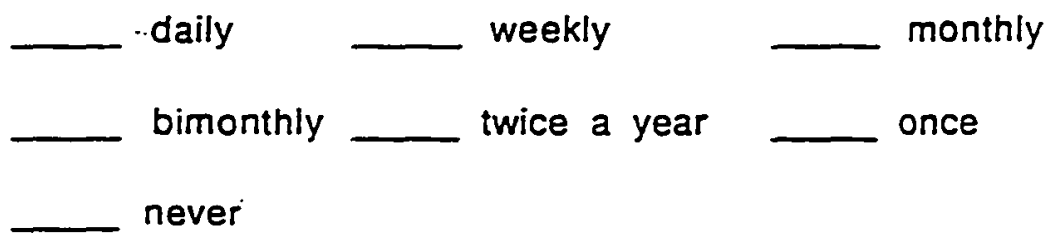

10. Who initiated most of the meetings?

$$
\text { mentor } \quad \text { mentee }
$$

11. Which of the following communication did you have with your mentee?

11.A notes of encouragement

11.8 birthday card

11.C congratulations on grades/attendance

11.D special occasion card (Christmas, Thanksgiving, Valentines, etc.) other (please explain) 
12. Which of the following did you participate in with your mentor?

12.A lunch at school

12.8 lunch or dinner off campus

12.C attend an after school activity together

12.D visit your mentee's home

Please explain briefly:

13. Did you have communication with the mentee's guardian/parent(s)? yes no

If "yes" what kind of communication did you have with parents? Check one box used most frequently.

13.A

13.B letter

13.C phone call face to face meeting

14. Please rate the topics discussed in any meetings you have had with your mentee? Please rate them " 1 " thru " 6 " with " 1 " = most times and $" 6 "=$ least times.

$$
\begin{aligned}
& \text { progress in class(es) } \\
& \text { family issues } \\
& \text { teacher issues } \\
& \text { help with homework } \\
& - \text { friends } \\
& \text { involvement in activities }
\end{aligned}
$$


15. PLEASE INDICATE IN RÁNK ORDER WHICH OF THE FOLLOWING WERE YOUR EXPECTATIONS AS YOU BEGAN, AND YOUR PERCEPTIONS OF THE OUTCOMES AS YOU ACTUALLY EXPERIENCED AS A PARTICIPANT IN THE MENTORSHIP PROGRAM. PLACE THE NUMBER " 1 " NEXT TO YOUR HIGHEST EXPECTATION IN THE COLUMN LABELED OUTCOMES, ETC. THE NUMBER "5" SHOULD BE PLACED NEXT TO THE EXPECTATION AND THE OUTCOME THAT YOU CONSIDERED TO BE OF LEAST IMPORTANCE.

Expectations Outcomes

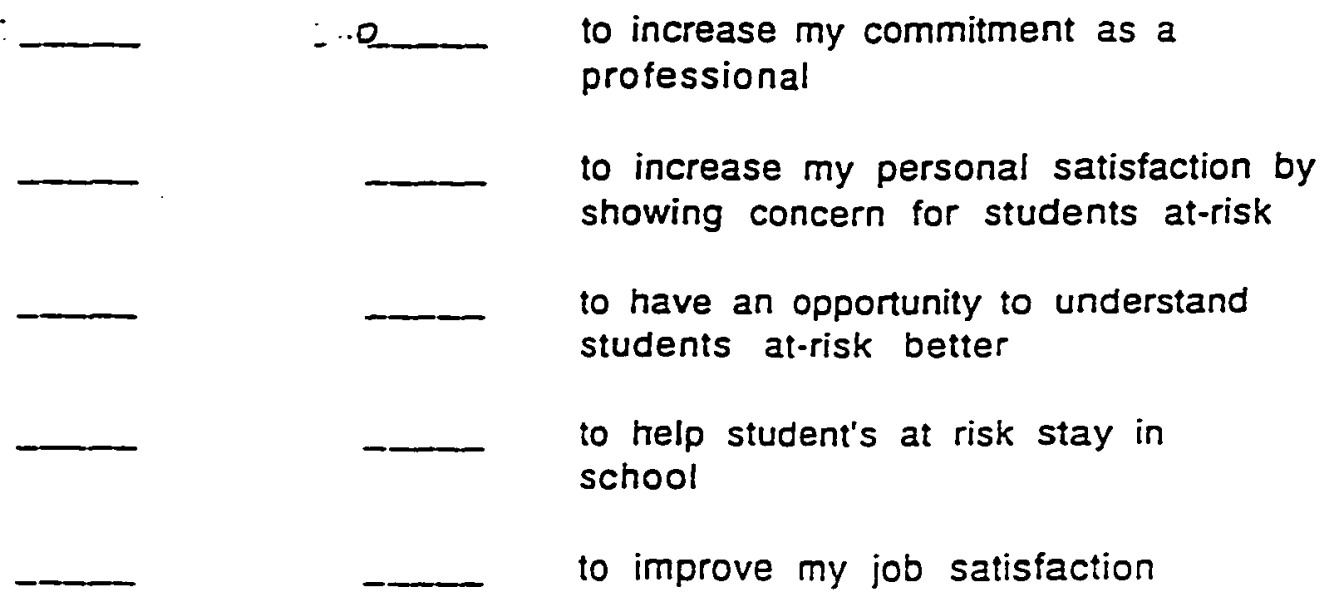

THE NEXT SERIES OF QUESTIONS WILL REQUIRE A "YES" OR "NO" RESPONSE. FROM YOU. PLEASE CHECK IN THE SPACE PROVIDED.

16. Did you provide feedback to your mentee about his/her performance in school?

yes

17. Did you receive training or any inservice on mentoring prior to participation in the program?

yes no 
18. PLEASE INDICATE IN RÁNK ORDER WHICH OF THE FOLLOWING WERE YOUR EXPECTATIONS/NEEDS AS PART OF INSERVICE TRAINING AND WHAT YOU ACTUALLY RECEIVED IN INSERVICE. PLACE THE NUMBER " " NEXT TO YOUR HIGHEST NEED IN THE COLUMN LABELED NEED AND " $9 "$ BEING OF LEAST IMPORTANCE.

Needlexp Qutcome

at-risk student behavior
laws surrounding student/eacher activities
other mentorship programs
-

19. Is your mentee(s) still in school?

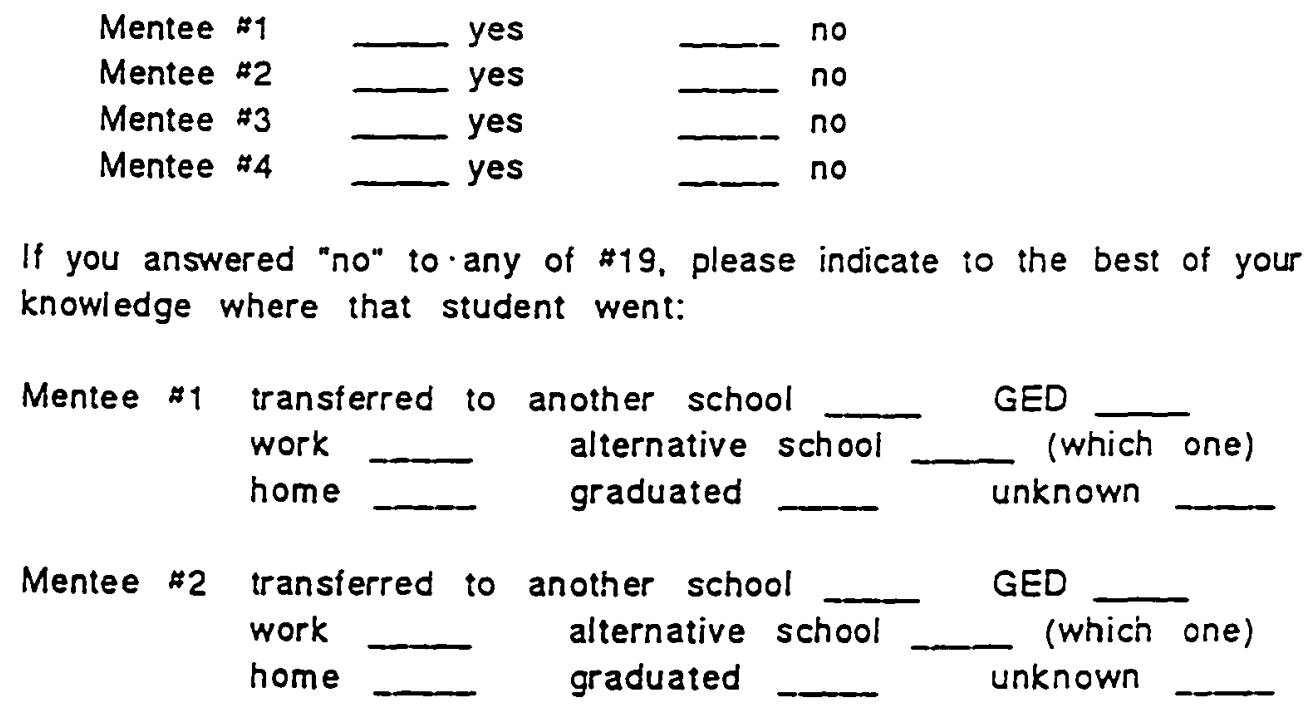




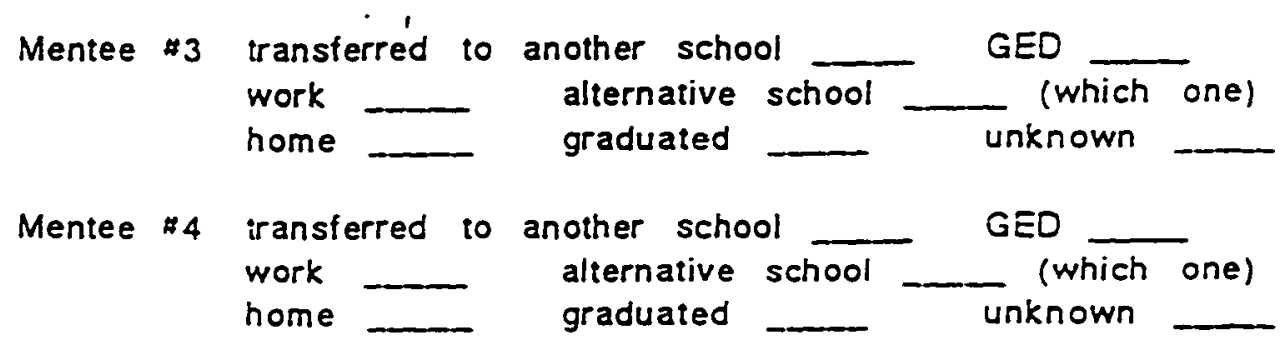

20. If your mentee left school, did you counsel him or her as to their plans?

- yes _- no

21. Please rank order the following attributes that you consider to be important to the success of any mentorship program. ("1" being the highest, etc.)

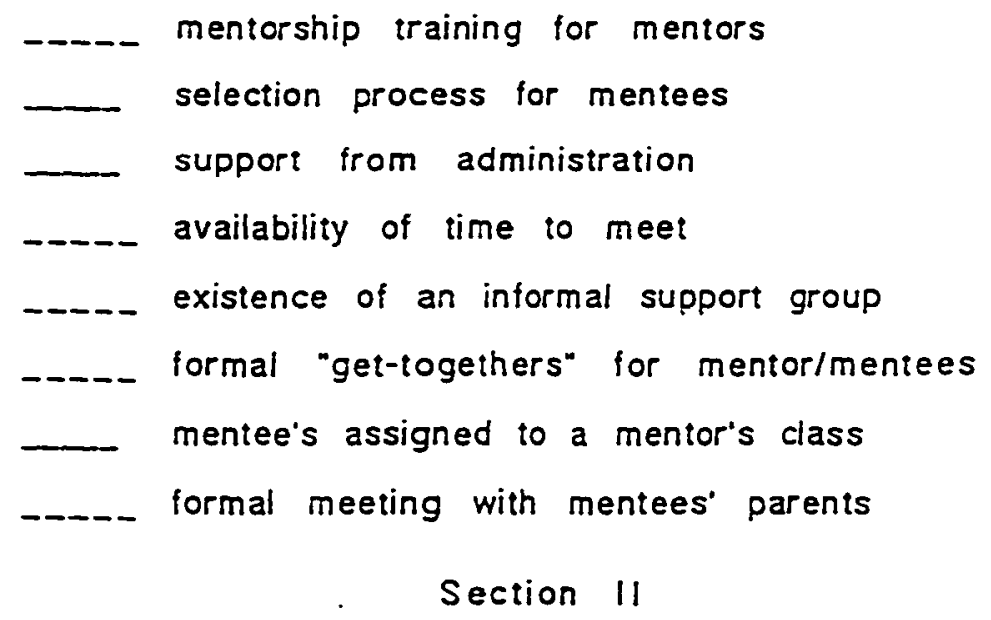

THIS LAST SECTION OF THE QUESTIONAIRE ASKS DEMOGRAPHIC OUESTIONS FOR STATISTICAL PURPOSES ONLY. AGAIN, YOUR RESPONSES WILL BE CONFIDENTIAL: DATA WILL BE COMPILED IN SUCH A WAY AS TO NOT IDENTIFY ANY ONE INDIVIDUAL WHO COMPLETES THE FORM.

22. Describe your professional status.

___ administrative _._._ certified _.... classified 
23. How long have you been in your present position?

- years

24. How would you rate your career satisfaction? Please circle the number that applies using the following scale: $1=$ very satisfied: 2 = satisfied; 3 = neutral: 4 = dissatisfied: 5 = very dissatisfied .

$\begin{array}{lllll}1 & 2 & 3 & 4 & 5\end{array}$

25. Please indicate your highest level of education attained.

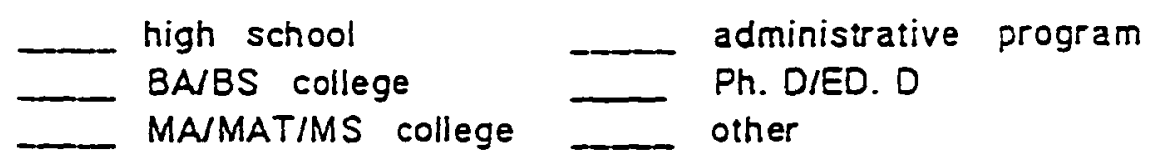

26. As a participant in the C.A.K.E. program. what year (or years) were you a mentor?

1989-90 _ 1990-91 1991-92

27. Do you have or have you ever had an informal mentor or sponsor in your career?

yes ㄴ. no

Please explain briefly:

28. If a certified staff member, please check your appropriate content area:

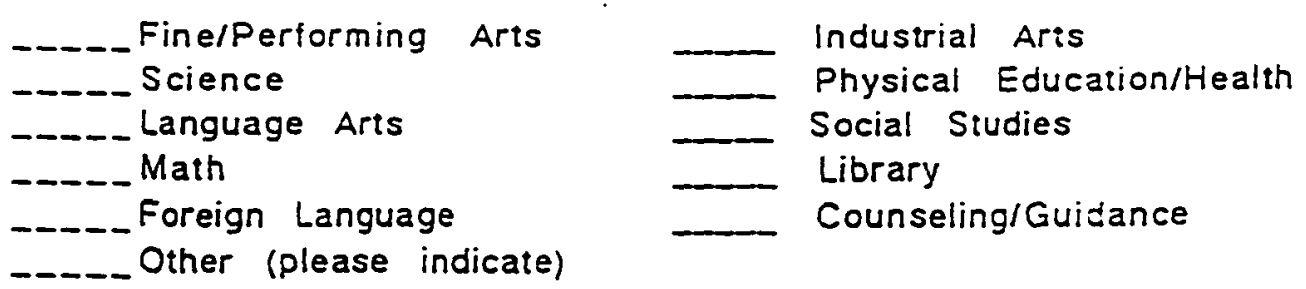


If a classified staff member. please indicate your area:

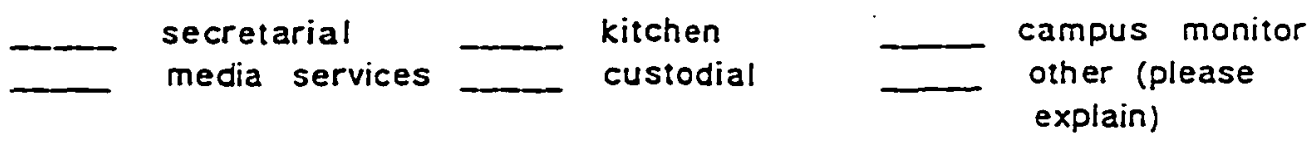

29. Please check you appropriate age category:

$\begin{array}{llll}- & 20-24 \\ - & 25-29 & 45-49 \\ - & 30-34 & & 50-54 \\ - & 35-39 & 55-59 \\ - & 40-44 & & \end{array}$

30. Please indicate your racial/ethnic group:

\begin{tabular}{ll} 
Native American & Asian American \\
\hdashline- Aírican American Hispanic \\
\hline Caucasian/White & Other
\end{tabular}

31. Please check the appropriate category:

male

female

Any additional comments:

(Suggestions to make the CAKE program better. more efective?) 
APPENDIX C

MENTEE (STUDENT) CAKE SURVEY 
Dear Milwaukie C.A.K.E. Participant.

Your response to this survey is necessary to complete the feedback we have been gathering on the C.A.K.E. mentor progam at Milwaukie High School.

The feedback from this survey will give us information on how to improve our mentor program next year.

All questionaires are coded to assist us in the data collection process. However, the information from the questionaires will be compiled in such a. way as to not identify any one individual who has completed a form: your response will be confidential and used only for data collection. 
code number

A QUESTIONAIRE DESIGNED TO GATHER DESCRIPTIVE DATA CONCERNING THE MENTORSHIP PROGRAM AT MILWAUKIE HIGH SCHOOL (CAKE)

DIRECTIONS: PLEASE ANSWER EACH OF THE FOLLOWING QUESTIONS BY MARKING DIRECTLY ONTO THE SURVEY FORM. PLEASE RETURN THIS OUESTIONAIRE TO GAIL HAYES. APPRECIATE YOUR WILLINGNESS TO SHARE YOUR THOUGHTS CONCERNING THIS MENTOR PROGRAM.

\section{SECTION I}

1. Were you a mentee in the mentorship program. C.A.K.E.?

$$
\text { yes }
$$$$
\text { no }
$$

PLEASE CIRCLE THE NUMBER THAT APPLIES FOR EACH OF THE FOLLOWING QUESTIONS BY USING THIS SCALE:
1 = very satisfied
2 = satisfied
$3=$ neutral
4 = dissatisfied
5 = very dissatisfied

2. How would you rate your participation in the CAKE mentorship program?

$$
\begin{array}{lllll}
1 & 2 & 3 & 4 & 5
\end{array}
$$

very satisfied satisfied. neutral dissatisfied very dissatisfied

3. How would you rate having a mentor at Milwaukie helpful to your development towards a positive attitude towards school?

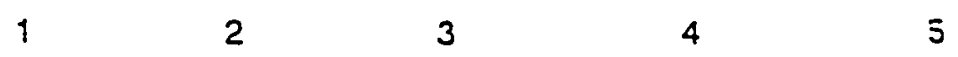

very satisfied satisfied neutral dissatisfied very dissaisfied 
4. Were you in any of your mentor's class(es)?

PLEASE CIRCLE THE NUMBER THAT APPLIES FOR EACH OF THE FOLLOWING OUESTIONS BY USING THIS SCALE:

$$
\begin{array}{ll}
1=\text { strongly agree } & 2=\text { agree } \quad 3=\text { undecided } \\
4 \text { = disagree } & 5=\text { strongly disagree }
\end{array}
$$

5. Answer only one: $5 A$ or $5 B$

A. Was the fact that you were in your mentor's class helpful?

$\begin{array}{ccccc}1 & 2 & 3 & 4 & 5 \\ \text { strongly agree } & \text { agree } & \text { undecided } & \text { disagree } & \text { strongly disagree }\end{array}$

B. Was the fact that you were not in a class taught by your mentor helpful?

$\begin{array}{ccccc}1 & 2 & 3 & 4 & 5 \\ \text { strongly agree } & \text { agree } & \text { undecided } & \text { disagres } & \text { stongly disagree }\end{array}$

Please briefly explain why (optional):

6. Were you and your mentor well-matched with respect to interests? Circle the number that applies.

$\begin{array}{ccccc}1 & 2 & 3 & 4 & 5 \\ \text { strongly agree } & \text { agree } & \text { undecided } & \text { disagrce } & \text { strongly disagree }\end{array}$


7. Was time available during the school day a negative factor in your mentee experience?

$\begin{array}{ccccc}1 & 2 & 3 & 4 & 5 \\ \text { strongly agree } & \text { agree } & \text { undecided } & \text { disagree } & \text { stongly disagree }\end{array}$

Please explain briefly:

8. Were you told that you were a part of the mentor program?

yes $\quad$ no

If not, how did the mentor explain their interest in how you were doing in school. Would you want to know if you had a mentor?

9. Which of the following best describes the frequency with which you met (face-to-face) with your mentor? Check the one answer that applies.

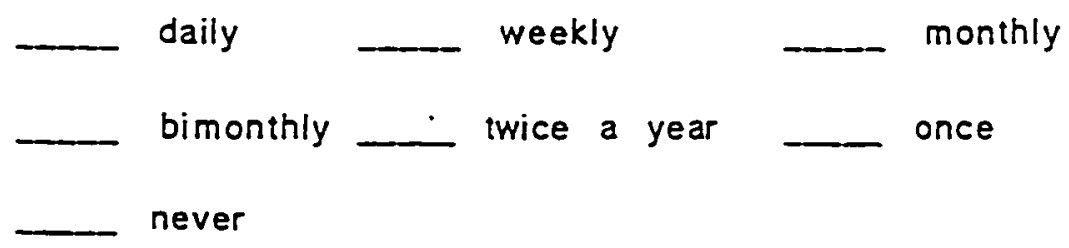

10. Who initiated most of the meetings?

-_ mentor __ mentee (you) 
11. Which of the following communication did you receive from your mentor?

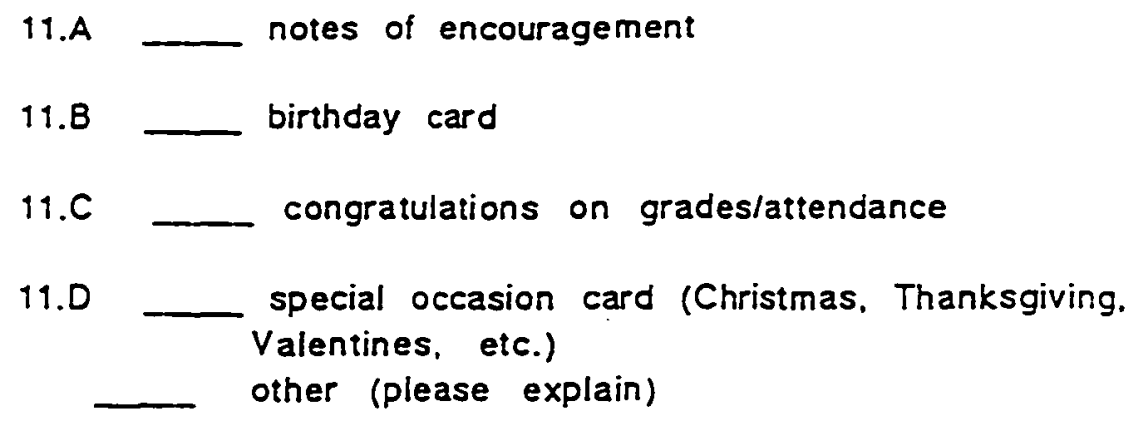

12. Which of the following did you participate in with your mentor?

12.A lunch at school

12.8 lunch or dinner off campus

12.C attend an after school activity logether

12.D visit your home

Please explain briefly:

13. Did your mentor have communication with your guardian/parent(s)? _- yes __ no

If "yes" what kind of communication with parents? Check one box used most frequently.
13.A letter
13.B phone call
13.C face to face meeting 
14. Please rate the topics' discussed in any meetings you have had with your mentor? Please rate them ${ }^{\prime \prime}{ }^{\prime \prime}$ thru $" 7^{\prime \prime}$ with $"{ }^{\prime \prime}=$ most times and ${ }^{7 "}=$ least times.

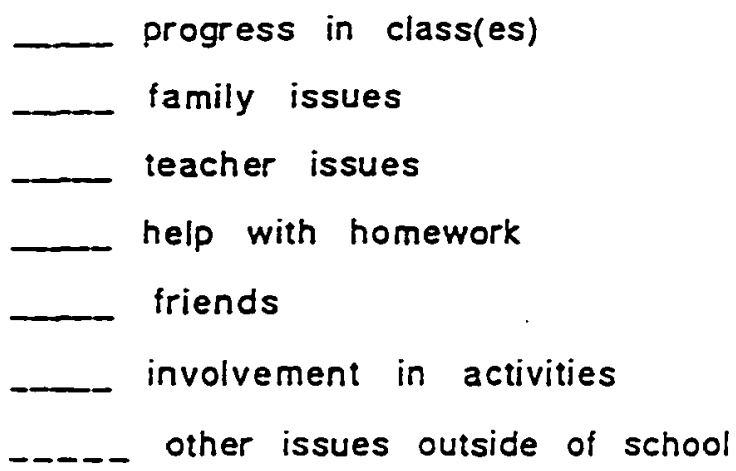

15. PLEASE INDICATE IN RANK ORDER WHICH OF THE FOLLOWING WERE YOUR EXPECTATIONS AS YOU BEGAN, AND YOUR PERCEPTIONS OF THE OUTCOMES AS YOU ACTUALLY EXPERIENCED AS A PARTICIPANT IN THE MENTORSHIP PROGRAM. PLACE THE NUMBER " 1 " NEXT TO YOUR HIGHEST EXPECTATION IN THE COLUMN LABELED OUTCOMES. ETC. THE NUMBER " 5 " SHOULD BE PLACED NEXT TO THE EXPECTATION AND THE OUTCOME THAT YOU CONSIDERED TO BE OF LEAST IMPORTANCE.

Expectations Outcomes

to better understand the workings of a
large high school


THE NEXT OUESTION WILL REOUIRE A "YES" OR "NO" RESPONSE FROM YOU. PLEASE CHECK IN THE SPACE PROVIDED.

16. Did you receive feedback from your mentor about your performance in school?

$$
\text { yes } \quad \text { no }
$$

PLEASE CIRCLE THE NUMBER THAT APPLIES FOR EACH OF THE FOLLOWING QUESTIONS BY USING THIS SCALE:

$$
\begin{array}{ll}
1=\text { strongly agree } & 2=\text { agree } \quad 3=\text { undecided } \\
4=\text { disagree } & 5=\text { strongly disagree }
\end{array}
$$

17. Having a mentor in high school has made a positive difference in how 1 am performing in school.

$\begin{array}{ccccc}1 & 2 & 3 & 4 & 5 \\ \text { strongly agree } & \text { agree } & \text { undecided } & \text { disagree } & \text { strongly disagree }\end{array}$

18. I feel as though 1 can go to my mentor anytime I need help.

$\begin{array}{ccccc}1 & 2 & 3 & 4 & 5 \\ \text { strongly agice } & \text { agree } & \text { undecided } & \text { disagrce } & \text { strongly disagree }\end{array}$

19. I was able to talk to my mentor most of the time I needed to.

$\begin{array}{ccccc}1 & 2 . & 3 & 4 & 5 \\ \text { strongly agree } & \text { agree } & \text { undecided } & \text { disagree } & \text { strongly disagree }\end{array}$

20. Compared to last year, I am doing better this year.

$\begin{array}{ccccc}1 & 2 & 3 & 4 & 5 \\ \text { strongly agrec } & \text { agree } & \text { undecided } & \text { disagree } & \text { strongly disagree }\end{array}$


21. Coming to school has value to me.

$\begin{array}{ccccc}1 & 2 & 3 & 4 & 5 \\ \text { strongly agree } & \text { agree } & \text { undecided } & \text { disagrce } & \text { strongly disagree }\end{array}$

22. I feel having an adult mentor in school is important because:

- help with homework

I have someone to talk to

---- someone cares about me

23. I am still in school progressing towards graduation.

$$
\longrightarrow \text { yes } \quad \text { no }
$$

If you answered no to question $\# 22$. complete the next section.

24. I am presently:

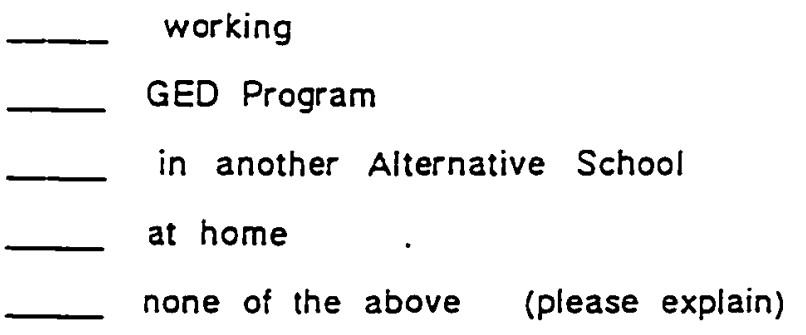


Please rank order any that apply: $\quad\left({ }^{m} 1^{-}=\right.$most important)

25. I left school primarily because:

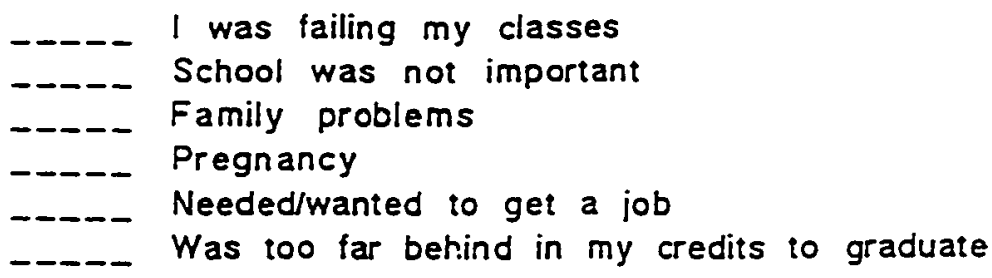

26. I told my mentor before leaving where I was going and why.

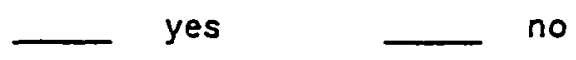

If no, please explain further:

\section{Section II}

27. What year in school are you now?

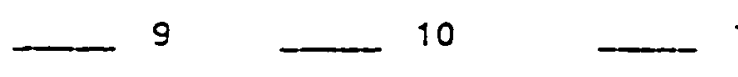

28. How many years have you had a mentor?

$\begin{array}{lll}- & 2 \\ - & 3\end{array}$

29. I am currently living with:

$$
\begin{aligned}
& \text { both parents } \\
& \text { father only } \\
& -\ldots \text { mother only } \\
& \ldots \text { a step-parent and a parent } \\
&
\end{aligned}
$$


30. My favorite subject 'is:

31. My favorite teacher is: Why:

32. My grades are better than in the past.

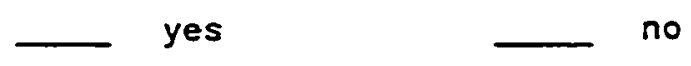

33. I come to school more often than I used to:

- yes _ _ no _ _ about the same

34. Please indicate your raciallethnic group:

$\begin{array}{lll}\text {-__ Native American } & - & \text { Asian American } \\ \text { African American } & - & \text { Hispanic } \\ - \text { Caucasian/White } & - & \text { Other }\end{array}$

35. Please check the appropriate category:

$$
\text { -nole male female }
$$

36. Additional comments: 
APPENDIX D

PRETREATMENT ANALYSES 


\begin{tabular}{|c|c|c|c|c|c|c|}
\hline \multicolumn{4}{|c|}{$\begin{array}{l}\text { Pretreatment } \\
\text { (analysis }\end{array}$} & \multicolumn{3}{|c|}{$\begin{array}{l}\text { Comparisons: cohorts } 1 \\
\text { : not at-risk students) }\end{array}$} \\
\hline & Mean & StdDev & $\mathbf{N}$ & F-value & Prob & $\begin{array}{l}-3 \\
\text { Differences }\end{array}$ \\
\hline Coton 1 (ab) & 170.0 & 11.5 & 134 & \multirow[t]{3}{*}{11.64} & \multirow[t]{3}{*}{.0000} & \multirow[t]{3}{*}{$\operatorname{coh} 3 \cdot \operatorname{coh} 1>>\operatorname{coh} 2$} \\
\hline Cothon 2 (Sh) & 165.0 & 22.8 & 125 & & & \\
\hline Coton $3(\mathrm{sab})$ & 173.5 & 5.8 & 155 & & & \\
\hline
\end{tabular}

\begin{tabular}{|c|c|c|c|c|c|c|}
\hline \multicolumn{4}{|c|}{$\begin{array}{c}\text { Pretroatmont } \\
\text { (analgsis }\end{array}$} & \multicolumn{3}{|c|}{$\begin{array}{l}\text { omparisons: Cohorts } 1 \\
\text { not at-risk students) }\end{array}$} \\
\hline & Mean & StdDev & $\mathbf{N}$ & F-value & Prob & $\frac{-3}{\text { Differences }}$ \\
\hline Cobon I (Bab) & 3.04 & 0.72 & 134 & \multirow[t]{3}{*}{10.52} & \multirow[t]{3}{*}{.0000} & \multirow[t]{3}{*}{$\operatorname{coh} 1 \cdot \operatorname{coh} 3>>\operatorname{coh} 2$} \\
\hline Cotbon 2 (9ab) & 2.65 & 0.74 & 120 & & & \\
\hline Cohon 3 (BCh) & 2.97 & 0.71 & 157 & & & \\
\hline
\end{tabular}

\begin{tabular}{|c|c|c|c|c|c|c|}
\hline \multicolumn{7}{|c|}{$\begin{array}{r}\text { Pretreatment Average } \\
\text { (analysis of }\end{array}$} \\
\hline & Mean & StdDev & $\mathbf{N}$ & F-value & Prob & Significant Differences \\
\hline Cothon I (8th) & 2.25 & 0.73 & 54 & \multirow[t]{3}{*}{5.94} & \multirow[t]{3}{*}{.0037} & \multirow[t]{3}{*}{$\operatorname{coh} 1 . \operatorname{coh} 3>>\operatorname{coh} 2$} \\
\hline Cobon 2 (19h) & 1.42 & 0.73 & 13 & & & \\
\hline Cothon $3(8 b)$ & 2.16 & 0.91 & 30 & & & \\
\hline
\end{tabular}

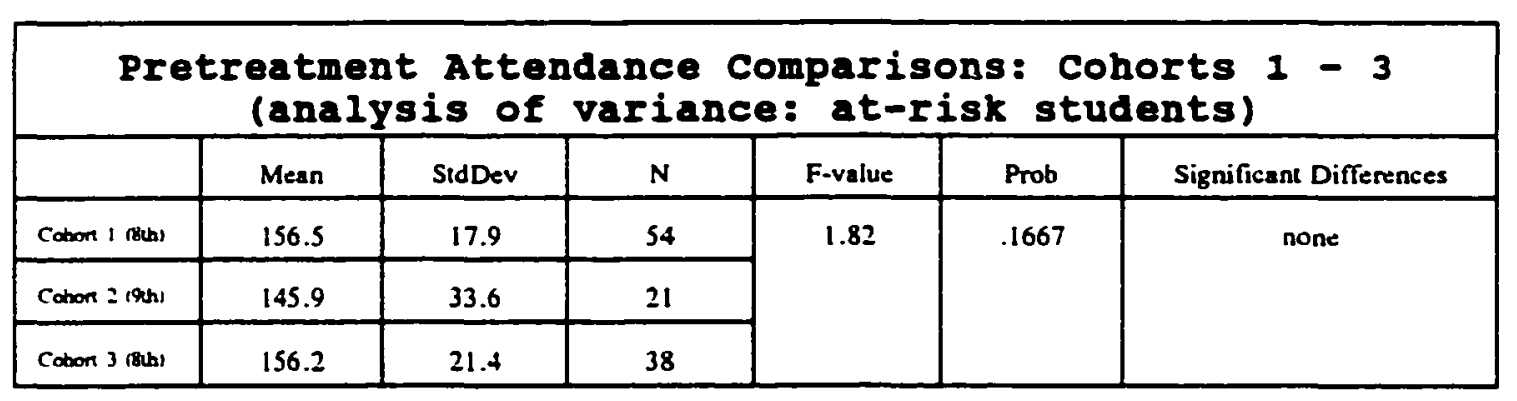


APPENDIX $\mathbf{E}$

ANALYSES OF QUESTIONS 1 THROUGH 4 


\begin{tabular}{|c|c|c|c|c|c|c|c|c|}
\hline & \multicolumn{3}{|c|}{ Pretreatment } & \multicolumn{5}{|c|}{ Comparisons for osL } \\
\hline & \multicolumn{3}{|c|}{ At-Risk } & \multicolumn{3}{|c|}{ Nol At-Risk } & \multirow[b]{2}{*}{$\mathbf{F}$} & \multirow[b]{2}{*}{ Prob } \\
\hline & Mean & SudDev & $\mathbf{N}$ & Mean & SudDev & $\mathbf{N}$ & & \\
\hline \multicolumn{9}{|c|}{ Satisfaction with School } \\
\hline Cohon 1 & 1.88 & 1.72 & 64 & 2.69 & 1.71 & 196 & 10.69 & .0012 \\
\hline Cohon 2 & 1.92 & 1.77 & 21 & 2.58 & 1.74 & 142 & 2.59 & .1092 \\
\hline Cohort 3 & 2.53 & 1.63 & 43 & 2.97 & 1.68 & 226 & 2.54 & .1119 \\
\hline \multicolumn{9}{|c|}{ Commitment to Classwork } \\
\hline Cohon 1 & 2.87 & 2.95 & 64 & 5.47 & 2.94 & 196 & 14.18 & .0002 \\
\hline Cohon 2 & $3 / 87$ & 3.18 & 21 & 4.72 & 2.71 & 142 & 1.72 & .1917 \\
\hline Cohor 3 & 4.86 & 2.61 & 43 & 5.84 & 2.85 & 226 & 4.34 & .0381 \\
\hline \multicolumn{9}{|c|}{ Reactions to Teachers } \\
\hline Cohor I & 4.90 & 2.66 & 64 & 6.19 & 2.69 & 196 & 11.31 & .0009 \\
\hline Cohon 2 & 5.41 & 3.45 & 21 & $3.3 i$ & 2.84 & 142 & 1.73 & .1901 \\
\hline Cohon 3 & 5.05 & 2.98 & 43 & 6.48 & 2.53 & 226 & 10.8703 & .0011 \\
\hline \multicolumn{9}{|c|}{ Total QSL Score } \\
\hline Cohor 1 & 10.65 & 6.40 & 64 & 14.35 & 6.20 & 196 & 16.91 & .0001 \\
\hline Cohon 2 & 11.20 & 7.59 & 21 & 13.61 & 6.16 & 142 & 2.63 & .1068 \\
\hline Cohor 3 & 12.44 & 5.99 & 43 & 15.29 & 6.04 & 226 & 8.05 & .0049 \\
\hline
\end{tabular}




\begin{tabular}{|c|c|c|c|c|c|c|c|c|c|}
\hline \multicolumn{10}{|c|}{$\begin{array}{c}\text { Differences between At-risk and Not At-risk Students by Cohort: } \\
\text { Rates of Attendance : Year } 0\end{array}$} \\
\hline & \multicolumn{3}{|c|}{ AT-RISK } & \multicolumn{3}{|c|}{ NOT AT-RISK } & \multirow{2}{*}{$\begin{array}{l}\text { Mean } \\
\text { Difr }\end{array}$} & \multicolumn{2}{|c|}{ t-test } \\
\hline & Mean & S.D. & $N$ & Mean & S.D. & $N$ & & t-value & sig. \\
\hline $\begin{array}{l}\text { Cohort } 1 \\
\text { (Grade 8) }\end{array}$ & 156.5 & 17.9 & 54 & 170.2 & 11.3 & 139 & 13.7 & 5.22 & .000 \\
\hline $\begin{array}{l}\text { Cohort } 2 \\
\text { (Grade 9) }\end{array}$ & 145.9 & 33.6 & 21 & 165.3 & 21.9 & 137 & 19.4 & 2.56 & .018 \\
\hline $\begin{array}{l}\text { Cohort 3* } \\
\text { (Grade 8) }\end{array}$ & 156.2 & 21.4 & 38 & 173.5 & 5.8 & 155 & 17.3 & 4.92 & .000 \\
\hline $\begin{array}{l}\text { Cohorts } 1 \& 3 \\
\text { (Grade 8) }\end{array}$ & 156.4 & 19.3 & 92 & 171.9 & 9.0 & 294 & 15.5 & 7.46 & .000 \\
\hline $\begin{array}{l}\text { Cohorts } 1-3 \\
\text { (Grades 8,9) }\end{array}$ & 154.4 & 22.8 & 113 & 169.8 & 14.7 & 431 & 15.4 & 6.79 & .000 \\
\hline
\end{tabular}




\begin{tabular}{|c|c|c|c|c|c|c|c|c|}
\hline & \multicolumn{8}{|c|}{$\begin{array}{c}\text { Differences berween Al-risk and Not At-risk Students by Cohort: } \\
\text { Average GPA }: \text { Year } 0\end{array}$} \\
\hline & \multicolumn{3}{|c|}{ AT-RISK } & \multicolumn{3}{|c|}{ NOT AT-RISK } & \multicolumn{2}{|c|}{ t-test } \\
\hline & Mean & StdDev & $\mathbf{N}$ & Mean & StdDer & $\mathbf{N}$ & t-value & sig. \\
\hline $\begin{array}{l}\text { Cohort } 1 \\
\text { (Grade 8) }\end{array}$ & 2.25 & 0.73 & 54 & 3.05 & 0.72 & 139 & 6.90 & .000 \\
\hline $\begin{array}{l}\text { Cohort } 2 \\
\text { (Grade 9) }\end{array}$ & 1.42 & 0.73 & 13 & 2.68 & 0.73 & 132 & 5.96 & .000 \\
\hline $\begin{array}{l}\text { Cohort } 3 \\
\text { (Grade 8) }\end{array}$ & 2.16 & 0.91 & 30 & 2.97 & 0.71 & 156 & 5.44 & .000 \\
\hline $\begin{array}{l}\text { Cohorts } 1 \& 3 \\
\text { (Grade 8) }\end{array}$ & 2.22 & 0.79 & 84 & 3.01 & 0.71 & 295 & 8.70 & .000 \\
\hline $\begin{array}{l}\text { Cohorts 1-3 } \\
\text { (Grades 8,9) }\end{array}$ & 2.11 & 0.83 & 97 & 2.90 & 0.73 & 427 & 9.40 & .000 \\
\hline
\end{tabular}

average GPA for semesters 1 and 2 


\begin{tabular}{|c|c|c|c|c|c|c|c|c|c|}
\hline \multicolumn{10}{|c|}{$\begin{array}{c}\text { Question 2: Analysis of Covariance: } \\
\text { Quality of School Life Questionnaire } \\
\text { At-Risk: Mentor vs No Mentor (Cohort 1) }\end{array}$} \\
\hline & & \multicolumn{3}{|c|}{ Mcutor } & \multicolumn{3}{|c|}{ No Mentor } & \multirow[b]{2}{*}{ F-value } & \multirow[b]{2}{*}{ Prob. } \\
\hline & & Mean & StdDev & $\mathbf{N}$ & Mean & StdDev & $\mathbf{N}$ & & \\
\hline \multirow[t]{2}{*}{ SAT } & Yr.1 & 1.90 & 1.73 & 48 & 1.81 & 1.76 & 16 & 8.32 & .006 \\
\hline & Yr.2 & 2.91 & 1.87 & 45 & 1.33 & 1.87 & 12 & & \\
\hline \multirow[t]{2}{*}{ COM } & Yr.1 & 4.06 & 3.01 & 48 & 3.31 & 2.75 & 16 & 10.76 & .002 \\
\hline & Yr.2 & 6.27 & 3.21 & 45 & 2.75 & 3.44 & 12 & & \\
\hline \multirow[t]{2}{*}{$\mathrm{TCH}$} & Yr.I & 4.06 & 2.76 & 48 & 5.00 & 2.39 & 16 & 9.71 & .003 \\
\hline & Yr. 2 & 7.37 & 2.57 & 45 & 4.83 & 3.66 & 12 & & \\
\hline \multirow[t]{2}{*}{ QSL } & Yr.1 & 10.83 & 6.51 & 48 & 10.13 & 6.21 & 16 & 13.75 & .000 \\
\hline & Yr.2 & 16.55 & 6.77 & 45 & 8.92 & 8.34 & 12 & & \\
\hline
\end{tabular}

\begin{tabular}{|c|c|c|c|c|c|c|c|c|c|}
\hline & & & $\begin{array}{l}\text { Questio } \\
\text { Quality } \\
\text { Risk: M }\end{array}$ & $\begin{array}{l}\text { An: } \\
\text { icho } \\
\text { or v: }\end{array}$ & $\begin{array}{l}\text { of Cor } \\
\text { re Ques } \\
\text { Mentor }\end{array}$ & $\begin{array}{l}\text { Iriance: } \\
\text { ionnair } \\
\text { (Cohor }\end{array}$ & & & \\
\hline & & & Mentor & & & o Mente & & & \\
\hline & & Mean & StdDev & $\mathbf{N}$ & Man & StdDev & $\mathbf{N}$ & F-valuc & Prob. \\
\hline SAT & Yr.1 & 1.75 & 1.91 & 12 & 2.15 & 1.64 & 9 & 5.13 & .053 \\
\hline & Yr.2 & 3.86 & 1.68 & 7 & 1.40 & 1.95 & 7 & & \\
\hline COM & Yr.1 & 3.52 & 3.57 & 12 & 4.33 & 2.69 & 9 & 1.41 & .244 \\
\hline & Yr.2 & 7.00 & 4.00 & 7 & 3.60 & 3.71 & 5 & & \\
\hline $\mathrm{TCH}$ & Yr.1 & 5.58 & 3.92 & 12 & 5.18 & 2.92 & 9 & 1.09 & .380 \\
\hline & Yr.2 & 8.14 & 3.34 & 7 & 5.21 & 3.42 & 5 & & \\
\hline QSL & Yr.1 & 10.85 & 8.82 & 12 & 11.66 & 6.05 & 9 & 2.32 & .166 \\
\hline & Yr.2 & 19.00 & 8.04 & 7 & 10.20 & 8.29 & 7 & & \\
\hline
\end{tabular}




\begin{tabular}{|c|c|c|c|c|c|c|c|c|c|}
\hline \multicolumn{10}{|c|}{$\begin{array}{l}\text { Question 2: Analysis of Covariance: } \\
\text { At-Risk: Mentor vs No Mentor (Cohort 3) }\end{array}$} \\
\hline & & \multicolumn{3}{|c|}{ Mentor } & \multicolumn{3}{|c|}{ No Mentor } & \multirow[b]{2}{*}{ F-value } & \multirow[b]{2}{*}{ Prob } \\
\hline & & Mean & SidDer & $N$ & Mean & StdDev & $N$ & & \\
\hline \multirow[t]{2}{*}{ SAT } & Yr.1 & 2.25 & 1.57 & 24 & 2.88 & 1.69 & 19 & 0.55 & .468 \\
\hline & $Y_{5.2}$ & 2.84 & 1.75 & 16 & 3.67 & 1.37 & 6 & & \\
\hline \multirow[t]{2}{*}{ COM } & Yr.I & 4.58 & 2.48 & 24 & 5.21 & 2.78 & 19 & 0.09 & .770 \\
\hline & Yr.2 & 6.13 & 6.12 & 16 & 6.83 & 2.79 & 6 & & \\
\hline \multirow[t]{2}{*}{$\mathrm{TCH}$} & Yr.1 & 4.63 & 2.58 & 24 & 5.59 & 3.41 & 19 & 0.01 & .921 \\
\hline & Yr. 2 & 6.83 & 3.14 & 16 & 7.33 & 2.73 & 6 & & \\
\hline \multirow[t]{2}{*}{ QSL } & Yr.1 & 11.46 & 5.40 & 24 & 13.68 & 6.59 & 19 & 0.07 & .790 \\
\hline & Yr.2 & 15.80 & 7.30 & 16 & 17.83 & 5.31 & 6 & & \\
\hline
\end{tabular}

\begin{tabular}{|l|l|rrr|rrr|rr|}
\hline \multicolumn{8}{|c|}{ At-Risk: Mentor vs No Mentor (Cohorts 1,2) } \\
\hline \multirow{2}{|c|}{} & \multicolumn{7}{|c|}{ Mentor } & \multicolumn{3}{c|}{ No Mentor } & & \\
\hline \multirow{2}{*}{ SAT } & Mr.1 & 1.87 & 1.75 & 60 & 1.93 & 1.69 & 25 & 12.30 & .001 \\
& Yr.2 & 3.04 & 1.86 & 52 & 1.35 & 1.84 & 17 & & \\
\hline COM & Yr.1 & 3.96 & 3.11 & 60 & 3.68 & 2.72 & 25 & 11.89 & .001 \\
& Yr.2 & 6.37 & 3.29 & 52 & 3.00 & 3.43 & 17 & & \\
\hline TCH & Yr.1 & 5.01 & 3.01 & 60 & 5.06 & 2.54 & 25 & 10.38 & .002 \\
& Yr.2 & 7.48 & 2.66 & 52 & 4.94 & 3.49 & 17 & & \\
\hline \multirow{2}{*}{ QSL } & Yr.1 & 10.83 & 6.95 & 60 & 10.68 & 6.07 & 25 & 15.85 & .000 \\
& Yr.2 & 16.88 & 6.92 & 52 & 9.29 & 8.08 & 17 & & \\
\hline
\end{tabular}




\begin{tabular}{|c|c|c|c|c|c|c|c|c|c|}
\hline \multicolumn{10}{|c|}{$\begin{array}{l}\text { E-sstion 2: Analysis of Covariance: } \\
\text { At-Kisk: Mentor vs No Mentor (Cohorts 1,3) }\end{array}$} \\
\hline & & \multicolumn{3}{|c|}{ Mentor } & \multicolumn{3}{|c|}{ No Mentor } & \multirow[b]{2}{*}{$\bar{F}$-value } & \multirow[b]{2}{*}{ Prob. } \\
\hline & & Mean & StdDev & $\mathrm{N}$ & Mean & StdDer & $N$ & & \\
\hline \multirow[t]{2}{*}{ SAT } & Yr.I & 2.02 & 1.67 & 72 & 2.39 & 1.78 & 35 & 10.51 & .000 \\
\hline & Yr.2 & 2.89 & 1.82 & 61 & 2.11 & 2.03 & 18 & & \\
\hline \multirow[t]{2}{*}{ COM } & Yr.1 & 4.24 & 2.84 & 72 & 4.34 & 2.89 & 35 & 6.59 & .012 \\
\hline & Yr.2 & 6.23 & 3.16 & 61 & 4.11 & 3.72 & 18 & & \\
\hline \multirow[t]{2}{*}{$\mathrm{TCH}$} & Yr.l & 4.78 & 2.69 & 72 & 5.32 & 2.96 & 35 & 7.54 & .012 \\
\hline & Yr.2 & 7.23 & 2.72 & 61 & 5.67 & 3.51 & 18 & & \\
\hline \multirow[t]{2}{*}{ QSL } & Yr.1 & 11.04 & 6.14 & 72 & 12.06 & 6.57 & 35 & 8.36 & .005 \\
\hline & Yr.2 & 16.35 & 6.86 & 61 & 11.89 & 8.48 & 18 & & \\
\hline
\end{tabular}


Cohort 2

Analysis of Variance for Attendance

Mentor versus No Mentor

\begin{tabular}{cl|rrr|rrr|r|r|r}
\hline Cohort & Pre (94) & 152.2 & 19.5 & 11 & 138.9 & 44.5 & 10 & 13.30 & 0.81 & .3791 \\
2 & Year 1 & 129.8 & 45.2 & 12 & 136.5 & 41.7 & 10 & -6.70 & 0.13 & .7249 \\
& Year 2 & 110.1 & 56.6 & 12 & 1029 & 53.5 & 8 & 7.20 & 0.08 & .7863 \\
& Year 3 & 130.8 & 59.5 & 7 & 119.0 & 74.1 & 6 & 11.30 & 0.10 & .7562
\end{tabular}

Analysis of Variance for GPA

Mentor versus No Mentor

\begin{tabular}{cc|rcc|ccc|c|cc}
\hline Cohor & Pre (9) & 1.68 & 0.77 & 6 & 1.19 & 0.66 & 7 & 0.49 & 1.57 & 2368 \\
2 & Year 1 & .56 & 1.08 & 11 & 1.57 & 0.95 & 9 & -0.01 & 0.00 & .9948 \\
& Year 2 & 1.89 & 1.25 & 10 & 1.21 & 0.97 & 7 & 0.68 & 1.39 & .2570 \\
& Year 3 & 2.61 & 0.67 & 5 & 2.34 & 0.65 & 4 & 0.27 & 0.38 & .5586
\end{tabular}




\begin{tabular}{|c|c|c|c|c|c|c|c|c|c|}
\hline \multicolumn{10}{|c|}{$\begin{array}{l}\text { Post Iloc Comparicons of Adjusted Means from Analysis of Covariance } \\
\text { (QSL seales: all sandents in study for at least } 2 \text { yenss; all } 3 \text { cohorts) } \\
\text { (Arrendance. GPA: all possible sndents from cohorts } 1 \text { and 3) }\end{array}$} \\
\hline & $9 m$ & sigir & Hormeare & & coverace & mexs & $N$ & MS nicanis & SS, \\
\hline \multicolumn{10}{|c|}{ SAT-Salisfretion with Sehool } \\
\hline Mener > Nomener & 15.34 & $\cdots$ & 33.24 & Momer & 2006 & 3.20 & $6 x$ & & \\
\hline Mones s Nol Alditisk & 87.00 & $\because$ & 24.91 & No kloner & $2+1$ & 2.09 & 22 & & \\
\hline Menarids $>$ No & 923 & 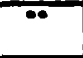 & $36 \sqrt{2}$ & Nol Antiats & $2 \pi$ & 270 & I113 & 2397 & 587.50 \\
\hline \multicolumn{10}{|c|}{ COM-Commitment to Schoolwork } \\
\hline Maver > No Menes & 9.31 & $\oplus$ & 33.24 & Maner & 4.42 & 65 & 6: & & \\
\hline Mever > Mol Aldide & 20.77 & $\infty$ & 24.91 & Nokleniar & 4.27 & 4.39 & 22 & & \\
\hline 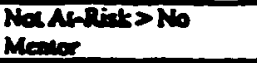 & 1.07 & as & 3600 & Nat ArRit: & 5.36 & 4.62 & 113 & 7.819 & 152271 \\
\hline \multicolumn{10}{|c|}{ TCH-Reations to Teachers } \\
\hline Menor > NoNener & 9.56 & $\cdots$ & 33.24 & Mester & 4.92 & 7.63 & 68 & & \\
\hline 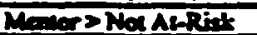 & IR.04 & $\infty$ & 84.91 & No Menes & 5.73 & 5.75 & 22 & & \\
\hline 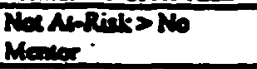 & $2 \sqrt{2}$ & as & 36.5 & Non Al-Ritis: & 6.32 & 6.19 & 113 & 6.662 & 1580.12 \\
\hline \multicolumn{10}{|l|}{ QSI-Total Seore } \\
\hline Meners Nolmontor & 5.34 & 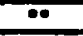 & 33.24 & Maneor & 11.40 & 17.66 & G & & \\
\hline Manos > Nol Al-Rint & 10.32 & 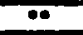 & 84.91 & No Mener & 1241 & 12.27 & 22 & & \\
\hline $\begin{array}{l}\text { NoxAl-Rints> No } \\
\text { Meneor }\end{array}$ & 121 & $a$ & 3623 & Nos AfRerat: & 14.45 & 13.38 & 113 & 33.473 & 7595.70 \\
\hline \multicolumn{10}{|c|}{ Altendanes (u dese presens) } \\
\hline Mener > No Mener & 9.83 & n.s. & 50.44 & Mandor & 156.07 & 160.61 & 75 & & \\
\hline Maler > Nox AbRinl. & $1: 74$ & ns & 12734 & No Mener & 14623 & 167.20 & 38 & & \\
\hline 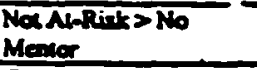 & 3.23 & as. & 69.77 & Nor Ab-Rist: & 17027 & 165.76 & $\$ 26$ & 353.99 & 192,33622 \\
\hline \multicolumn{10}{|c|}{ GPA (averase of semesters 1 and 2 ) } \\
\hline Mener > No Marlor & 0.16 & 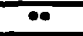 & $\Delta 1.98$ & Mlaneor & 218 & 237 & 65 & & \\
\hline Marer $>$ Nol Ai-Risk. & $91: 30$ & $\cdots$ & 11268 & No Merelor & 202 & 2.27 & 31 & & \\
\hline $\begin{array}{l}\text { Nol Al-Rick > No } \\
\text { Meotor }\end{array}$ & 51.75 & $\theta$ & 37.77 & No Al-Ristt & 291 & 271 & 423 & 0.386 & 34.73 \\
\hline
\end{tabular}

Tukey's test was used for post hoc mean comparisons. However, since the sampling distribution with a covariate differs from the studentized range statistic used for one-way analysis comparisons, the generalized studentized range distribution was used and the Bryant-Paulson procedure followed.

(Shavelson, p. 518, pp. 638-640) 


\begin{tabular}{|c|c|c|c|c|c|c|c|c|c|}
\hline \multicolumn{10}{|c|}{$\begin{array}{l}\text { Explanation of Post Hoc Comparisons } \\
\text { of Adjusted Means from Analysis or Covariance } \\
\text { (QSL Satlsfactlon with School scalc) }\end{array}$} \\
\hline & $\theta^{\circ}+\infty$ & sispir & $\underset{\text { Mear }}{\text { Hermonie }}$ & & $\begin{array}{l}\text { adjusted } \\
\text { means }\end{array}$ & corveriate & $\boldsymbol{N}$ & $M\left(S_{x=0,}\right.$ & ss: \\
\hline \multicolumn{10}{|c|}{ SAT - Sallafactlon with Sehool } \\
\hline Mentar > No Mentor & 15.34 & $\cdots$ & 3354 & Alentor & 320 & 206 & 68 & & \\
\hline Mator > Nox Al-Ritik & 17.09 & 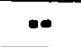 & 8491 & No Menter & 209 & 2.41 & 22 & & \\
\hline Nox Al-Rick > No Mertor & 9.33 & $\cdots$ & 36.82 & Not At-Rielt & 270 & 2.77 & 113 & 2.397 & 58750 \\
\hline
\end{tabular}

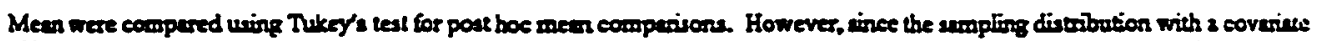

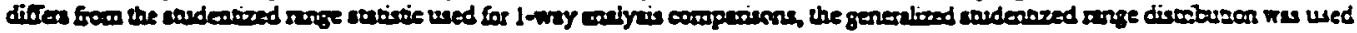
and the Bryeat-Peulean procedure followed.

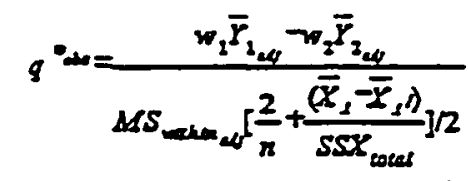

(Shavelson, po. 638-640)

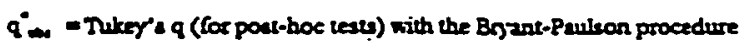

$w_{1}$ and $w_{2}$ ere weiphes (both are 1 for this andyis)

$Y_{1}$ and $Y_{2}$ ere sdjucted meurs

Xind $X_{4}$ ere deasured means

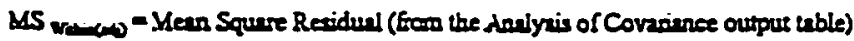

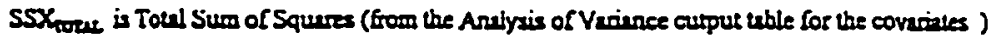

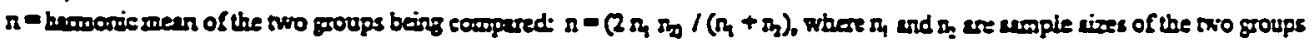

ce prob. $<.01$

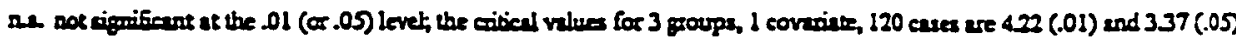

For anmpie, compunins SAT means for (1) Mertor and (2) No Mertor, compute:

$$
q^{\circ}=\frac{(1+3.20)(1+2.09)}{2.397 *\left[\frac{2}{33.24}+\frac{(2.06-2.41)^{2}}{587.50}\right] / 2}=15.34
$$

$\therefore$

Since $15.34>122$, these mears are ciorificantly difterent at the .01 level

(Shavelson, p.518) 
APPENDIX F

HUMAN SUBJECTS CONSENT FORM 
OFFICE OF RESEARCH AND SPONSORED PROJECTS

DATE: $\quad$ August 20, 1993

TO: Gail Hayes

FROM: for Martha Baishem, Chair, HSRRC 1993-94

Recyn Tovahed.

RE: HSRRC Approval of Your Application tited "A Descriptive Study of the Staff Mentor Program C.A.K.E...."

In accordance with your request, the Human Subjects Research Review Committee has reviewed your proposal referenced above for compliance with DHHS policies and regulations covering the protection of human subjects. The committee is satisfied that your provisions for protecting the rights and welfare of all subjects participating in the research are adequate, and your project is approved.

Please note to change our address to the Office of Research and Sponsored Projects, (503)725-3417 (instead of the Office of Graduate Studies) on the script of your informed consent.

Any changes in the proposed study, or any unanticipated problems involving risk to subjects, should be reported to the Human Subjects Research Review Committee. An annual report of the status of the project is required.

c. Office of Graduate Studies 